Key Words:

Cement

Saltstone

Slag

Performance Assessment

Disposal Unit

Retention:

Permanent

\title{
METHOD EVALUATION AND FIELD SAMPLE MEASUREMENTS FOR THE RATE OF MOVEMENT OF THE OXIDATION FRONT IN SALTSTONE
}

\author{
P. M. Almond \\ D. I. Kaplan \\ C. A. Langton \\ D. B. Stefanko \\ W. A. Spencer \\ A. Hatfield ${ }^{(a)}$ \\ Y. Arai ${ }^{(a)}$
}

(a) Clemson University

AUGUST 2012

Savannah River National Laboratory Savannah River Nuclear Solutions Aiken. SC 29808 


\section{DISCLAIMER}

This work was prepared under an agreement with and funded by the U.S. Government. Neither the U. S. Government or its employees, nor any of its contractors, subcontractors or their employees, makes any express or implied:

1. warranty or assumes any legal liability for the accuracy, completeness, or for the use or results of such use of any information, product, or process disclosed; or

2. representation that such use or results of such use would not infringe privately owned rights; or

3. endorsement or recommendation of any specifically identified commercial product, process, or service.

Any views and opinions of authors expressed in this work do not necessarily state or reflect those of the United States Government, or its contractors, or subcontractors.

Printed in the United States of America

Prepared for

U.S. Department of Energy 
Key Words:

Cement

Saltstone

Slag

Performance Assessment

Disposal Unit

Retention:

Permanent

\section{METHOD EVALUATION AND FIELD SAMPLE MEASUREMENTS FOR THE RATE OF MOVEMENT OF THE OXIDATION FRONT IN SALTSTONE}

P. M. Almond
D. I. Kaplan
C. A. Langton
D. B. Stefanko
W. A. Spencer
A. Hatfield
Y. $^{(\mathbf{a})}$
.arai

(a) Clemson University

AUGUST 2012

Savannah River National Laboratory

Savannah River Nuclear Solutions

Savannah River Site

Aiken, SC 29808 


\section{REVIEWS AND APPROVALS}

Philip M. Almond, Co-author, Engineering Process Development

Date

Daniel I. Kaplan, Co-author, Environmental Analysis

Date

Chris A. Langton, Co-author, Engineering Process Development

Date

David B. Stefanko, Co-author, Advanced Characterization and Process

Date

William A. Spencer, Co-author, Analytical R\&D Programs

Date

Alex D. Cozzi, Technical Reviewer, Engineering Process Development

Date

Kevin M. Fox, Manager, Engineering Process Development

Date

Sharon L. Marra, Manager, E\&CPT Research Programs

Date

Kent H. Rosenberger, SRR, Manager, Closure \& Disposal Assessment

Date

- ii - 


\section{TABLE OF CONTENTS}

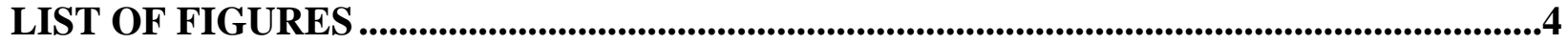

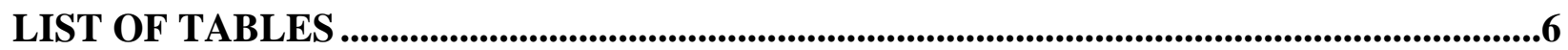

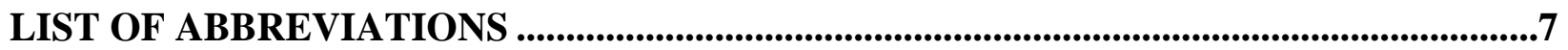

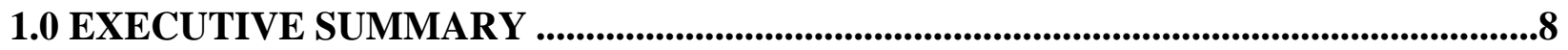

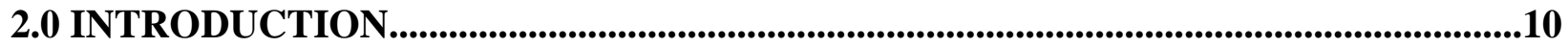

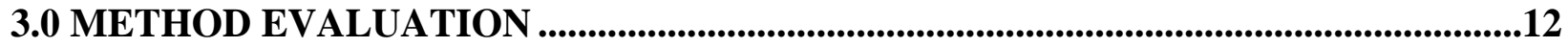

3.1 Sample Preparation and Curing Conditions .............................................................12

3.2 X-ray Absorption Spectroscopy .............................................................................................14

3.2.1 Materials and Methods ..................................................................................................... 14

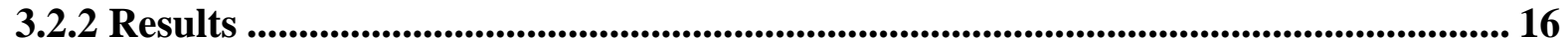

3.2.3 Summary of XAS Analyses.............................................................................. 19

3.3 Diffuse Reflectance Spectroscopy...........................................................................19

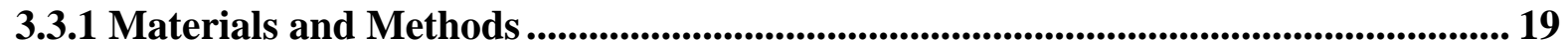

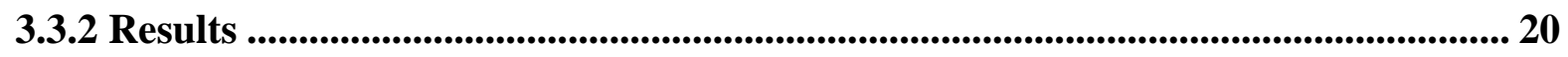

3.3.3 Summary of Diffuse Reflectance Spectroscopy Analyses......................................... 22

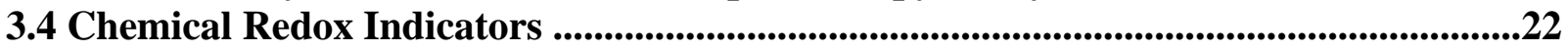

3.4.1 Materials and Methods .................................................................................... 22

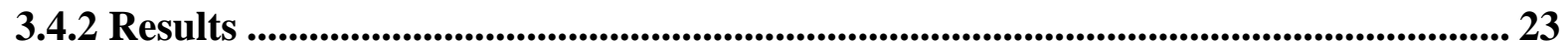

3.4.3 Summary of Redox Indicator Analyses...................................................................... 24

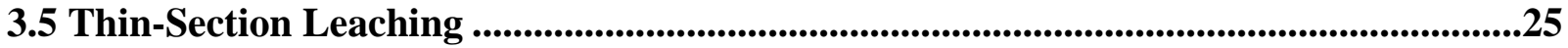

3.5.1 Materials and Methods ................................................................................. 25

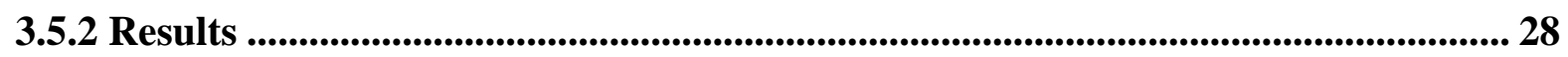

3.5.3 Summary of Thin-Section Leaching Analyses......................................................... 34

3.6 Method Validation ..................................................................................................................35

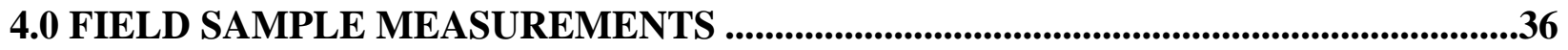

4.1 Sample Preparation and Curing Conditions ................................................................36

4.2 Thin-Section Leaching .............................................................................................................37

4.2.1 Materials and Methods .............................................................................................. 38

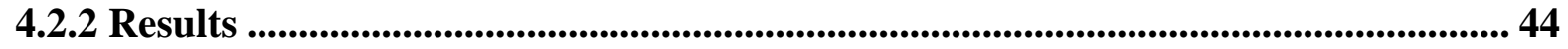

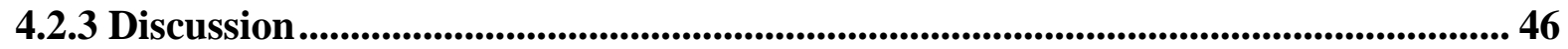

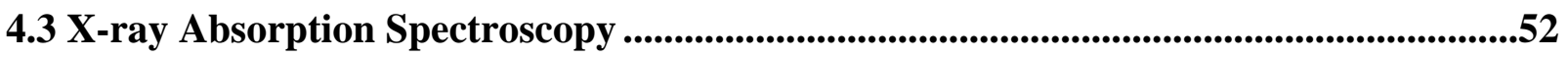

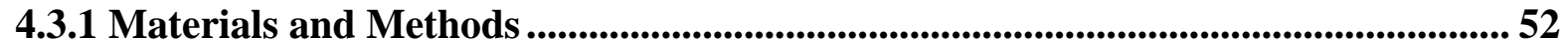

4.3.2 Results and Discussion .............................................................................................. 54

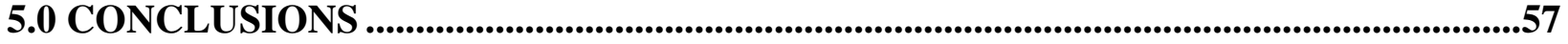

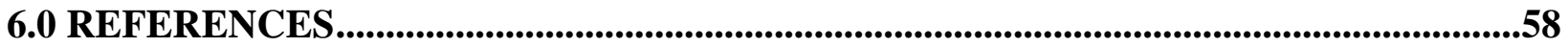

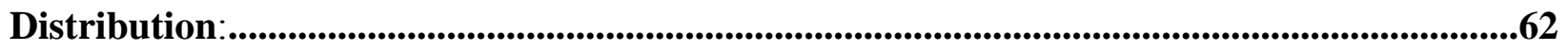




\section{LIST OF FIGURES}

Figure 1. Saltstone simulant samples prepared for method evaluation using 1 1/2"x 3 11/16"

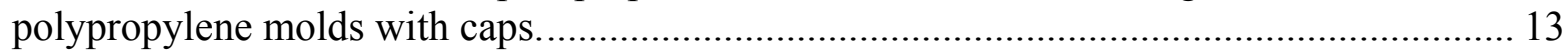

Figure 2. Humid chamber used to store method evaluation samples in the laboratory while

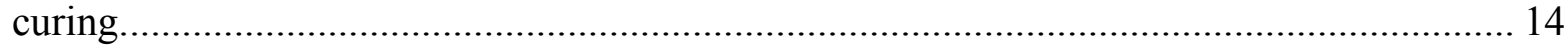

Figure 3. Sample holder for XAS measurements designed for holding radiological samples in inert gas environment. (a) Each layer of stainless steel or Tedlar. (b) The assembled unit (4 of the 24 screws used to hold assembly together are shown). .......................................... 15

Figure 4. XANES of saltstone samples containing slag (S) and no slag (NS) spiked with varying concentrations $(0,500,1000$, and $5000 \mathrm{mg} / \mathrm{kg})$ of oxidation-state tracers $(\mathrm{Cr}$ and $\mathrm{V})$. All oxidation state tracers added in oxidized form, $\mathrm{Cr}^{\mathrm{VI}} \mathrm{O}_{4}{ }^{2-}$ and $\mathrm{V}^{\mathrm{V}} \mathrm{O}_{2}{ }^{+}$. An example of the sample label description is Cr1000_NS: no-slag saltstone sample spiked with $1000 \mathrm{mg} / \mathrm{kg}$ $\mathrm{Cr}^{\mathrm{VI}} \mathrm{O}_{4}^{2-}$ 18

Figure 5. DRS analysis of oxidized and reduced zones of saltstone and no slag sample plotted in absorbance (arb) vs wavelength (nm). ........................................................................... 20

Figure 6. A compilation of saltstone samples analyzed through DRS comparing oxidized (tops of sample) and reduced (bottoms of sample) zones plotted in absorbance (arb) vs wavelength $(\mathrm{nm})$.

Figure 7. Redox indicators 1-6 consisting of a solid-free control (left), saltstone (middle), and no-slag grout (right) grouping, respectively. (a) redox indicators after $1 \mathrm{~h}$ of contact (b) redox indicators after $1 \mathrm{~d}$ of contact. Phenosafranin (\#7) not pictured.

Figure 8. (a) Saltstone sample removed from curing mold, (b) TECHCUT4 saw used for cutting disks from grout cylinders, and (c) cut sample wafer. ..................................................... 26

Figure 9. (a) Spatula generated subsample, (b) Mortar and pestle for size reducing grout sample disks, and (c) Balance used for determining subsample mass and leachate volume. ........... 27

Figure 10. Vials used for leaching crushed subsamples, (a) Supplier information and (b) vial components - cap, septum and glass bottle (from left to right).............................................. 27

Figure 11. (a) Leaching bottles being wrapped and stacked inside large-mouth plastic bottle for end-over-end tumbling and (b) equipment for tumbling crushed samples at $30 \mathrm{rpm}$ for $18 \pm 2$ hr. 28

Figure 12. Fractions leached from no-slag waste form samples............................................ 30

Figure 13. Fractions leached from slag saltstone samples.......................................................... 31

Figure 14. Fraction leached (nitrites) for no-slag waste forms and slag-saltstone samples. ........ 32

Figure 15. Fractions leached (sodium) for no-slag waste forms and slag-saltstone samples ....... 33

Figure 16. (a) SPF premix silos in Z-area. (b) Field sample chamber located below premix silos. (c) Field sample chamber closed (d) Field sample chest open revealing samples and an open container of water........................................................................................................ 36

Figure 17. Plot of relative humidity and temperature from within field sample chest while

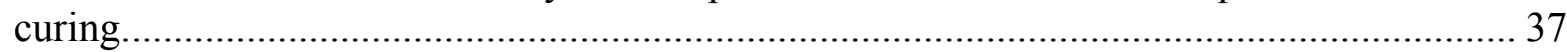

Figure 18. Appearance of three field cured samples illustrating color differences and dark specks

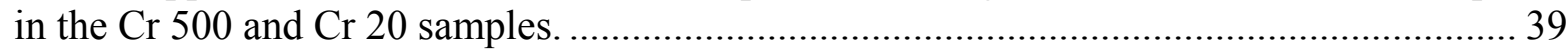

Figure 19. Appearance of the 3 chromium-spiked saltstone samples leached in this study....... 40 Figure 20. Selected filtered leachates (17L to 22L) for field cured saltstone spiked with $1000 \mathrm{mg} / \mathrm{kg}$ chromium.

Figure 21. Filtered leachates from all of the subsamples cut from the field cured samples spiked with $20 \mathrm{mg} / \mathrm{kg}$ chromium. 
Figure 22. Appearance of leachates and residues for the $500 \mathrm{mg} / \mathrm{kg}$ chromium field cured sample. 43

Figure 23. Nitrate leached from field cured saltstone spiked with chromium. ............................ 45

Figure 24. Sodium leached from field cured saltstone spiked with chromium............................ 45

Figure 25. Chromium leached from field cured saltstone spiked with chromium........................ 46

Figure 26. Semi-log plot of percentages of chromium and $\mathrm{NO}_{3}{ }^{-}$leached as a function of sample distance from the exposed top surface.

Figure 27. Comparison of $\mathrm{NO}_{3}{ }^{-}$and chromium percentages leached for $\mathrm{Cr}-1000$ field and laboratory cured samples

Figure 28. Comparison of $\mathrm{NO}_{3}{ }^{-}$and chromium distribution ratios for the $18 \mathrm{~h}$ extraction of crushed saltstone (powdered) in de-aerated ASTM Type I water.

Figure 29. Simulant saltstone sample spiked with $1000 \mathrm{mg} \mathrm{kg}^{-1}(\sim 2 \mathrm{~cm}$ width $\mathrm{x} \sim 3.5 \mathrm{~cm}$ depth (along the direction that the oxidation front would move) $\mathrm{x} 0.15 \mathrm{~cm}$ thickness) used in the $\mu$ SXRF and $\mu$-XANES measurements. Sample holder was designed to maintain an inert environment. Upper portion of sample includes the air/saltstone interface. Blue line indicates location of where chemical analyses were conducted.

Figure 30. XANES spectra of $\mathrm{Cr}(\mathrm{III})$ and $\mathrm{Cr}(\mathrm{VI})$ standards. To create the $\mathrm{Cr}(\mathrm{III}) / \mathrm{Cr}(\mathrm{VI})$ maps of the field saltstone samples, the ratio of the fluorescence intensity at 5,993 and $6,003 \mathrm{eV}$ were used to generate a $\mathrm{Cr}(\mathrm{VI})$ map, while the threshold energy map at $6,003 \mathrm{eV}$ was used as a Cr(III) map.

Figure 31. 2-D chromium oxidation state map, with $\mathrm{Cr}(\mathrm{III})$ in red and $\mathrm{Cr}(\mathrm{VI})$ in green (mixed oxidation state samples are some color in between). Black regions are saltstone void spaces. (a) Top of scan represents the air/saltstone interface of the $1 \mathrm{~mm}$ (horizontal) $\mathrm{x}$ $18.8 \mathrm{~mm}$ (depth) profile, and (b) detailed enlargement. 56 


\section{LIST OF TABLES}

Table 1. Tank 50 Simulant Based on the CY11 First Quarter WAC Analysis (Reigel 2011).... 12

Table 2. Cement Constituent and Saltstone Composition (wt-\%) (Harbour et al. 2006) ............ 16

Table 3. Redox Indicator and Color of Oxidized and Reduced Form. ..................................... 23

Table 4. Ingredients and Proportions in Samples Prepared for the Leach Method Development. 


\section{LIST OF ABBREVIATIONS}

$\begin{array}{ll}\text { ACTL } & \text { Aiken County Technology Laboratory } \\ \text { AD } & \text { Analytical Development } \\ \text { ARP } & \text { Actinide Removal Process } \\ \text { BFS } & \text { Blast Furnace Slag } \\ \text { C\&WDA } & \text { Closure and Waste Disposal Authority } \\ \text { Ca }(\text { OH })_{2} & \text { Portlandite } \\ \text { CSSX } & \text { Caustic Side Solvent Extraction } \\ \text { DI } & \text { Deionized } \\ \text { DDA } & \text { Deliquification, Dissolution, and Adjustment } \\ \text { DRS } & \text { Diffuse Reflectance Spectroscopy } \\ \text { DSS } & \text { Decontaminated Salt Solution } \\ \text { ETP } & \text { Effluent Treatment Project } \\ \text { FA } & \text { Fly Ash } \\ \text { IC } & \text { Ion Chromatography } \\ \text { ICP } & \text { Inductively Coupled Plasma } \\ \text { K } & \text { Distribution coefficient } \\ \text { MCU } & \text { Modular CSSX Unit } \\ \text { NS } & \text { No Slag } \\ \text { PA } & \text { Performance Assessment } \\ \text { PTFE } & \text { Polytetrafluoroethylene } \\ \text { OPC } & \text { Ordinary Portland Cement } \\ \text { ORP } & \text { Oxidation-Reduction Potential } \\ \text { SDF } & \text { Saltstone Disposal Facility } \\ \text { SPF } & \text { Saltstone Production Facility } \\ \text { SHE } & \text { Standard Hydrogen Electrode } \\ \text { SSRL } & \text { Stanford Synchrotron Radiation Lightsource } \\ \text { SRNL } & \text { Savannah River National Laboratory } \\ \text { SXRF } & \text { Synchrotron XRF } \\ \text { TCLP } & \text { Toxicity Characteristic Leaching Procedure } \\ \text { WAC } & \text { Waste Acceptance Criteria } \\ \text { XAS } & \text { X-ray Absorption Spectroscopy } \\ \text { XANES } & \text { X-ray Absorption Near Edge Structure } \\ \text { XRF } & \text { X-ray Fluorescence } \\ \text { Z } & \text { Atomic Number of Element } \\ & \end{array}$




\subsection{EXECUTIVE SUMMARY}

In the current SRS liquid waste processing system, solutions from F \& H Tank Farm are treated to remove actinides and fission products, resulting in a Decontaminated Salt Solution (DSS). This solution is combined with the Effluent Treatment Project (ETP), and H-canyon process wastes in Tank 50. At the Saltstone Production Facility (SPF), low-level waste from Tank 50 is mixed with premix, comprised of blast furnace slag (BFS), thermally beneficiated Class F fly ash (FA), and ordinary portland cement (OPC) to form a grout mixture. The fresh grout is pumped to the Saltstone Disposal Facility (SDF) where the grout cures through hydration reactions to produce saltstone, a hardened monolithic waste form. In saltstone, reducing conditions are created by BFS to attenuate the release of some contaminants.

The rate of oxidation in saltstone, or change from reducing to oxidizing conditions as $\mathrm{O}_{2}$ diffuses through the saltstone pore space, is a critical modeling input that impacts the time of release of contaminants, particularly Tc-99. Models for the rate of slag oxidation have considered liquid phase transport and a diffusion dominated contaminant release process independent of flow through a fractured network. Data related to the rate of oxidation of saltstone can be used both to verify modeling assumptions of oxidation rates, as well as to provide a basis for potential processing changes, such as clean cap installation criteria, based on maximum allowable saltstone atmospheric exposure time.

Conceptually, the experimental measurement of oxidized and reduced zones in saltstone can be applied to a sample as a function of depth from the air/cementitious material interface to probe oxidation front movement over time giving a rate of oxidation. The objective of this work was to develop and evaluate a series of methods and validate their capability to measure differences in oxidized versus reduced saltstone. Validated methods were then applied to samples cured under field conditions to simulate Performance Assessment (PA) needs for the SDF.

Four analytical approaches were evaluated using laboratory-cured saltstone samples. These methods were X-ray absorption spectroscopy (XAS), diffuse reflectance spectroscopy (DRS), chemical redox indicators, and thin-section leaching methods.

XAS and thin-section leaching methods were validated as viable methods for studying oxidation movement in saltstone. Each method used samples that were spiked with chromium $(\mathrm{Cr})$ as a tracer for oxidation of the saltstone. The two methods were subsequently applied to field-cured samples containing chromium to characterize the oxidation state of chromium as a function of distance from the exposed air/cementitious material surface.

Leaching experiments entailed taking multiple thin sections of a monolith from the air/cementitious interface and measuring chromium leachability for each section. As observed in method development experiments with saltstone, $\mathrm{Cr}(\mathrm{VI})$ leaches more readily than the reduced $\mathrm{Cr}$ (III) species in saltstone. The difference in leachability for chromium was utilized to identify an oxidation front based on the concentration of chromium leached from each thin section in field samples.

Three field samples containing 20,500, and $1000 \mathrm{mg} / \mathrm{kg}$ chromium were visually characterized and leached. Sample monoliths were separated into thin sections as a function of depth from the 
surface, crushed, and individually leached. Samples were taken to a depth of 18, 89, and $54 \mathrm{~mm}$, respectively for each monolith. To preclude oxidation, oxygen exposure to the sample was limited during leaching by using deoxygenated water in zero-head space sealed containers.

Results indicated a distinct change in chromium leachability as a function of depth from the exposed surface. Based on characterization of samples collected for one exposure time (111 to 118 days) and for two different levels of chromium spike, the oxidation front appears to have advanced from the as-cured exposed surface to a depth of 15 to $20 \mathrm{~mm}$ for the sample spiked with $1000 \mathrm{mg} / \mathrm{kg}$ chromium and to a depth of 5 to $10 \mathrm{~mm}$ for the sample spiked with $500 \mathrm{mg} / \mathrm{kg}$ chromium. The $20 \mathrm{mg} / \mathrm{kg}$ sample results were below analytical detection limits for chromium.

XAS characterization provided a direct indication of chromium oxidation state from a saltstone field sample that cured for 134 days. A slice was cut perpendicular to the exposed surface for analysis. The saltstone slice was stored in inert gases for approximately 10 days from sample cutting through sample analysis at the beam line to preclude oxidation.

A 188,000 point 2-D scan was conducted to create a map of the oxidation state of Cr(III/VI) over a $1 \times 18.8 \mathrm{~mm}$ portion of the sample. The resulting image was mottled from red to orange to yellow. A detectable change in chromium oxidation state as a function of distance from the exposed surface was not observed over $18.8 \mathrm{~mm}$ indicative of a well-defined oxidation front. The scan indicated the predominance of $\mathrm{Cr}$ (III) (indicated by red) and potential presence of some $\mathrm{Cr}(\mathrm{VI})$ throughout the sample (indicated by orange to yellow). One observation from the mottled pattern in the 2-D oxidation map was that the occurrence of $\mathrm{Cr}(\mathrm{VI})$ was common near pore spaces.

In summary, two methods - XAS and leaching methods were developed that are applicable to the study of Saltstone oxidation. These two methods were applied to simulated field samples and results were reported. This work is an initial step in developing the capability to experimentally quantify oxidation rates in grout samples cured outside of the laboratory environment. Therefore, a change in the modeling approach to oxidation is not suggested at this time. 


\subsection{INTRODUCTION}

In the current SRS liquid waste processing system, solutions from F \& H Tank Farm are treated to remove actinides and fission products, resulting in a Decontaminated Salt Solution (DSS). This solution is combined with the Effluent Treatment Project (ETP), and H-canyon process wastes in Tank 50. At the Saltstone Production Facility (SPF), low-level waste from Tank 50 is mixed with premix, comprised of blast furnace slag (BFS), thermally beneficiated Class F fly ash (FA), and portland cement (OPC) to form a grout mixture. The fresh grout is pumped to the Saltstone Disposal Facility (SDF) where the grout cures through hydration reactions to produce saltstone, a hardened monolithic waste form. In saltstone, reducing conditions are created to attenuate the release of some contaminants.

BFS contributes to the reducing environment within saltstone. It significantly lowers the Eh, or redox potential, relative to OPC and is credited with improving retention of redox-active contaminants, where the reduced form of the contaminant is better retained (Angus and Glasser 1985). For example, the solubilities of some contaminants, such as technetium (Tc), have been observed as a function of their oxidation state. $\mathrm{TcO}_{4}{ }^{-}$present in the DSS is reduced in saltstone to $\mathrm{Tc}(\mathrm{IV})$ and forms a low solubility sulfide compound $\left(\mathrm{TcS}_{\mathrm{x}}\right)$ or a $\mathrm{TcO}_{2} \bullet \mathrm{xH}_{2} \mathrm{O}$ phase which is somewhat more soluble than the sulfide (Lukens et al. 2005; Icenhower et al. 2010; MMES 1992). Controlling contaminant behavior through reduction mechanisms requires that reducing conditions be maintained. The total reduction capacity of BFS was measured and used to estimate that saltstone would have enough reduction capacity to remain in a reduced state over the period of performance (Lukens et al. 2005; Roberts and Kaplan 2009). Experimental studies regarding the persistence of reducing conditions and their impact on contaminant behavior can reduce uncertainty in the performance Assessment (PA) (SRR-CWDA-2009-00017; Allen et al. 1997; Kaplan et al 2005; Kaplan et al. 2008; Pabalan 2009; Painter and Pabalan 2009; Pabalan et al. 2012).

Saltstone disposal units are anticipated to degrade over a 10,000 year period of performance, where the rates of contaminant release are dominated by changes in physiochemical properties. The chemical properties of the waste form are impacted as groundwater and dissolved oxygen result in decreasing $\mathrm{pH}$ and increasing Eh potentials, or oxidation. The rate of oxidation of saltstone has been calculated to be less than $0.5 \mathrm{~mm}$ per year based on oxygen diffusion models where diffusion rates change as a function of the square root of time (Painter and Pabalan 2009). Models for the rate of slag oxidation have considered liquid phase transport (Flach et al. 2009) and a diffusion dominated process independent of flow through a fractured network (Flach 2011) using the shrinking core model (Smith and Walton 1993).

Experimental data related to the rate of oxidation of saltstone can be used both to verify modeling assumptions of oxidation rates, as well as to provide a basis for potential processing changes, such as clean cap installation criteria based on maximum allowable saltstone atmospheric exposure time.

Conceptually, the experimental measurement of oxidized and reduced zones in saltstone can be applied to a sample as a function of depth from the air/cementitious material interface to probe oxidation front movement over time giving a rate of oxidation. The objective of this work was to develop and evaluate a series of methods and validate their capability to measure differences in 
oxidized versus reduced saltstone. Validated methods were then applied to samples cured under field conditions to simulate Performance Assessment (PA) needs for the SDF.

Four analytical approaches were evaluated: X-ray absorption spectroscopy (XAS), diffuse reflectance spectroscopy (DRS), chemical redox indicators, and thin-section leaching methods. For all approaches, sectioning of a sample monolith is necessary to measure sample redox change as a function of depth from the air/cementitious interface. As part of method development, once a sample is sectioned, steps may be taken to preserve its redox condition, as handling and storage environment (i.e. oxygen exposure and time) may adversely affect measurement results. XAS is a method that requires the sample transfer to a synchrotron beamline for analysis; however, it can be tuned to provide a two-dimensional map of oxidation state of a specific element within a complex matrix, such as saltstone (Lukens et al. 2005). DRS can measure visible and near-infrared wavelength differences observed between different chemical species (Hunt 1977). Identification of distinct spectroscopic features indicative of reduced or oxidized species within saltstone was targeted for this method. Chemical redox indicators have been used as chemical probes to study the redox behavior of environmental systems (Tratnyek et al. 2001). They are an approved method for use by soil surveyors interested in delineating wetlands where "redox features" can be tested with a redox indicator to determine whether the feature is oxidized or reduced. Leaching methods have been used to study contaminant partitioning in saltstone (Langton 1988, Kaplan et al. 2008; Almond and Kaplan 2011). Leaching experiments will seek to characterize redox conditions based on preferential leachability between oxidized and reduced species in saltstone.

Analytical approaches and work scope were outlined in the Method Development and Qualification of the Rate of Movement of the Oxidation Front in Saltstone Task Technical and Quality Assurance Plan (Almond and Kaplan 2012). The work was initiated through a Technical Task Request HLW-SSF-TTR-2012-0007 from C\&WDA (Smith 2012). Funding was provided under SLA-WSTD-00023. 


\subsection{METHOD EVALUATION}

\subsection{SAMPLE PREPARATION AND CURING CONDITIONS}

Simulated saltstone samples were prepared and cured at SRNL for method evaluation work. A portion of the samples was spiked with a single redox active transition metal in its fully oxidized form (V(V), $\mathrm{Cr}(\mathrm{VI}), \operatorname{Re}(\mathrm{VII})$, or Mn(VII)). The spikes were added at nominal concentrations of 20 ppm, 500 ppm, 1000 ppm, 5000 ppm, 10000 ppm, and 20000 ppm based on sample mass.

The sample matrix provided a wide range of samples available for use, depending on the method detection limits and testing strategy employed. Saltstone samples without spikes inherently contain the redox active elements $\mathrm{Fe}$ and $\mathrm{S}$.

Saltstone samples were prepared by using a Tank 50 simulant that was based on the CY11 first quarter Waste Acceptance Criteria (WAC) analysis provided in Table 1. The simulant was mixed with a premix of $45 \%$ BFS, $45 \%$ thermally beneficiated Class F fly ash, and $10 \%$ ordinary portland cement by mass at a nominal 0.6 water to premix ratio. Samples containing no BFS (NS) were mixed with a premix consisting of $45 \%$ fly ash and $55 \%$ cement premix components where BFS was substituted by cement.

Table 1. Tank 50 Simulant Based on the CY11 First Quarter WAC Analysis (Reigel 2011).

\begin{tabular}{crrr}
\hline Compound & $\begin{array}{r}\text { Molarity } \\
(\text { moles/liter })\end{array}$ & $\begin{array}{r}\text { Molecular Mass } \\
(\text { grams/mole })\end{array}$ & $\begin{array}{r}\text { Amt / Liter } \\
(\text { grams })\end{array}$ \\
\hline $\mathrm{Al}\left(\mathrm{NO}_{3}\right)_{3} \bullet 9 \mathrm{H}_{2} \mathrm{O}$ & 0.110 & 375.129 & 41.26 \\
50 wt. \% $\mathrm{NaOH}$ & 1.551 & 39.998 & 124.07 \\
$\mathrm{Na}_{2} \mathrm{SO}_{4}$ & 0.059 & 142.042 & 8.32 \\
$\mathrm{Na}_{2} \mathrm{CO}_{3}$ & 0.148 & 105.990 & 15.64 \\
$\mathrm{NaNO}_{3}$ & 2.116 & 84.995 & 179.86 \\
$\mathrm{NaNO}_{2}$ & 0.336 & 68.996 & 23.20 \\
\hline
\end{tabular}

Samples were prepared in batches ranging from 150 to 1500 grams. Batches were prepared by first adding the simulant solution to a beaker. The simulant solution was stirred by a mechanical mixer containing a 6-blade paddle impeller at $\sim 250 \mathrm{rpm}$. Spikes were added to the simulant solution before premix addition and allowed to stir for a minimum of 5 minutes or longer until the spike material appeared dissolved. After some mixing time, it was observed that some of the higher ppm spikes (1-2\%) did not completely dissolve in the simulant, this was particularly true of the vanadium spike. Samples analyzed in this study were generally spiked to $1000 \mathrm{ppm}$ and below, and the tracer was assumed to be homogeneously mixed in the grout. Spike chemicals were sodium chromate $\left(\mathrm{Na}_{2} \mathrm{CrO}_{4}\right)$, sodium metavanadate $\left(\mathrm{Na}_{3} \mathrm{VO}_{4}\right)$, sodium perrhenate $\left(\mathrm{NaReO}_{4}\right)$, and sodium permanganate $\left(\mathrm{NaMnO}_{4}\left(\mathrm{H}_{2} \mathrm{O}\right)\right)$. The premix components were blended in a bag and then added to the simulant as the simulant stirred. The resultant grout slurry was 
mixed for $\sim 3$ minutes at an increased rpm that produced a vortex in the grout without entraining air. The grout was subsequently poured into $11 / 2$ " x $311 / 16$ " (referred to as $1 \times 4$ ) polypropylene sample cylinders at a fill volume of $\sim 80 \%$ and capped (Figure 1). The samples were cured (stored) in a humid chamber (Figure 2) at ambient temperature and 65-70\% relative humidity, until the samples were used for testing.

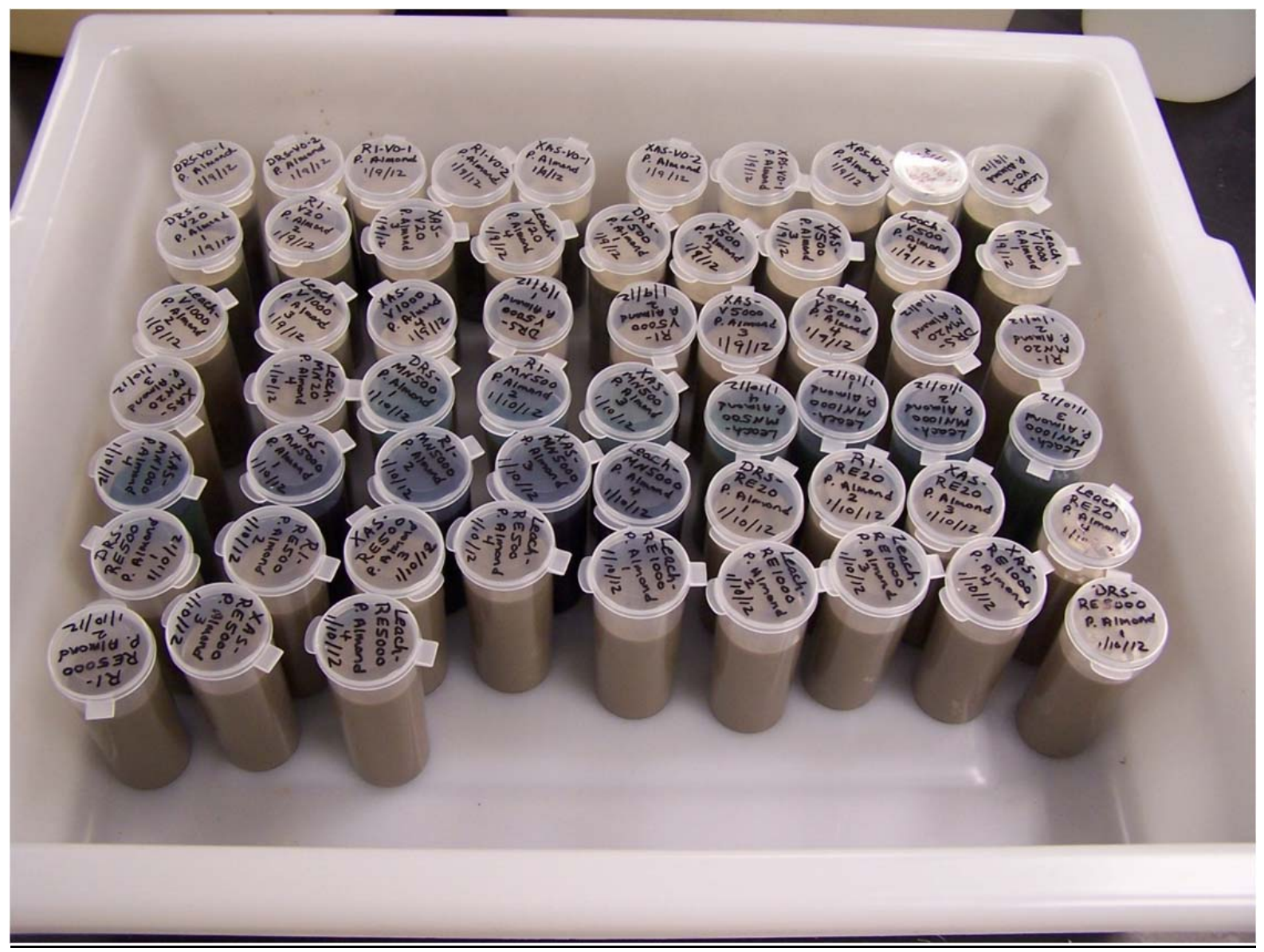

Figure 1. Saltstone simulant samples prepared for method evaluation using 1 1/2”x 3 11/16" polypropylene molds with caps. 


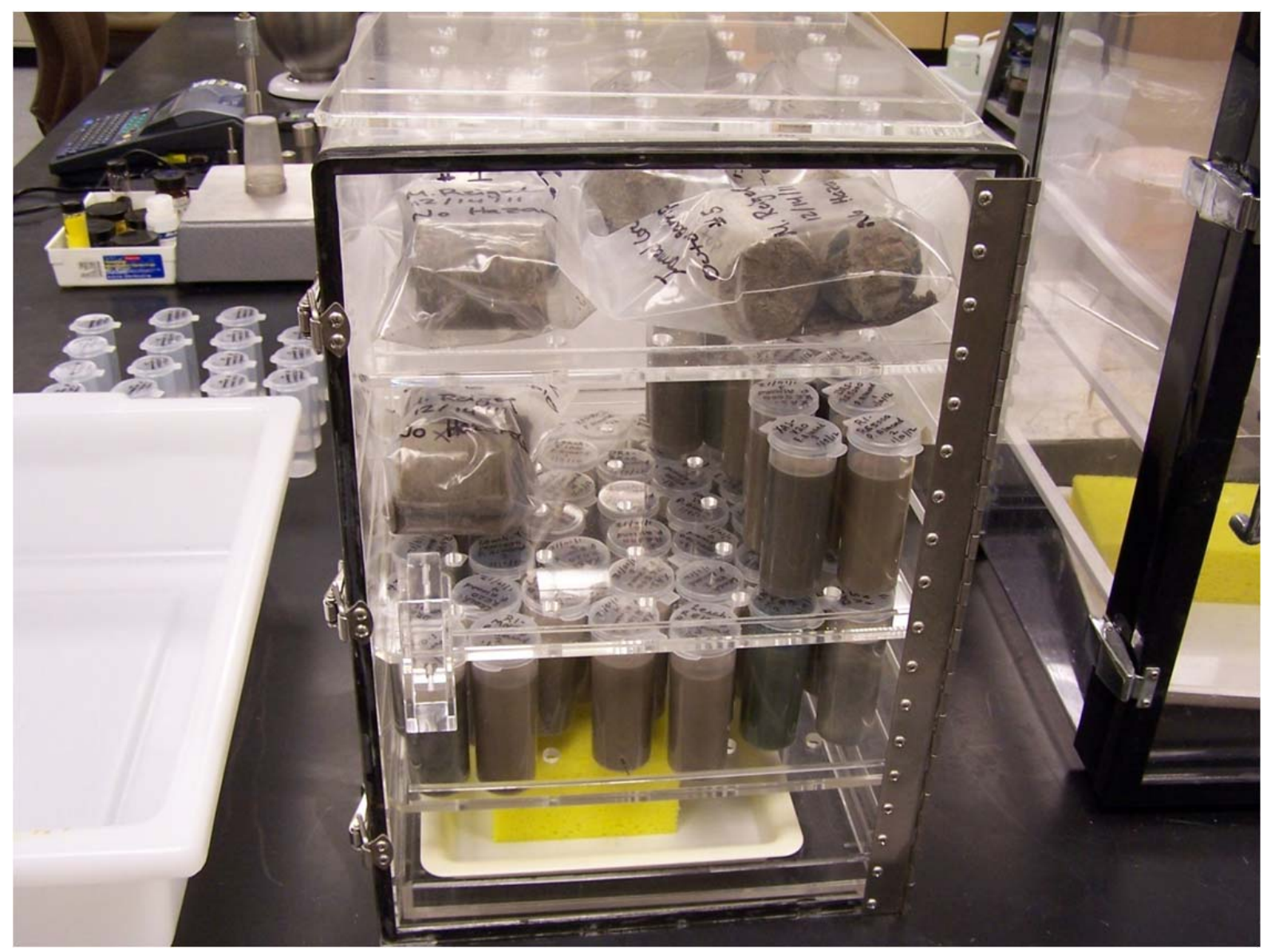

Figure 2. Humid chamber used to store method evaluation samples in the laboratory while curing.

\subsection{X-RAY ABSORPTION SPECTROSCOPY}

X-ray Absorption Spectroscopy (XAS) is a characterization method that is element specific, and can be used to identify oxidation state, coordination environment, and interatomic distances. Important for studying contaminants in saltstone, XAS does not require long-range order in a sample. To evaluate this method, XAS was performed to characterize an oxidized versus reduced saltstone sample by measuring the oxidation state of specific elements within the saltstone sample matrix (Shuh et al. 1994; Shuh et al. 2000; Allen et al. 1997; Lukens et al. 2005).

\subsubsection{Materials and Methods}

The oxidation state of surface $\mathrm{Fe}, \mathrm{Cr}, \mathrm{V}$, and $\mathrm{S}$ in the cementitious materials described in Section 3.1 was probed at the Stanford Synchrotron Radiation Lightsource (SSRL), Menlo Park, CA. The saltstone samples were spiked with oxidized forms of chromium $(\mathrm{Cr}(\mathrm{VI}))$ or vanadium $(\mathrm{V}(\mathrm{V}))$ to provide oxidation state indicators. Ambient concentrations of Fe and $\mathrm{S}$ in the cementitious samples were also probed by XAS. The 2 month old samples prepared at SRNL were transferred to Clemson University in their sealed sample cylinders where they were moved into an inert $\left(\mathrm{N}_{2}\right)$ atmosphere glovebox. Inert gloveboxes are designed to exclude air, more 
specifically $\mathrm{O}_{2}$, which may alter the saltstone redox state. In the glovebox, dark interior fragments from the monolith samples were ground with a mortar and pestle and loaded into a XAS sample holder (Figure 3).

The sample holder was fabricated based on a Los Alamos National Laboratory design that was successfully used at SSRL. The sample holder permits radiological samples to be analyzed in an inert atmosphere. Although the samples in this study are not radioactive, it is anticipated that future cementitious samples for this study or other studies will contain radionuclides. The samples were shipped to and measured at SSRL in an inert environment to maintain the redox status of elements in the samples. The sample holder was made of stainless steel and Tedlar. As many as eight samples were loaded into a single holder (Figure 3).

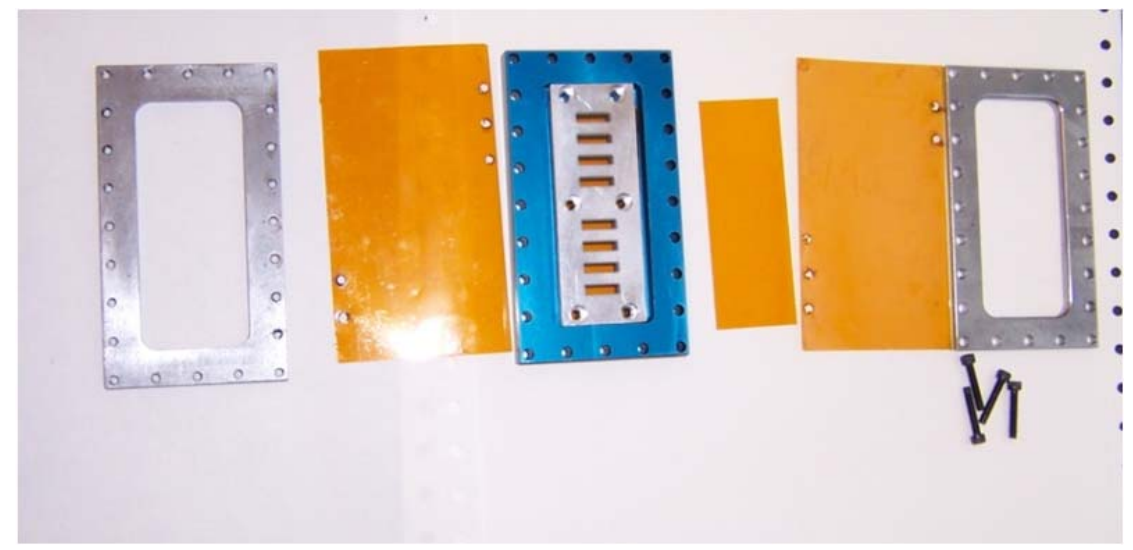

(a)

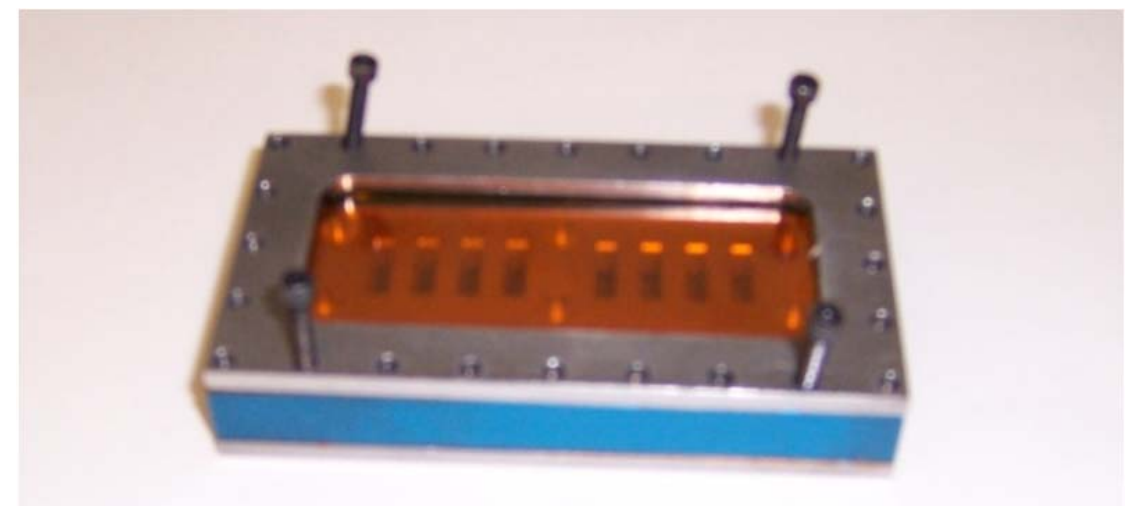

(b)

Figure 3. Sample holder for XAS measurements designed for holding radiological samples in inert gas environment. (a) Each layer of stainless steel or Tedlar. (b) The assembled unit (4 of the 24 screws used to hold assembly together are shown).

Iron was analyzed at room temperature from K -edge spectra $(7112 \mathrm{eV})$, sulfur from K-edge spectra $(2472 \mathrm{eV})$, vanadium from K-edge spectra $(5465 \mathrm{eV})$, and chromium from K-edge 
spectra $(5989 \mathrm{eV})$. All saltstone sampled were ground in an anaerobic glove chamber, and loaded in a sample holder sealed with a $0.2 \mathrm{~mm}$ polypropylene window film (SPEX SamplePrep, LLC, Metuchen, NJ) to maximize the attenuation of incident X-rays, and kept in an argon purged glovebag prior to the XAS data collection. All low Z X-ray Absorption Near Edge Structure (XANES) spectra were collected at beamline 4-3 at SSRL. The XAS spectra were collected in fluorescence mode at room temperature in a helium purged sample chamber. The XAS spectra were collected in 0.5 to $10 \mathrm{eV}$ steps between the pre-edge to extended regions. The monochromator consisted of two parallel Si(111) crystals with a vertical entrance slit of $0.5 \mathrm{~mm}$. The sample holder was oriented at $45^{\circ}$ to the unfocused incident beam. Data collection of the sorption samples was performed at room temperature. Many conditions and settings used in these analyses have been described in detail previously (Arai and Fuller 2012; Arai et al. 2007).

\subsubsection{Results}

The objectives of these tests were to determine whether it was possible to differentiate oxidation states of $\mathrm{Cr}(\mathrm{III} / \mathrm{VI}), \mathrm{Fe}(\mathrm{II} / \mathrm{III}), \mathrm{S}(\mathrm{O} / \mathrm{II} / \mathrm{VI})$, and $\mathrm{V}(\mathrm{III} / \mathrm{V})$ in slag-free and slag containing cementitious materials. The chemical composition of saltstone has been shown to contain weight percent levels of iron and sulfur (Harbour et al. 2006) (Table 2). Of particular importance with regard to these analyses is that the iron and sulfur originated from multiple sources and these elements likely comprised different oxidation states and chemical environments. For example, sulfur, the primary reductant in saltstone, exists in the premix components fly ash $(\sim 2 \%)$, portland cement $(\sim 3.3 \%)$, and slag $(\sim 1.8 \%)$. Prior to mixing these saltstone constituents, the sulfur in the Portland cement and fly ash was expected to be primarily oxidized, $\left(\mathrm{S}^{+6} \mathrm{O}_{4}\right)^{2-}$, whereas that of the slag was expected to be primarily reduced, e.g., $\mathrm{S}^{2-}$. Additionally, the saltstone also contained low concentrations of chromium originating from the premix.

Table 2. Cement Constituent and Saltstone Composition (wt-\%) (Harbour et al. 2006)

\begin{tabular}{|c|c|c|c|c|}
\hline $\begin{array}{l}\text { Oxide } \\
\text { (wt- \%) }\end{array}$ & Fly ash & $\begin{array}{c}\text { Portland } \\
\text { cement }\end{array}$ & Slag & Saltstone \\
\hline & $\begin{array}{l}\text { Average } \\
\text { rep } 1 \& 2\end{array}$ & $\begin{array}{l}\text { Average } \\
\text { rep } 1 \& 2\end{array}$ & $\begin{array}{l}\text { Average } \\
\text { rep } 1 \& 2\end{array}$ & $\begin{array}{c}45 \% \text { ash } / 45 \% \text { slag } / \\
10 \% \text { cement }\end{array}$ \\
\hline $\mathrm{Al}_{2} \mathrm{O}_{3}$ & 28.6 & 5.3 & 7.5 & 16.8 \\
\hline $\mathrm{CaO}$ & 0.7 & 64.0 & 36.8 & 23.2 \\
\hline $\mathrm{Fe}_{2} \mathrm{O}_{3}$ & 5.8 & 3.8 & 0.4 & 3.1 \\
\hline $\mathrm{K}_{2} \mathrm{O}$ & 2.6 & 0.6 & 0.4 & 1.4 \\
\hline $\mathrm{MgO}$ & 0.9 & 1.2 & 13.0 & 6.4 \\
\hline $\mathrm{Na}_{2} \mathrm{O}$ & 0.4 & 0.2 & 0.3 & 0.3 \\
\hline $\mathrm{SO}_{4}$ & 0.2 & 3.3 & 1.8 & 1.2 \\
\hline $\mathrm{SiO}_{2}$ & 55.5 & 20.4 & 39.2 & 44.6 \\
\hline $\mathrm{TiO}_{2}$ & 1.5 & 0.3 & 0.4 & 0.9 \\
\hline Volatiles & 2.0 & 0.0 & 0.0 & 0.9 \\
\hline Total & 98.0 & 98.9 & 99.6 & 98.8 \\
\hline
\end{tabular}

Figure 4 contains typical spectra collected from the XAS measurements. To distinguish among the oxidation states, attention was directed at the XANES portion of the XAS spectrum. Differences between slag and slag-free samples were noted in the chromium and sulfur spectra, 
but not in the iron and vanadium spectra. For all of these elements, when they are in the oxidized form they include a pre-edge feature (peak(s)) located at slightly lower energy levels than the dominant peak. For example, the spectra for V(V)-oxide and V(III)-oxide standards are presented in Figure 4 in the vanadium XANES plots. For the V(V) oxide standard, a pre-edge feature at $\sim 5480 \mathrm{eV}$ was observed; this same peak was not evident in the reduced form of the element, V(III). This pre-edge distinction provides an analytical feature to determine whether the probed element was in the oxidized or reduced form. Looking at the other spectra in that plot, it was observed that the vanadium, added as V(V), remained as V(V), irrespective of whether slag was included. The trend for standard reduction potentials, a measure of the tendency for reduction to occur, is $\mathrm{Cr}(\mathrm{III} / \mathrm{VI})>\mathrm{Tc}(\mathrm{IV} / \mathrm{VII})>\mathrm{Fe}(\mathrm{II} / \mathrm{III})>\mathrm{V}(\mathrm{III} / \mathrm{V})>\mathrm{Re}(\mathrm{IV} / \mathrm{VII})$ (Bethke 2008). Indicating that upon coming in contact with a reductant, $\mathrm{Cr}$ would undergo reduction first, followed by $\mathrm{Tc}$, then Fe, etc. Perhaps, under these chemical conditions, either V could not be reduced by the slag or it is a very slow reaction and had not had sufficient time to undergo reduction.

Looking at the chromium spectra in Figure 4, the pre-edge feature in the spectrum $(\sim 6000 \mathrm{eV})$ was detected in the slag-free sample, Cr1000_NS (1000 ppm chromium in non-slag cement), but not in the three slag containing samples $(\mathrm{Cr} 500 \mathrm{~S}$; $\mathrm{Cr} 1000 \mathrm{~S}$; and $\mathrm{Cr} 5000 \mathrm{~S})$. Based on $\mathrm{Cr}$ (III) and $\mathrm{Cr}(\mathrm{VI})$ standards, this shows that the pre-edge feature is indicative of the presence of $\mathrm{Cr}(\mathrm{VI})$. These results are consistent with previous chromium XANES analyses conducted with SRS saltstone (Bajt et al. 1993).

As mentioned above, sulfur was not spiked into the samples, instead ambient sulfur was probed. Sulfur XANES was conducted on slag and no-slag samples spiked with chromate and vanadate (Figure 4). Addition of chromate and vanadate did not influence the sulfur XANES spectra. In samples containing slag (samples identified with "_S" in Figure 4), a peak can be observed at $\sim 2473 \mathrm{eV}$. Based on standards, this spectra indicates the presence of $\mathrm{S}^{2-}$ along with predominantly sulfate (S(VI)). In the no slag containing samples, this $2473 \mathrm{eV}$ peak was not present. The sulfur was determined to exist in the oxidized S(VI) state.

As noted earlier, iron was not added as an oxidation state tracer; instead the ambient concentrations were analyzed. No differences were noted between the spectra of the no-slagand slag-containing samples. Like iron, vanadium XANES spectra were very similar irrespective of whether slag was present. 


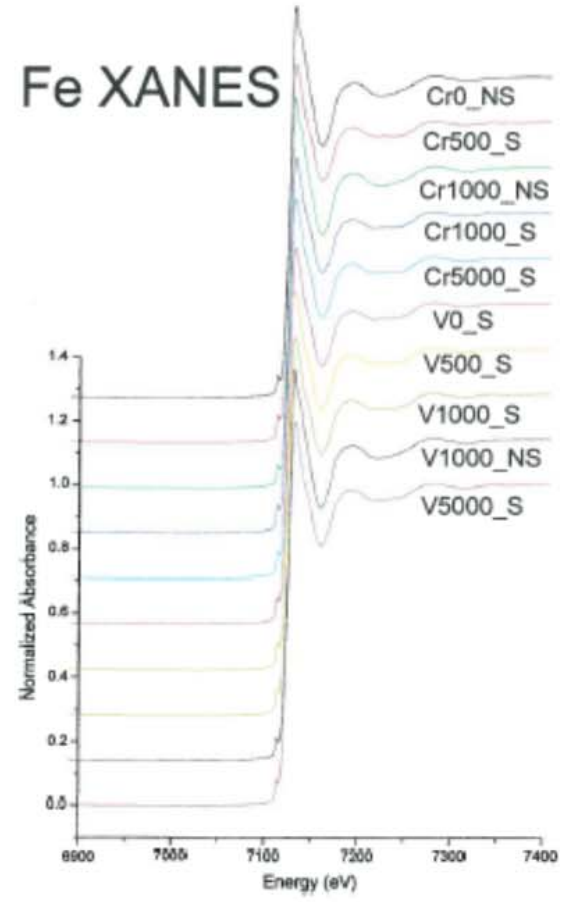

V XANES

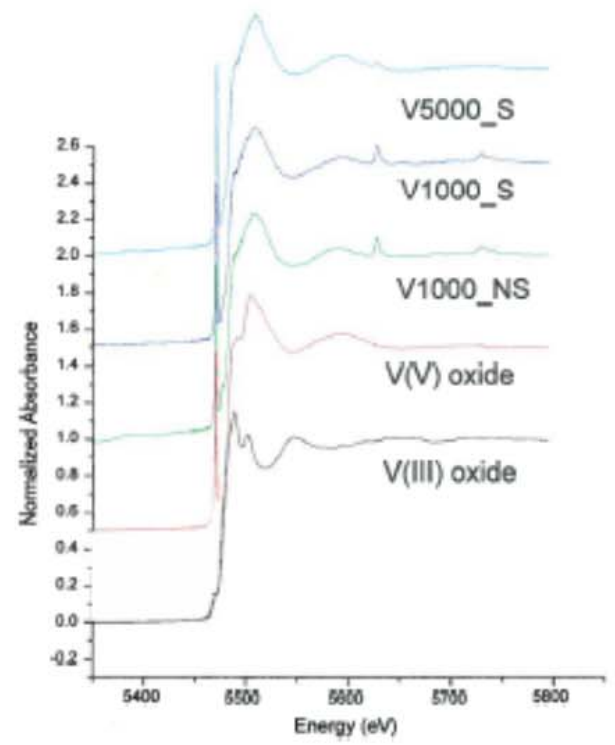

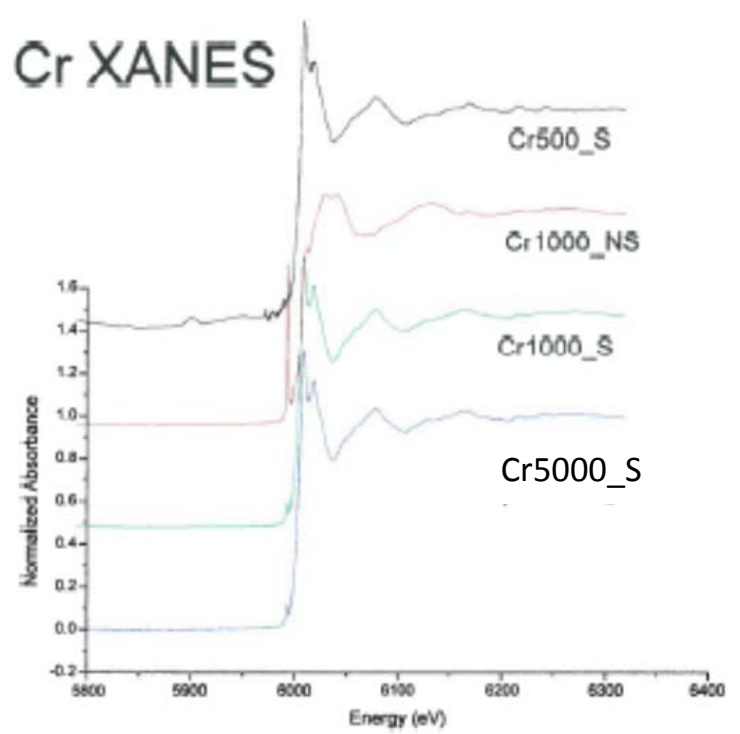

S XANES

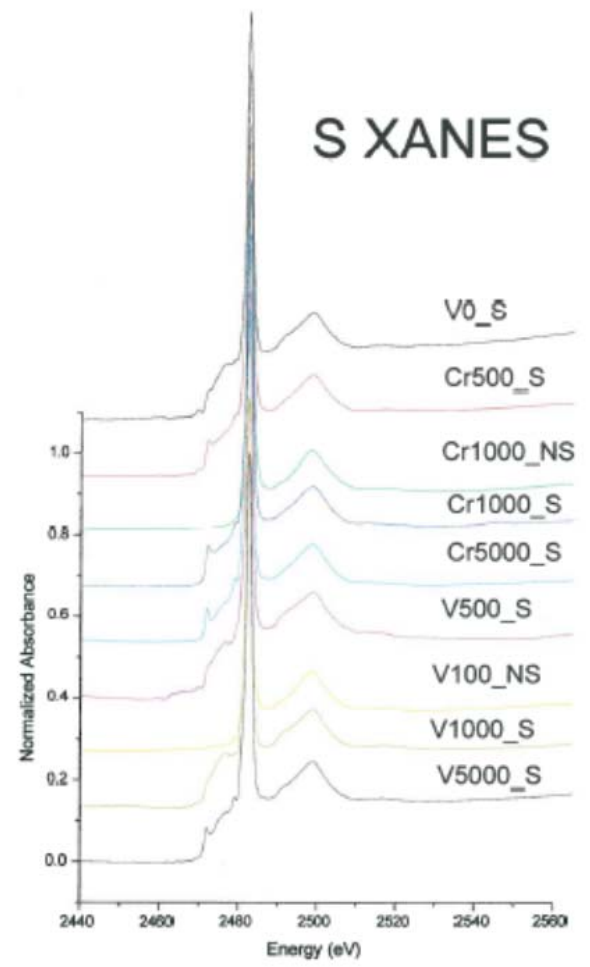

Figure 4. XANES of saltstone samples containing slag (S) and no slag (NS) spiked with varying concentrations $(0,500,1000$, and $5000 \mathrm{mg} / \mathrm{kg})$ of oxidation-state tracers $(\mathrm{Cr}$ and V). All oxidation state tracers added in oxidized form, $\mathrm{Cr}^{\mathrm{VI}} \mathrm{O}_{4}{ }^{2-}$ and $\mathrm{V}^{\mathrm{V}} \mathrm{O}_{2}{ }^{+}$. An example of the sample label description is Cr1000_NS: no-slag saltstone sample spiked with 1000 $\mathrm{mg} / \mathrm{kg} \mathrm{Cr}^{\mathrm{VI}} \mathrm{O}_{4}{ }^{2-}$. 


\subsubsection{Summary of XAS Analyses}

In summary, these results indicate that either ambient concentrations of sulfur or $1000 \mathrm{mg} / \mathrm{kg}$ chromium may be probed by bulk-XANES to monitor the redox status in saltstone. The 1000 $\mathrm{mg} / \mathrm{kg}$ chromium spike provides an excellent probe for the redox status of these simulant samples, but in the event that it is decided to evaluate saltstone facility cores, modifications to the analytical instrument setting (including larger beam size and longer data collection) will have to be made to address the lower chromium concentrations (Waste Acceptance Criteria limit for chromium in saltstone in Tank 50 salt solution is $300 \mathrm{mg} / \mathrm{L}$, giving a concentration of $\sim 130$ $\mathrm{mg} / \mathrm{kg}$ in saltstone).

\subsection{DIFFUSE REFLECTANCE SPECTROSCOPY}

Diffuse Reflectance Spectroscopy (DRS) was used to analyze saltstone and saltstone containing spiked redox active transition metals to probe visible and near-infrared wavelength differences observed between a reduced and an oxidized zone in a sample. Conceptually, these differences could be applied to a sample as a function of depth from the air/cementitious material interface to probe oxidation front movement.

DRS is a rapid, portable, nondestructive optical measurement that often can provide absorption features that are a function of the composition of the material. The absorption features are a manifestation of energy absorption from the material by vibrational state transitions. Because these vibrational states correspond to distinct energy levels, the absorption features occur at welldefined wavelength positions. The energy levels that define these wavelengths are a function of the size of the ionic radii of the cations bonded to different molecules. The bonds will vibrate at different wavelengths as a function of the length of the bond. If the bond lengths between a specific atom and molecule are consistent, it is possible to predict compositions and compositional changes in materials being analyzed by the wavelengths and wavelength shifts (Hunt 1977). It was anticipated that in the saltstone matrix, changes in the bond distances surrounding an oxidized element would be sufficiently different from those around a reduced element, producing a signature spectrum.

\subsubsection{Materials and Methods}

Samples prepared for method evaluation (see Section 3.1) were analyzed including saltstone, slag free saltstone, and spiked saltstone up to $10000 \mathrm{ppm}$ with chromium, manganese, vanadium, and rhenium tracers (see Section 3.1). Sample tops were typically light gray in color where they had been exposed to air, and some were colored by the tracer when higher concentrations of tracers were used. Chipping or scraping the top of a saltstone sample provided an olive green inner surface to analyze for reduced material. Sample bottoms of saltstone were green in color from being tightly sealed within the mold, and it was determined during experimentation that sample bottoms provided results analogous to inner material analysis. Therefore to facilitate the method evaluation, samples were analyzed on their top to represent an oxidized sample and their bottom to represent a reduced sample.

The diffuse reflectance measurements followed the guidelines for reflectivity measurements expressed in ASTM 1331-09. Spectra were taken using an Ocean Optics USB 2000 
spectrometer covering 340 - $1027 \mathrm{~nm}$ attached by optical fiber to a Mikropack $50 \mathrm{~mm}$ Integrating sphere (Model ISP-50-8-R-GT). The sphere was set to block the specular reflection. The illumination source was a J.A. Woolam QTH-200 Light Source with a quartz halogen bulb and was coupled to the sphere via an optical fiber. Measurements were calibrated against a set of Labsphere reflectivity standards (RSS-08-010 kit), which included disks for 99, 80, 60, 40, 20, 10,5 , and 2 percent reflectivity. Ocean Optics OOI_32 software was used to collect and save the spectra. Data was processed and plotted as absorbance (arb) vs. wavelength (nm).

It was observed that upon exposing a new saltstone surface, increases in sample reflectivity were observed over time. Therefore, to preserve the condition of the samples for analysis, samples were analyzed immediately after exposing a new surface, either by removing the sample from the mold or by removing surface material.

\subsubsection{Results}

The absorbance spectra from a sample of gray (considered oxidized) and green (considered reduced) saltstone and a slag-free sample (NS) are presented in Figure 5.

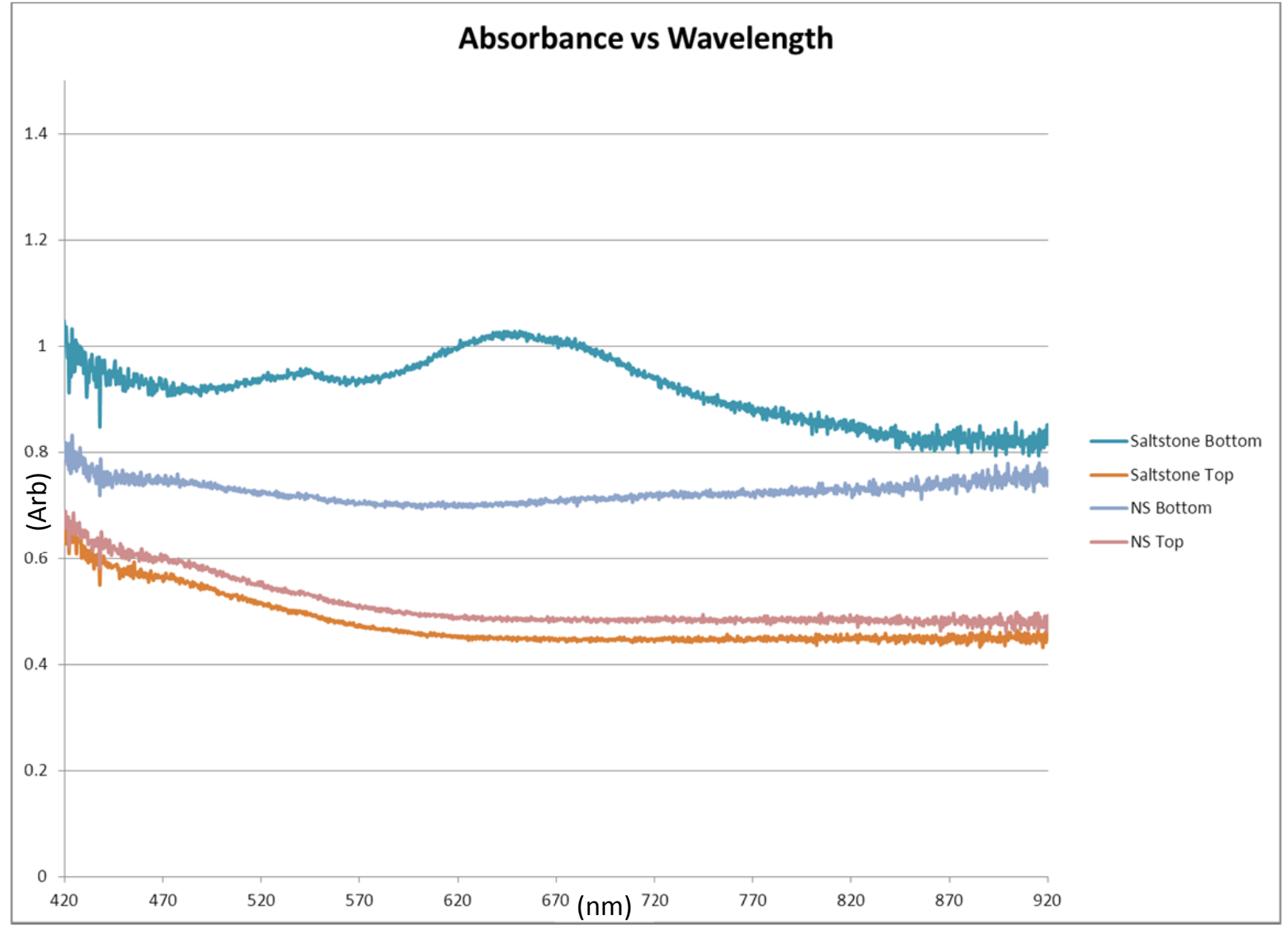

Figure 5. DRS analysis of oxidized and reduced zones of saltstone and no slag sample plotted in absorbance (arb) vs wavelength (nm). 
DRS detected mostly changes in the amount of water associated with the sample. Inner surfaces were much wetter. These samples were darker with lower reflectivity. Dryer outer surfaces were lighter in color. The water effect on reflectivity was a broadband phenomenon over the wavelengths measured that basically caused a shift in the baseline of the spectrum. A smaller signal was observed that appeared to be associated with the oxidation state. The reduced saltstone with slag sample displayed broad peaks centered at 540 and $649 \mathrm{~nm}$ compared to the oxidized slag saltstone which in some cases had a slightly increased relative absorption towards the UV that might be associated with increased amounts of nitrate. Characteristic peaks were not observed for the slag-free sample. Those samples showed only the baseline shift associated with water. The differences observed could not be clearly identified with the oxidation condition of the sample.

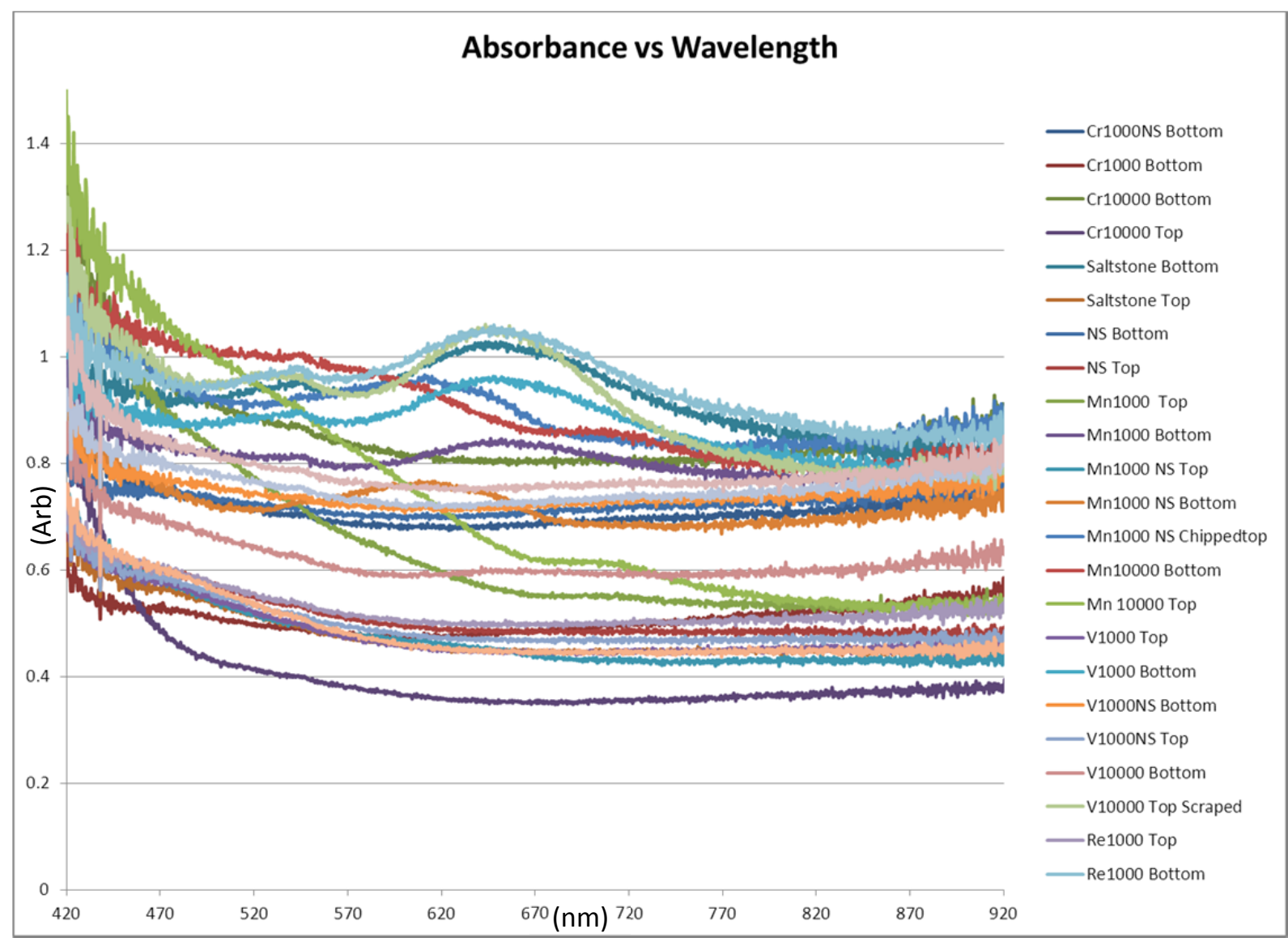

Figure 6. A compilation of saltstone samples analyzed through DRS comparing oxidized (tops of sample) and reduced (bottoms of sample) zones plotted in absorbance (arb) vs wavelength (nm).

A compilation of saltstone samples (for brevity) is presented in Figure 6 that compares oxidized and reduced zones of each sample that contain spikes. The saltstone samples containing transition metal spikes did not display distinct absorption features in the spectra, which would have indicated an oxidized or reduced species, even at spike concentrations as high as $1 \mathrm{wt} \%$. It was anticipated that distinct absorption features might be used to identify oxidized and reduced phases (e.g. Cr(VI) vs. Cr(III)) indicative of oxidized and reduced zones in saltstone. The 
changes with oxidation were broad and gradual. The water reflectivity greatly masked possible other changes.

\subsubsection{Summary of Diffuse Reflectance Spectroscopy Analyses}

The saltstone samples containing transition metal spikes did not display distinct absorption features in the spectra, which would indicate an oxidized or reduced transition metal. Therefore, the method was not validated as a candidate for studying field samples. In summary, these results indicate that DRS is not a viable method to monitor the redox status in saltstone.

\subsection{CHEMICAL REDOX INDICATORS}

Redox indicators have been used as chemical probes to study the redox behavior of environmental systems (Tratnyek et al. 2001). They are an approved method for use by soil surveyors interested in delineating wetlands. Wetlands commonly form "redox features" that can be tested with a redox indicator as to whether the feature is oxidized or reduced. A review of the literature found no instances of a redox indicator identified for the high $\mathrm{pH}$ surfaces of cementitious materials. Seven commercially available redox indicator dyes with a range of redox potentials were tested with saltstone and slag-free saltstone to investigate whether the indicators can identify an oxidized versus a reduced saltstone sample. The use of redox dyes can result in visual color changes that can be quite dramatic. Visual observation of indicator solution color can identify if a sample creates a potential in solution that is above or below the respective indicator reduction potential. The use of chemical redox indicators, while easy to perform, requires method development for the high $\mathrm{pH}$ conditions of cementitious materials.

\subsubsection{Materials and Methods}

A series of commercially available redox indicators provided in Table 3 were selected for use to study their feasibility in indicating saltstone redox condition. Samples without a spike were contacted with 7 redox indicators to observe variation in indictor color between saltstone with and without slag. A control sample was also used containing only indicator.

A stock solution of each indicator was prepared by dissolving $20 \mathrm{mg}$ of indicator in $10 \mathrm{~mL}$ of DI water. Cementitious material was then ground with a mortar and pestle on the benchtop and added to a sample vial containing one drop of stock indicator that was mixed into $\sim 8 \mathrm{~mL}$ of DI water. Samples were intentionally not agitated after cementitious material addition to observe whether a dramatic visual color change formed immediately in the vicinity of the solids. Samples were photographed after 1 hour and 1 day. 
Table 3. Redox Indicator and Color of Oxidized and Reduced Form.

\begin{tabular}{llrlrl}
\hline \# & Redox Indicator & $\begin{array}{r}\lambda \text {-max- } \\
\text { oxidized } \\
(\mathrm{nm})\end{array}$ & Color & $\begin{array}{r}\lambda \text {-max- } \\
\text { reduced } \\
(\mathrm{nm})\end{array}$ & Color \\
\hline 1 & 2,6 dichloroindophenolate hydrate & 601 & blue & 256 leuco \\
2 & Indigo 5,5',7,7' tetrasulfonate & 589 blue & 433 yellow \\
3 & Resazurin/Resorufin & 600 purple & 569 pink \\
4 & Indigo-5,5',7-trisulfonate & 600 blue & 421 yellow \\
5 & Indigo-5,5' disulfonate & 610 blue & 407 yellow \\
6 & Methylene Blue & 663 blue & 253 leuco \\
7 & Phenosafranin & 516 red & 249 leuco \\
\hline
\end{tabular}

*Pink represents the oxidized form of resorufin, the product of resazurin reduction.

\subsubsection{Results}

Samples were contacted with 2,6 dichloroindophenolate hydrate (\#1) and showed no visible difference between the slag and no slag sample after 1 day (Figure 7(a)). Indicators tetra-, tri-, and di-sulfonate $(\# 2,4$, and 5) behaved similarly to each other producing a distinct shift from blue to colorless for the no slag samples after 1 hour. However, the color change was from colored to colorless, signifying the indicator was reduced in the slag free sample initially. After 1 day the saltstone samples also became colorless above all solids (Figure 7(b) \#2,4, and 5). A subsequent experiment was performed with Indigo 5,5',7,7' tetrasulfonate (\#2), where the redox solution was exposed to surface scrapings of an unspiked saltstone sample, assumed to be oxidized. The solution also turned colorless indicating that the sulfonate indicators were not a promising candidate for measuring oxidized or reduced zones in saltstone. Indicators Methylene Blue (\#6) and Phenosafranin (\#7), like with 2,6 dichloroindophenolate hydrate (\#1), did not change color with saltstone or the slag-free sample, and were also screened out in these experiments. 

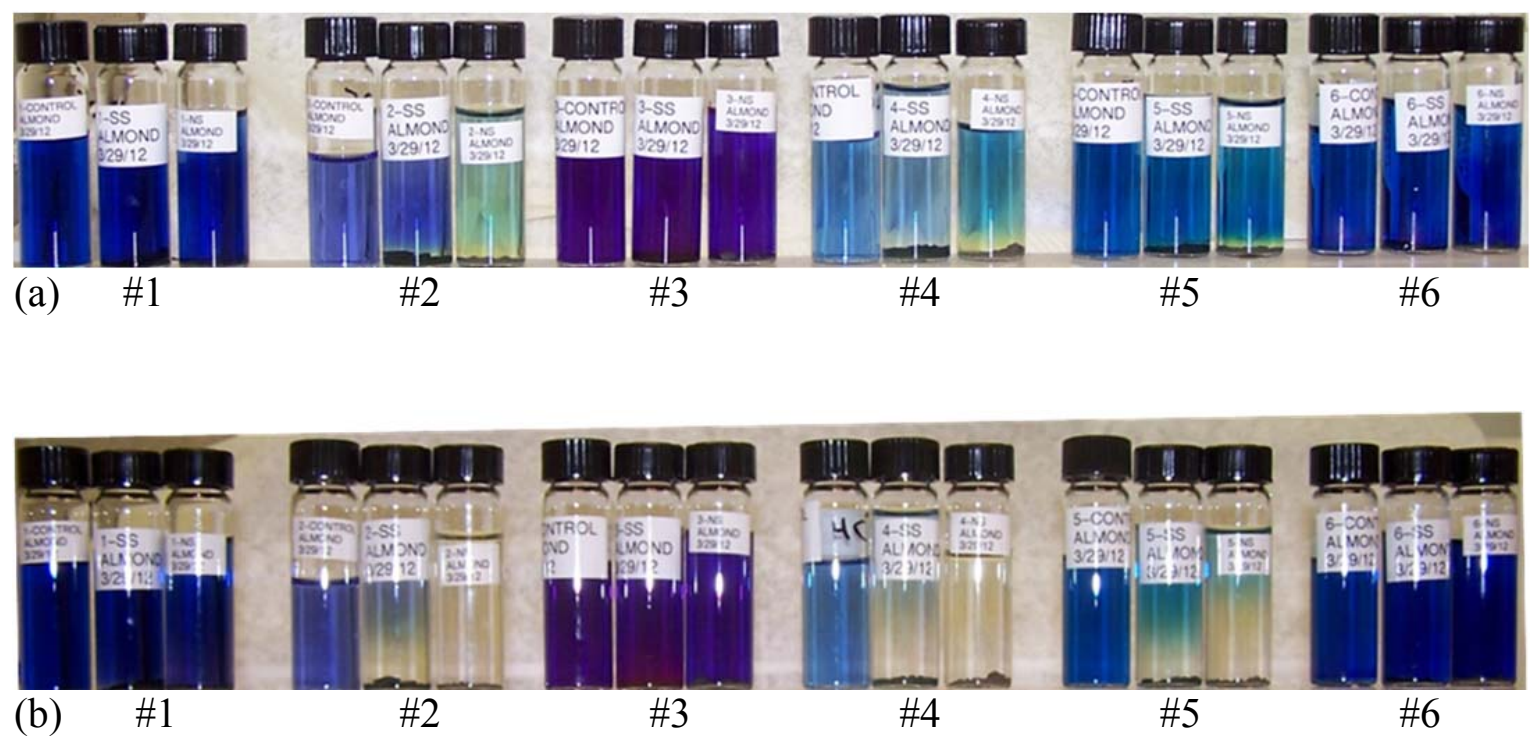

\#1) 2,6 dichloroindophenolate hydrate, \#2) Indigo 5,5',7,7' tetrasulfonate, \#3) Resazurin/Resorufin, \#4) Indigo-5,5',7-trisulfonate, \#5) Indigo-5,5' disulfonate, \#6) Methylene Blue

Figure 7. Redox indicators 1-6 consisting of a solid-free control (left), saltstone (middle), and no-slag grout (right) grouping, respectively. (a) redox indicators after $1 \mathrm{~h}$ of contact (b) redox indicators after $1 \mathrm{~d}$ of contact. Phenosafranin (\#7) not pictured.

The chemical redox indicator resazurin (\#3) reduces in 2 steps. Resazurin (purple at alkaline $\mathrm{pH}$ ) is reduced irreversibly to resorufin (pink) and then reduced reversibly to dihydroresorufin (colorless) (Tratnyek et al. 2001). Resazurin produced a color change of purple to pink for the saltstone sample, yet the slag-free sample remained purple implying a reduced solution with saltstone and an oxidized solution with the no slag sample. Additional experiments with resazurin with saltstone demonstrated that the amount of sample used had an impact on whether or not the color changed, leading to an ambiguous result.

To validate this analytical approach, an understanding of the mechanism and experimental conditions that cause the color change is needed. Additionally, analysis of redox solutions using $\mathrm{UV}-\mathrm{V}$ is spectroscopy could aid in tracking changes in the redox indicators (by $\lambda$-max) and quantifying the amount of indicator that was reduced in each experiment.

\subsubsection{Summary of Redox Indicator Analyses}

In summary, these results did not confirm that chemical redox indicators studied under these conditions could be used as a viable method to monitor the redox status in saltstone.

Observations from this work indicate that while the data are inconclusive, resazurin and chemical redox indicators in general cannot be ruled out altogether for use as a probe of redox condition in saltstone and may warrant further study. 


\subsection{THIN-SECTION LEACHING}

An approach for measuring an oxidation front based on leaching of spiked contaminants is described in this section. Chromium and rhenium (Re) were evaluated as oxidation-reduction tracers in the saltstone sample using laboratory-cured samples (Section 3.1). The premise of this method is that the oxidized form of the tracer is soluble and therefore leachable, whereas the reduced form is insoluble and does not significantly contribute to the spike in the leachate. Demonstrating a divergence in leachability for the tracer in reduced versus oxidized saltstone, and developing the ability to measure the leachability profile of the tracer versus depth of a saltstone monolith was targeted for method evaluation. The comprehensive leaching experimental setup and results are described in SRNL-L3100-2012-00033 (Langton and Stefanko 2012a).

\subsubsection{Materials and Methods}

Leaching was performed using a modified Toxicity Characteristic Leaching Procedure (TCLP) approach (EPA Manual SW-846 Method 1311).

Subsamples of the cured saltstone cylinders were collected as a function of distance from the top surface which was exposed to air in the partially filled curing container. ${ }^{1}$ The objective was to evaluate the depth to which chromium and rhenium solubility was impacted by the surface being exposed to air during the 35 to 37 days the samples were cured. The fraction of soluble chromium and rhenium is used as an indication of the oxidation front into the sample from the surface. $^{2}$

The saltstone sample was removed from the capped plastic vials and examined for color change which was confirmed to be a rough indication of the depth of the oxidation front. ${ }^{3}$ See Figure 8(a). A caliper was used to measure sample dimensions. The smallest division for the caliper used to measure samples was $1 / 10 \mathrm{~mm}$. Measurements less than the smallest division were estimated based on relative position between readings. Sample heights and thicknesses were always measured in two directions (i.e., $90^{\circ}$ apart or opposite).

\footnotetext{
${ }^{1}$ Measurements were actually made with respect to distance from the bottom surface because wafers were removed from the top.

${ }^{2}$ The top of the sample was lighter color than the bulk sample. The sides of the cylindrical samples were also a light gray color. No attempt was made to exclude the light colored material on the sides from the subsamples.

${ }^{3}$ For saltstone spiked with $1000 \mathrm{mg} / \mathrm{kg} \mathrm{Cr}$, dark color is an indication of chemically reduced conditions. Light gray to tan to yellow color is indicative of oxidized material.
} 


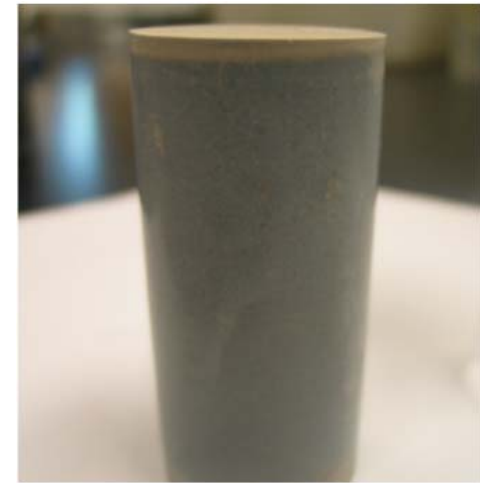

(a)

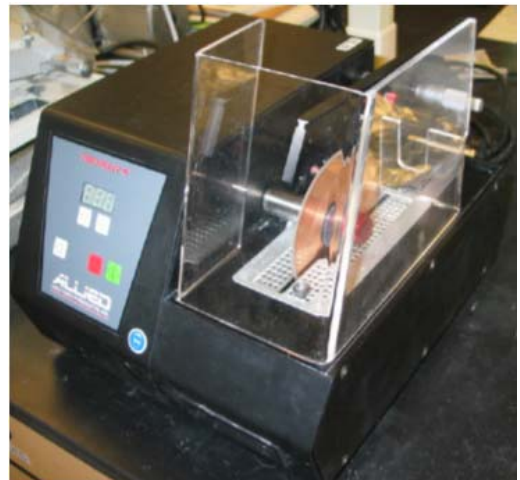

(b)

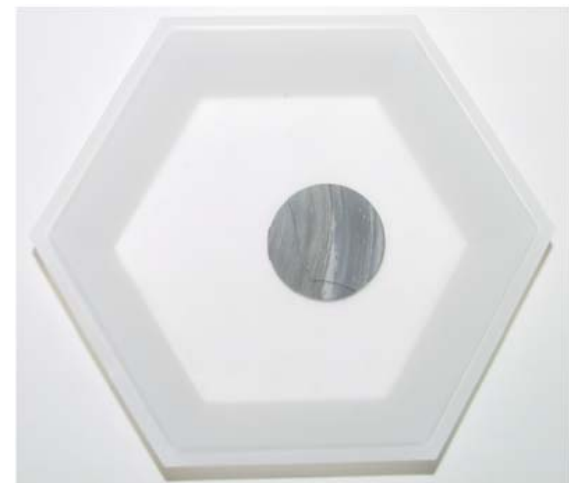

(c)

Figure 8. (a) Saltstone sample removed from curing mold, (b) TECHCUT4 saw used for cutting disks from grout cylinders, and (c) cut sample wafer.

Wafers were sliced from the samples starting from the top surface which was exposed to air in the curing vial. A TECHCUT4 ${ }^{\mathrm{TM}}$ saw with a low concentration diamond blade and jig for holding the sample were used to cut the wafers. See Figure 8(b). Practice cuts were made on a test specimen. The nominal blade speed while cutting samples was $200 \mathrm{rpm}$. The samples were cut dry (no water or other lubrication), and plastic forceps were used for handling cut pieces to reduce cross-contamination. ASTM type I water (ASTM D1193) and tissue paper were used to clean the saw blade between cuts to avoid cross-contamination. Care was taken to minimize the sample handling time and thereby the time the demolded samples were exposed to air (oxygen). Minimal oxidation during sample preparation was later confirmed by the chromium leaching results for the bulk material, which were $1000 \mathrm{X}$ less that the results for the top surface.

The thinnest wafer that could be cut with the TECHCUT4 ${ }^{\mathrm{TM}}$ saw was $1.5 \mathrm{~mm}$. See Figure 8(c). Samples representing layers for depths less than $1.5 \mathrm{~mm}$ were achieved with a small stainless steel spatula by scraping the surface of the grout cylinders into a disposable polystyrene weighing dish. See Figure 9(a).

Each layer removed from the original sample was size reduced (crushed) with a mortar and pestle to produce a sample for the short term leach test (Modified EPA 1311). See Figure 9(b). The size reduced sample was placed into the leaching vial and weighed. Each vial contained a unique mass of material which depended on the thickness of the layer sampled. The amount of leachate also varied because each vial was completely filled. The vial was completely filled with the de-aerated ASTM water. Vials were always filled so no air pocket remained after capping. An analytical balance was used to determine the sample mass and leachate volume (assuming 1 $\mathrm{g} / \mathrm{mL}$ ). See Figure 9(c). The mortar and pestle was cleaned with ASTM water and tissue paper between subsamples. 


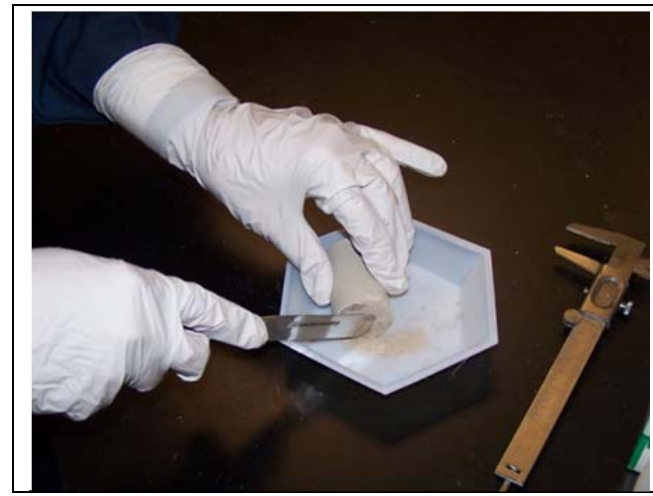

(a)

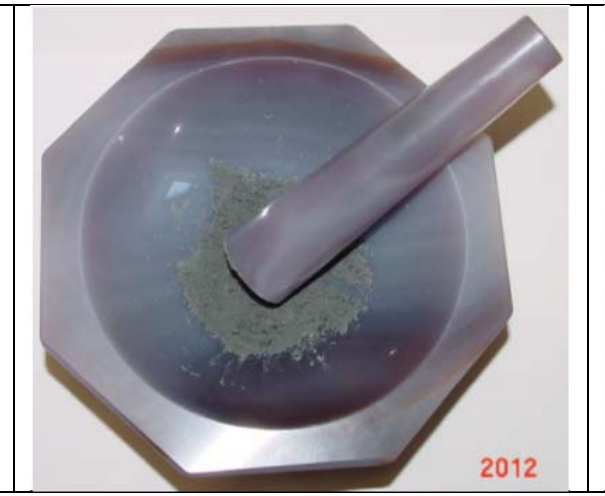

(b)

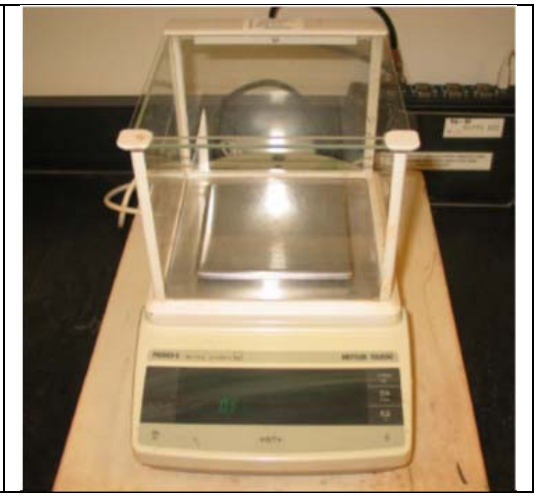

(c)

Figure 9. (a) Spatula generated subsample, (b) Mortar and pestle for size reducing grout sample disks, and (c) Balance used for determining subsample mass and leachate volume.

Leachate Preparation: ASTM Type I water (ASTM 1193) was selected as the leaching solution. (The leachate was not $\mathrm{pH}$ adjusted as in the TCLP Extraction Test.) The $\mathrm{pH}$ was 6.94. Because this water was to be used for a redox sensitive leaching study, the water was de-aerated by boiling in an open stainless steel container for 15 minutes. The water was subsequently cooled to room temperature in a sealed container that was placed in an ice bath before contacting the crushed samples. (Less than 5 hours elapsed between boiling the water and filling the leaching vials.)

Because this study involves leaching contaminants that are oxygen sensitive, a zero-head space leaching vessel configuration was used. The leaching vials were clear $40 \mathrm{ml}$, WHEATON-33 ${ }^{\mathrm{TM}}$ borosilicate glass. The vial lids had 2 pieces: cap and a PTFE/Silicon septum. See Figure 10(a and $b$, respectively).

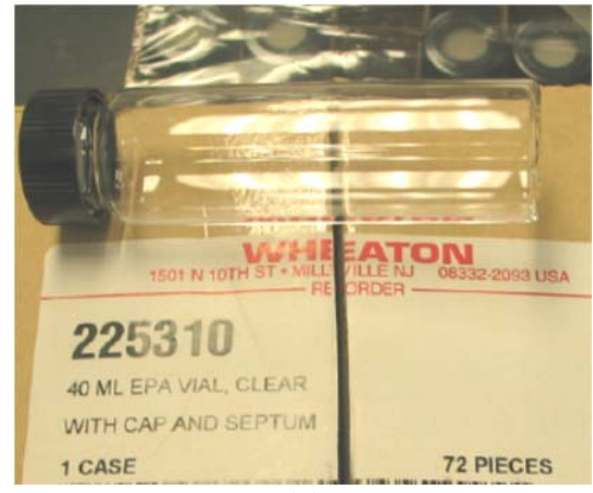

(a)

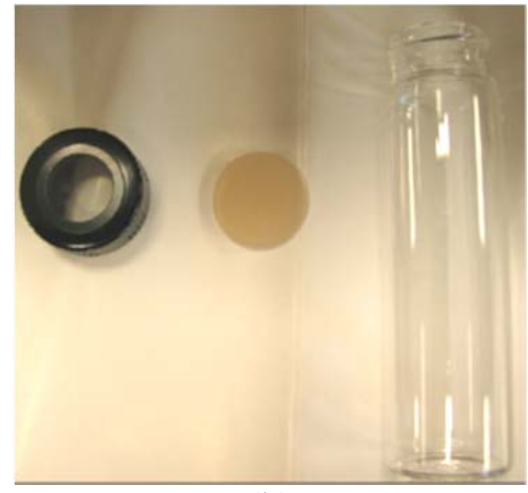

(b)

Figure 10. Vials used for leaching crushed subsamples, (a) Supplier information and (b) vial components - cap, septum and glass bottle (from left to right).

Multiple vials were individually wrapped and placed inside a large mouth bottle which was tumbled end-over-end for 20 hours. See Figure 11(a and b, respectively). The tumbler rotated at $30 \mathrm{rpm}$. 


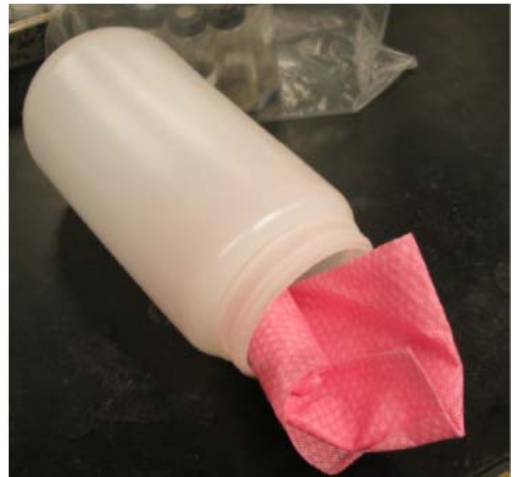

(a)

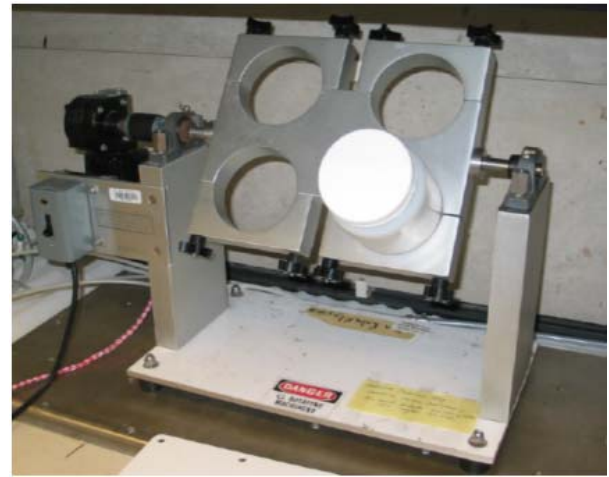

(b)

Figure 11. (a) Leaching bottles being wrapped and stacked inside large-mouth plastic bottle for end-over-end tumbling and (b) equipment for tumbling crushed samples at $30 \mathrm{rpm}$ for $18 \pm 2$ hr.

Leachate Analysis: After tumbling, leachates were extracted and filtered using a 0.45 micron membrane. The concentrations of $\mathrm{Ca}, \mathrm{K}, \mathrm{Al}, \mathrm{Cr}, \mathrm{Re}$, and $\mathrm{Na}$ were measured using an Inductively Coupled Plasma (ICP) optical emission spectrometer, Varian 730-ES. Concentrations of $\mathrm{Cl}^{-}$, $\mathrm{NO}_{2}^{-}, \mathrm{PO}_{4}^{-}, \mathrm{F}^{-}, \mathrm{NO}_{3}^{-}, \mathrm{SO}_{4}^{-}$and $\mathrm{C}_{2} \mathrm{O}_{4}{ }^{2-}$ were analyzed using Ion Chromatography (IC).

The filtrate was diluted up to $1000 \mathrm{X}$ in some cases to accommodate the detection ranges and equipment sensitivity for constituents. ${ }^{4}$ The $\mathrm{pH}$ and conductivity of the filtrates were also determined using an IQ Scientific $\mathrm{pH}$ meter and a Thermo Scientific Orion 4 Star conductivity meter. ASTM Type I/II water was used to clean the probes between samples. Leachate analyses were run in duplicate. Values were averaged and used to calculate the fraction leached (percent leached) for a sample set cured for 35 to 37 days. Percent of each species leached was calculated using the following equation:

$\%$ Leached $=100 *\left(\frac{m_{\text {i-leachate }}}{m_{\text {itotal-solid }}}\right)$

Where:

$\mathrm{m}_{\mathrm{i} \text {-leached }}=$ mass of species i leached $(\mathrm{mg})$.

The leachate was filtered prior to analysis using a $0.45 \mu \mathrm{m}$ filter.

$\mathrm{m}_{\mathrm{i} \text {-total }}=$ mass of species $\mathrm{i}$ in the waste form $(\mathrm{mg})$.

The total amount in the waste form was approximated and only reflects the contribution to the waste form from the spiked mixing solution.

\subsubsection{Results}

The fraction leached or the percent leached (fraction leached X 100) from each crushed wafer was selected as the parameter for contaminant leaching results and demonstrating applicability of this method in determining the effective oxidation front. The top surfaces of the samples were exposed to air in the sample vials and the redox sensitive contaminants such as chromium were expected to be oxidized to soluble species near the surface and reduced as insoluble species at

\footnotetext{
${ }^{4}$ Actual dilutions: $\mathrm{Na}(1000 \mathrm{X}), \mathrm{Ca}$ and $\mathrm{K}(100 \mathrm{X})$, other constituents (10X)
} 
some depth below the exposed surface. The contaminants that are not redox sensitive such as $\mathrm{NO}_{3}{ }^{-}$were expected to have about the same fraction leached regardless of location of the sample relative to the top surface.

Results for $\mathrm{Cr}, \mathrm{Re}, \mathrm{NO}_{3}{ }^{-}$and $\mathrm{NO}_{2}{ }^{-}$were plotted as a function of sample interval. Nitrate results were used to compare the effect of microstructure (microencapsulation) on the leaching results for species that are not chemically bound in the waste form. Nitrate is, at best, only weakly bound in slag and no slag matrices. The microstructures, (i.e., pore size distribution and tortuosity) are different for these two waste forms, and therefore, the nitrate extraction rate is expected to be slightly different.

The $\mathrm{NO}_{3}{ }^{-}$fraction leached from the three no-slag waste form samples cured for 35 to 37 days ranged from about 0.13 to about 0.15 regardless of the sample depth-interval. See Figures 12(a, $\mathrm{b}$ and c). The $\mathrm{NO}_{3}{ }^{-}$fraction leached from two slag saltstone samples cured for 35 to 37 days ranged from about 0.10 to about 0.15 regardless of the sample depth-interval. See Figures 13(b and c).

The chromium fraction leached from the no-slag waste form ranged between 0.05 and 0.08 and appeared to be independent of the sample depth-interval. The depth interval pattern is consistent with that for $\mathrm{NO}_{3}{ }^{-}$in the sample analyzed (Figure 12(e)). A comparison of chromium and $\mathrm{NO}_{3}{ }^{-}$ leached from the chromium-spiked sample suggests that chromium is slightly better bound in the no-slag sample (cement-fly ash matrix) than $\mathrm{NO}_{3}{ }^{-}$(about $2.25 \mathrm{X}$ better). A possible explanation for this is that a small fraction of the chromate is incorporated in the structure of the calcium alumino sulfate phases in place of sulfate ions (Perkins and Palmer 2000).

The chromium fraction leached from the slag saltstone sample ranges from about 0.17 from the exposed surface to 0.0002 from a layer 8.0 to $14.0 \mathrm{~mm}$ below the exposed surface. This is a difference of about 1000X as illustrated in the semi log plot provided in Figure 13(d). Figure 13(e) illustrates fractions of chromium leached as a function of distance from the top surface. In order to compare the cumulative fraction leached from the top $3.0 \mathrm{~mm}$ of the slag saltstone sample (4 layers) to the top $3.0 \mathrm{~mm}$ of the no-slag saltstone (1 layer), the cumulative fractions for the slag saltstone samples were added to give 0.078. This is illustrated in Figure 13(e). 


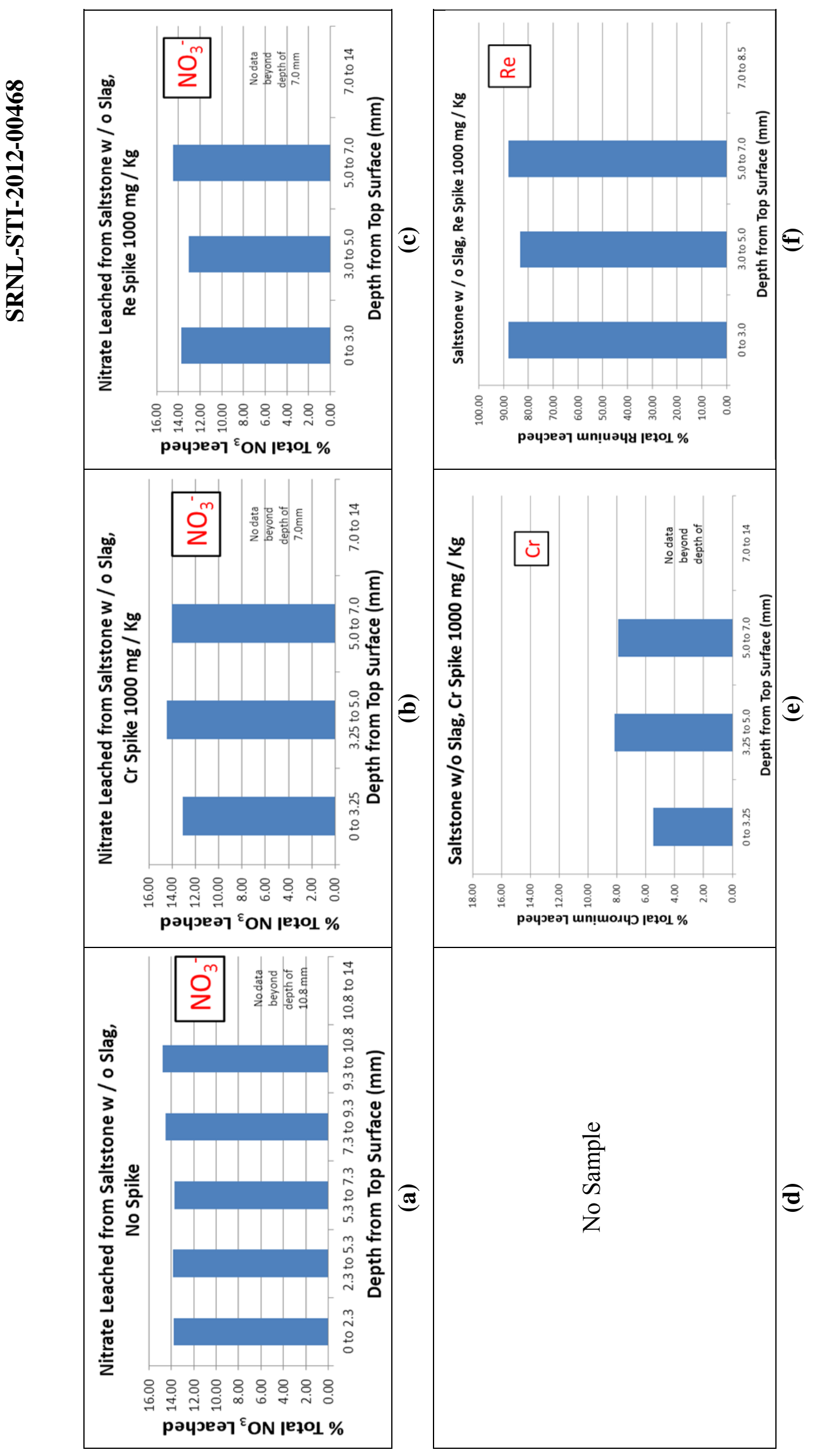




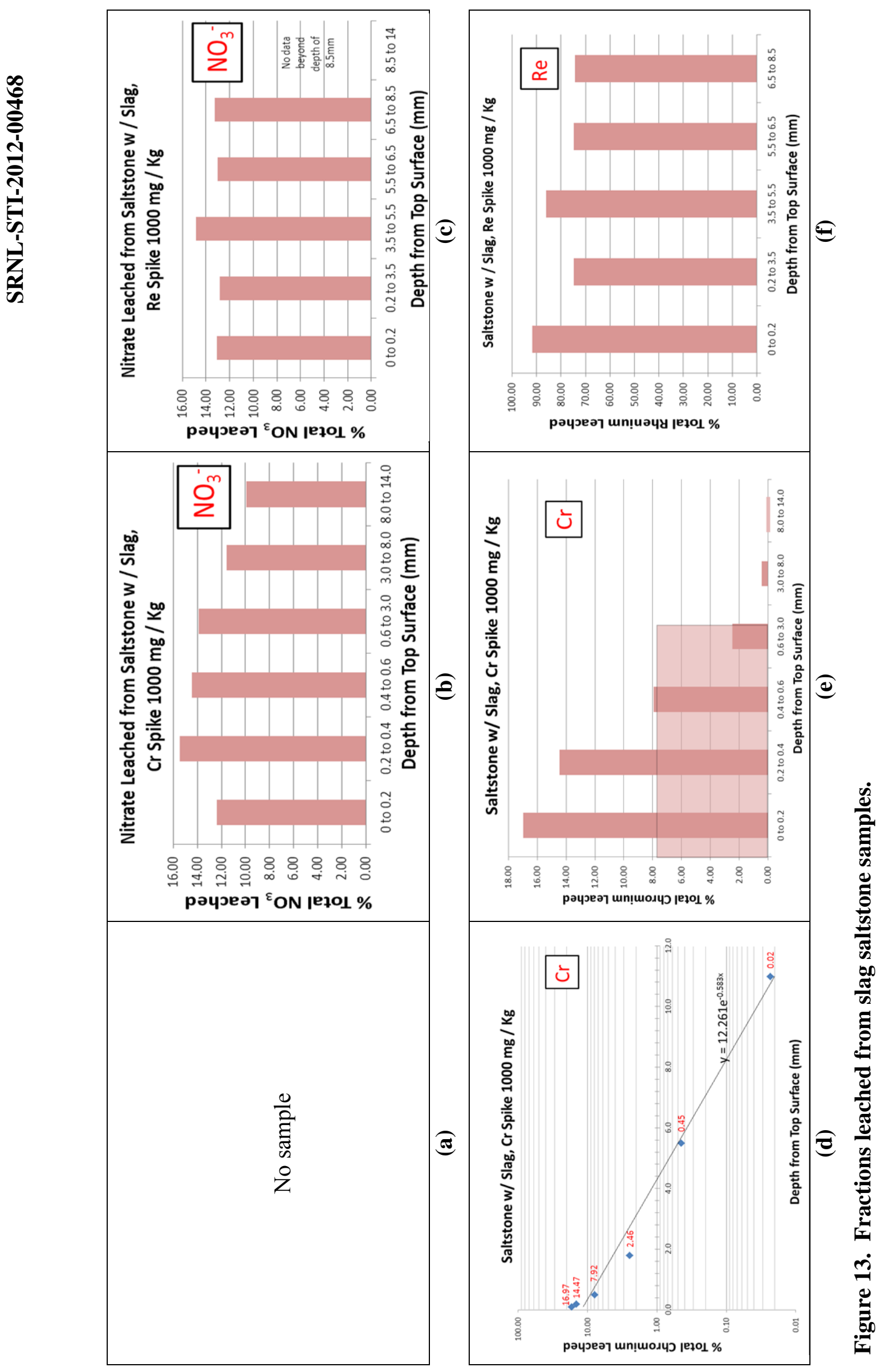



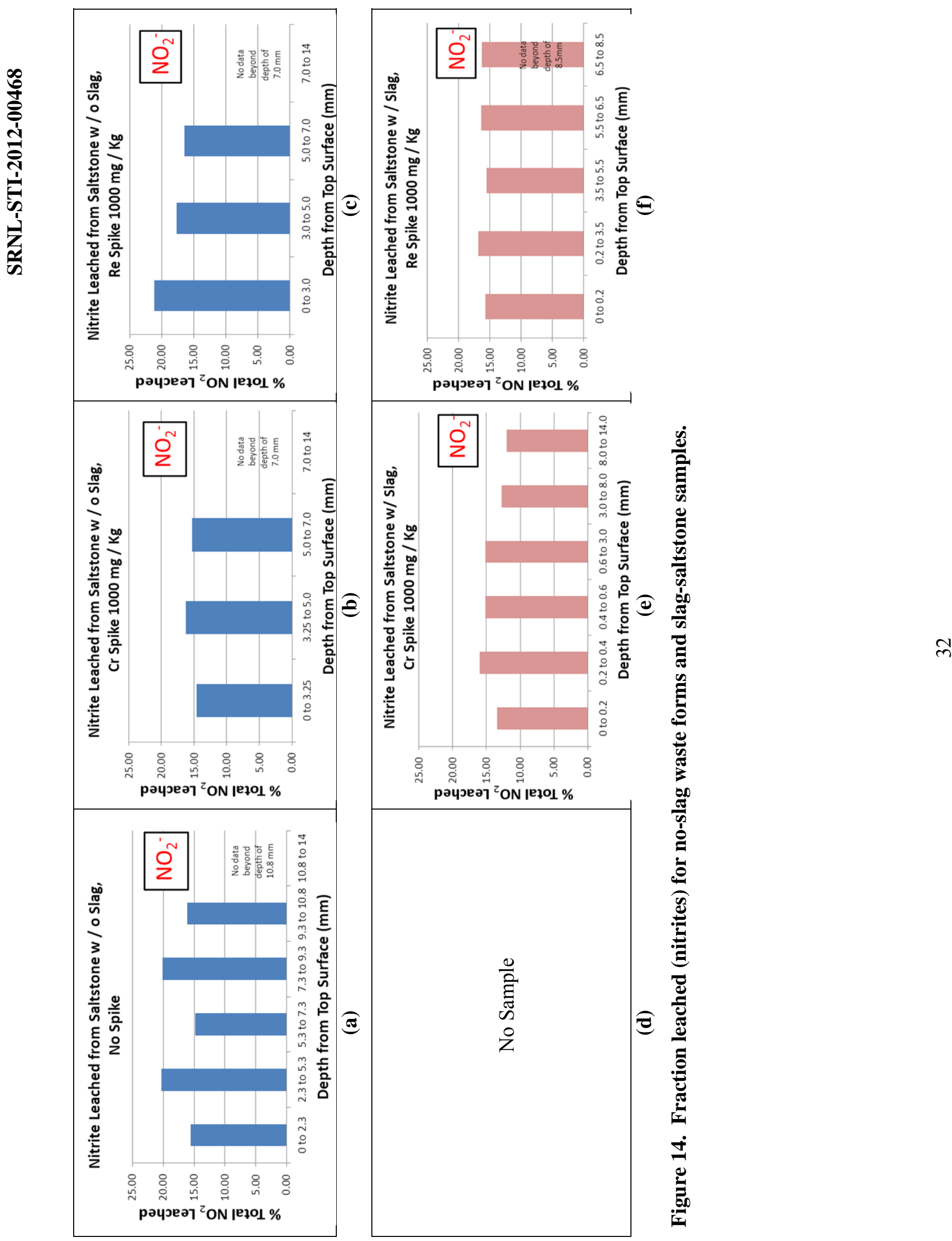


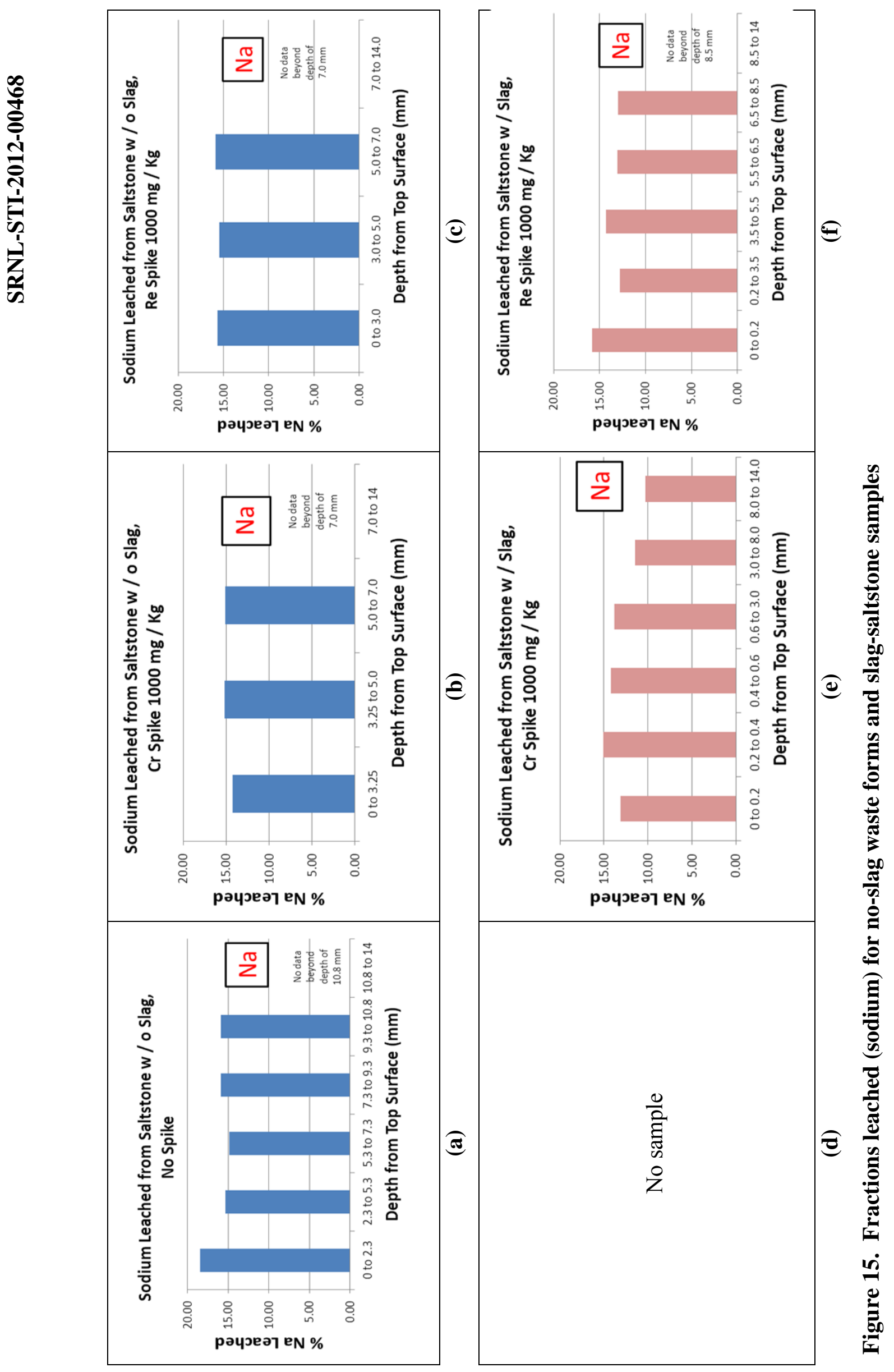


The chromium fractions leached from the top $7 \mathrm{~mm}$ of the slag saltstone sample indicates that chromium is stabilized below $7 \mathrm{~mm}$ and is progressively more soluble, and by inference, more oxidized, in samples collected nearer to the surface. The chromium fraction leached from the top layer ( 0 to $0.2 \mathrm{~mm}$ ) is $1000 \mathrm{X}$ greater than the fraction leached from the wafer taken from 8.0 to $14.0 \mathrm{~mm}$ below the top surface. The nitrate fraction leached from wafers cut from the top $14 \mathrm{~mm}$ was also about $1000 \mathrm{X}$ greater that the chromium fraction leached below $8.0 \mathrm{~mm}$ from the surfaced (reduced material). These results are interpreted to infer that chromium is chemically stabilized in the slag saltstone matrix to the extent that the fraction leached is $1000 \mathrm{x}$ less than that of $\mathrm{NO}_{3}{ }^{-}$which is only very slightly bound in the matrix.

The $\mathrm{NO}_{2}^{-}$fractions leached from the no-slag saltstone samples ranged from 0.15 to 0.21 for the different sampling depth intervals. See Figures 14(a, b, and c). The nitrite fractions leached from the chromium spiked slag-saltstone were from 0.12 to 0.16 with little variation between subsamples collected. See Figure 14(e). These results are consistent with microencapsulation but no chemical stabilization of nitrite in both the slag and no-slag saltstone compositions. Nitrite leaching from the Re-spiked slag saltstone samples ranged from 0.16 to 0.17 . See Figure 14(f).

The results for sodium leached from the oxidation study samples are included in Figures 15. The fractions leached for the no-slag waste forms ranged from 0.14 to 0.18 . See Figures 15 $(a, b$, and $c)$. The highest sodium leached was from the exposed surface for the samples not spiked with chromium or rhenium. Sodium leaching results for the two slag saltstone samples are presented in Figures 15(e and f). The highest fraction leached, 0.158, was from the rhenium spiked sample and from material removed within $0.2 \mathrm{~mm}$ of the top surface. The lowest fraction leached was from the chromium spiked slag-saltstone and material collected from the 8.0 to $14.0 \mathrm{~mm}$ depth interval.

In this set of samples, chromium is the only element that showed a marked difference in fraction leached as a function of distance from the top surface, i.e. the surface exposed to air. The rhenium leaching did not display a change in leachability vs. sample depth analogous to chromium. Chromate, $\mathrm{CrO}_{4}{ }^{2-}$, spiked into the salt solution at $1000 \mathrm{ppm}$ used to make the saltstone is $100 \%$ soluble in the solution (See Section 3.1). If this chromium had not been chemically reduced and precipitated as a low solubility solid or very strongly sorbed, the fraction leached would be expected to be similar to that of $\mathrm{NO}_{3}{ }^{-}$. Consequently it is assumed to be chemically stabilized. EXAFS and solution chemistry results indicate that chromate is chemically reduced and is assumed to be precipitated as $\mathrm{Cr}(\mathrm{OH})_{3}$ in slag alkaline reducing waste forms. This process is assumed to have occurred uniformly throughout the sample.

\subsubsection{Summary of Thin-Section Leaching Analyses}

The leaching results indicate that post curing conditions related to the exposed surface affected the chromium leachability from the slag saltstone samples. Even though the amount of oxygen in the air above the sample was somewhat limited it appears have contained enough oxygen to oxidize a portion of the chromium at the surface layer to a depth of about 8 $\mathrm{mm}$. The resulting oxidized chromium forms chromate ions and is soluble. The amount of 
chromium leached from the various layers cut from the no slag saltstone was fairly uniform regardless of the distance from the top surface.

Thin-section leaching was validated as a viable characterization method for determining an effective oxidation front progression in saltstone by probing chromium redox behavior. Minimal oxidation during sample preparation was confirmed by the chromium leaching results for the slag saltstone bulk material, which were indicative of the presence and persistence of a chemically reduced low solubility chromium phase.

\subsection{METHOD VALIDATION}

Method evaluation was conducted for 4 analytical approaches (Section 3). XAS and thinsection leaching methods were validated (see Sections 3.2 and 3.5, respectively) through experimentation with laboratory-cured samples. These validated methods were subsequently applied to field-cured samples. Results are presented in Section 4. 


\subsection{FIELD SAMPLE MEASUREMENTS}

\subsection{SAMPLE PREPARATION AND CURING CONDITIONS}

Field samples were prepared at SRNL similar to the method evaluation samples (see Section 3.1). However, samples were filled to the top to mitigate oxygen exposure to the sample until placement in the field. Samples were stored at SRNL in a humid box with their caps closed for a period of generally 1 to 3 weeks until they were transferred to the specified field location in Z-area. A location was selected by Closure and Waste Disposal Authority (C\&WDA) underneath the SPF premix silos (Figure 16 ( $a$ and b)) to provide exposure to environmental conditions while providing some shelter from rain and direct sunlight, in an attempt to simulate disposal unit performance. Two installments of samples were placed in the field, initially on $3 / 15 / 12$ and again on $4 / 25 / 12$. The samples were uncapped and placed into a closed chest along with an open container of water (Figure 16 (c and d)). The chest was secured with a zip-tie to restrict access. The samples cured in Z-area for $\sim 4$ months before they were analyzed.

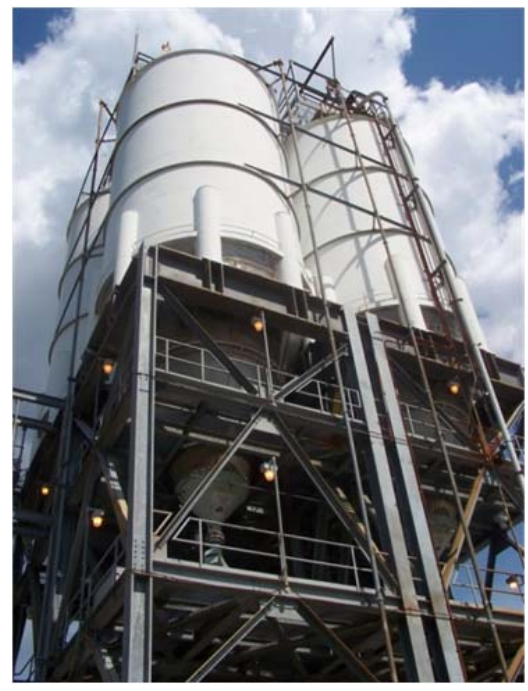

(a)

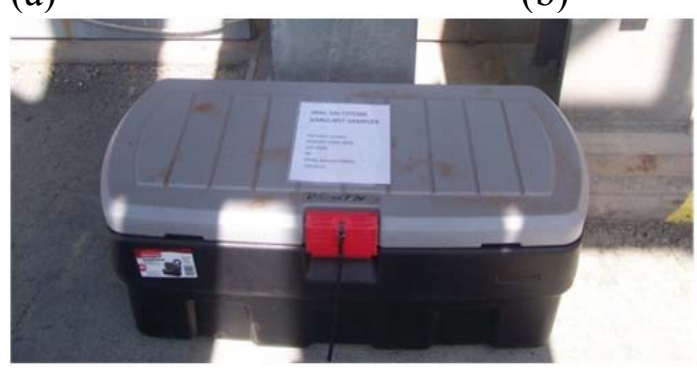

(c)

(b)
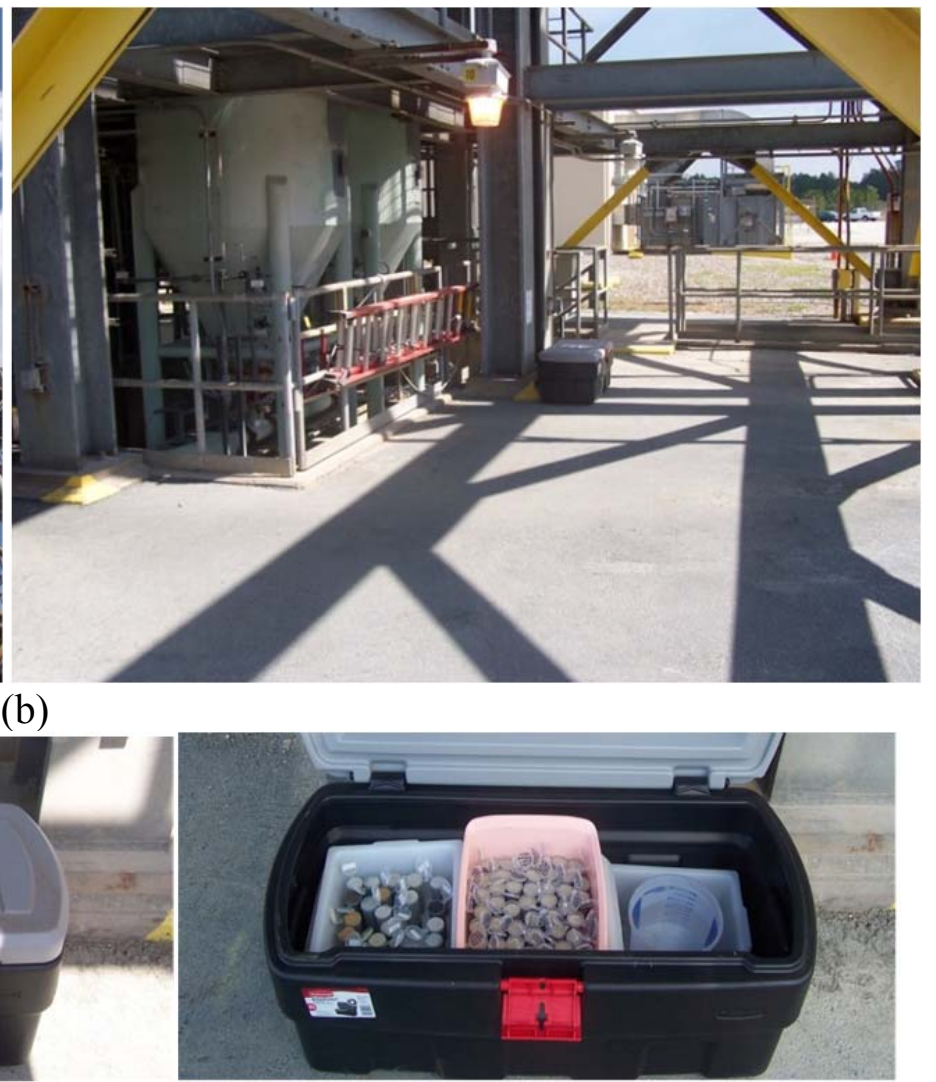

(d)

Figure 16. (a) SPF premix silos in Z-area. (b) Field sample chamber located below premix silos. (c) Field sample chamber closed (d) Field sample chest open revealing samples and an open container of water. 
Temperature and relative humidity were monitored from inside the sample chamber every hour using an EM50 series datalogger by Decagon using an EHT Temp/RH digital sensor. It was installed in the field on $4 / 25 / 12$ and data were retrieved on $6 / 25 / 12$. Relative humidity ranged from $26.3-99.6 \%$ and temperature ranged from $14.3-41.4{ }^{\circ} \mathrm{C}\left(57.7-106.5^{\circ} \mathrm{F}\right)$ fluctuating daily corresponding to daily weather conditions (Figure 17).

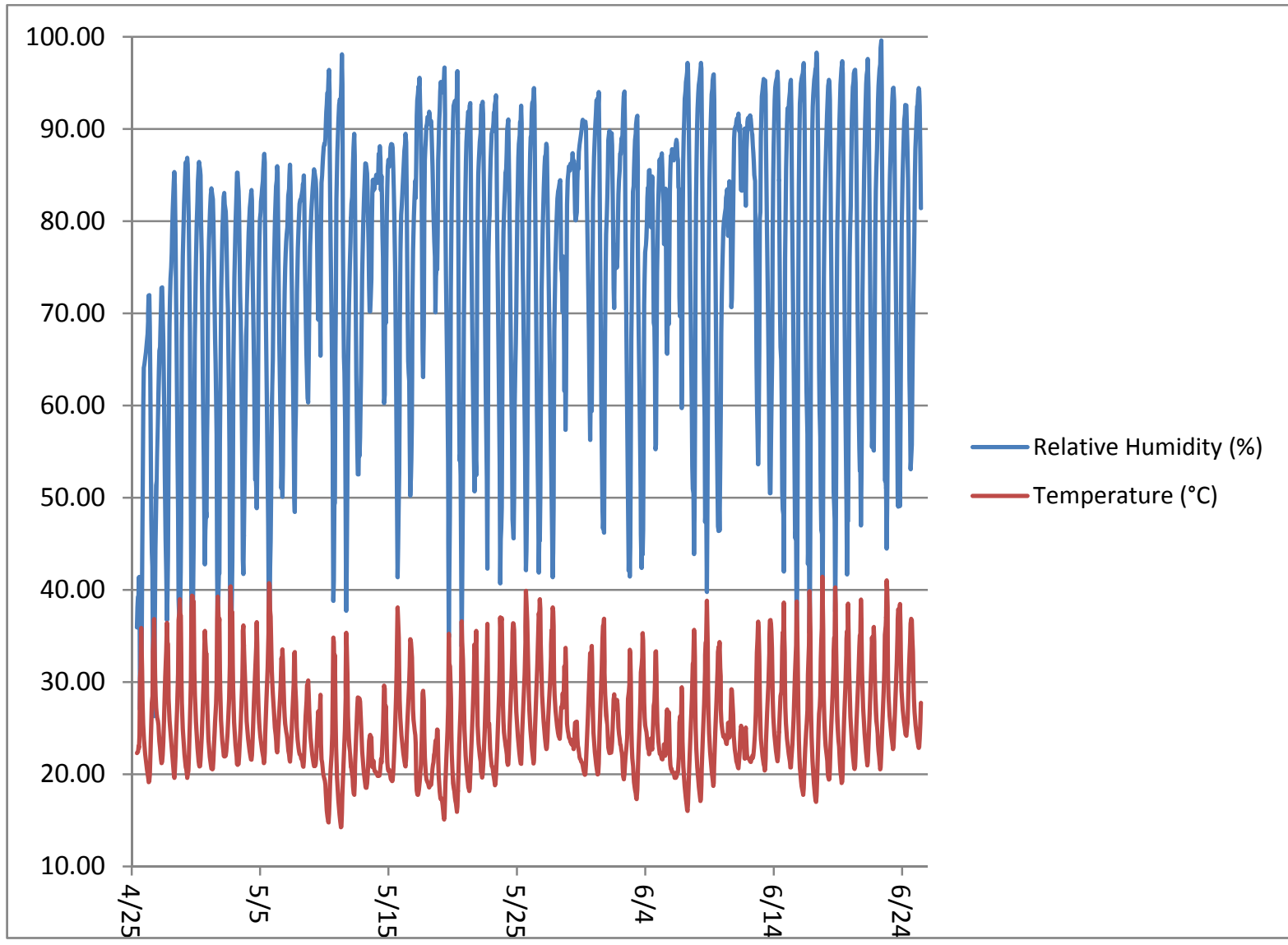

Figure 17. Plot of relative humidity and temperature from within field sample chest while curing.

\subsection{THIN-SECTION LEACHING}

The comprehensive experimental procedure and results for field sample analysis by leaching are described in SRNL-L3100-2012-00103 (Langton and Stefanko 2012b). The premise of this method is that $\mathrm{Cr}(\mathrm{VI})$ is soluble and therefore leachable, whereas $\mathrm{Cr}(\mathrm{III})$ is not soluble and does not significantly contribute to the chromium in the leachate. $\mathrm{Cr}(\mathrm{VI})$ is present in salt solution as the oxidized species $\mathrm{CrO}_{4}{ }^{2-}$, and $\mathrm{Cr}(\mathrm{III})$ is the reduced species which is assumed to be precipitated as $\mathrm{Cr}(\mathrm{OH})_{3}$. Consequently, if the chromium is reduced and precipitated during the first week of premix hydration, then the detection of $\mathrm{Cr}(\mathrm{VI})$ in the saltstone by leaching crushed material in deionized de-aerated water indicates oxidation of the sample. The depth below the surface that soluble chromium $(\mathrm{Cr}(\mathrm{VI}))$ is detected is an 
indication of the approximate oxidation front. The oxygen transport into the saltstone matrix is expected to be a diffusion process characterized by a concentration gradient decreasing as a function of distance from the exposed surface. Therefore, a gradient is also expected for soluble chromium as a function of depth.

\subsubsection{Materials and Methods}

The ingredients and proportions in the simulated salt solution used for preparing the saltstone samples are provided in Section 3.1 and Table 4.

Table 4. Ingredients and Proportions in Samples Prepared for the Leach Method Development.

\begin{tabular}{|l|c|c|c|c|c|c|}
\hline Sample Description & $\begin{array}{c}\text { Batch } \\
\text { Number }\end{array}$ & $\begin{array}{c}\text { Premix } \\
\text { Batch 1 } \\
\text { (g) }\end{array}$ & $\begin{array}{c}\text { Premix } \\
\text { Batch 2 } \\
\text { (g) }\end{array}$ & $\begin{array}{c}\text { Na } \mathbf{C r O}_{4} \\
\text { (g) }\end{array}$ & $\begin{array}{c}\text { Salt } \\
\text { solution } \\
\text { (g) }\end{array}$ & $\begin{array}{l}\text { water } \\
\text { /pre- } \\
\text { mix }\end{array}$ \\
\hline \hline Saltstone w/ Slag, 1000 mg / kg Cr & 11 & 249.1 & -- & 1.402 & 200.9 & 0.6 \\
\hline \hline Saltstone w/ Slag, 500 mg / kg Cr & 10 & -- & 249.1 & 0.7009 & 200.9 & 0.6 \\
\hline \hline Saltstone w/ Slag, $20 \mathrm{mg} / \mathrm{kg} \mathrm{Cr}$ & 9 & -- & 249.1 & 0.0280 & 200.9 & 0.6 \\
\hline
\end{tabular}

The chromium-spiked 1000 and $20 \mathrm{mg} / \mathrm{kg}$ samples were retrieved from Z-Area and sectioned on $6 / 20 / 12$. Total curing times for these samples were 118 and 105 days. The $500 \mathrm{mg} / \mathrm{kg}$ sample was retrieved and sectioned on $6 / 26 / 12$. The total curing time for this sample was 111 days. Temperature and humidity data inside the container were recorded (Section 4.1).

Figure 18 illustrates macroscopic differences among the samples spiked with 1000, 500, 20 $\mathrm{mg} / \mathrm{kg}$ chromium. The surface of $1000 \mathrm{mg} / \mathrm{kg}$ chromium sample was a medium tan color and the top $\sim 5 \mathrm{~mm}$ was light tan. The exterior surfaces of the 500 and $20 \mathrm{mg} / \mathrm{kg}$ chromium spiked samples were dark to medium gray. The top $\sim 5 \mathrm{~mm}$ of each of these the samples was light gray. The sample containers were completely filled and the color change was apparent before removing the samples from the containers. The difference in curing times for these three samples was 18 days. $^{5}$

\footnotetext{
${ }^{5}$ If more than one mechanism is responsible for the differences observed or if a non-time dependent mechanism is contributing to the observations, additional data will be required to obtain rate data.
} 


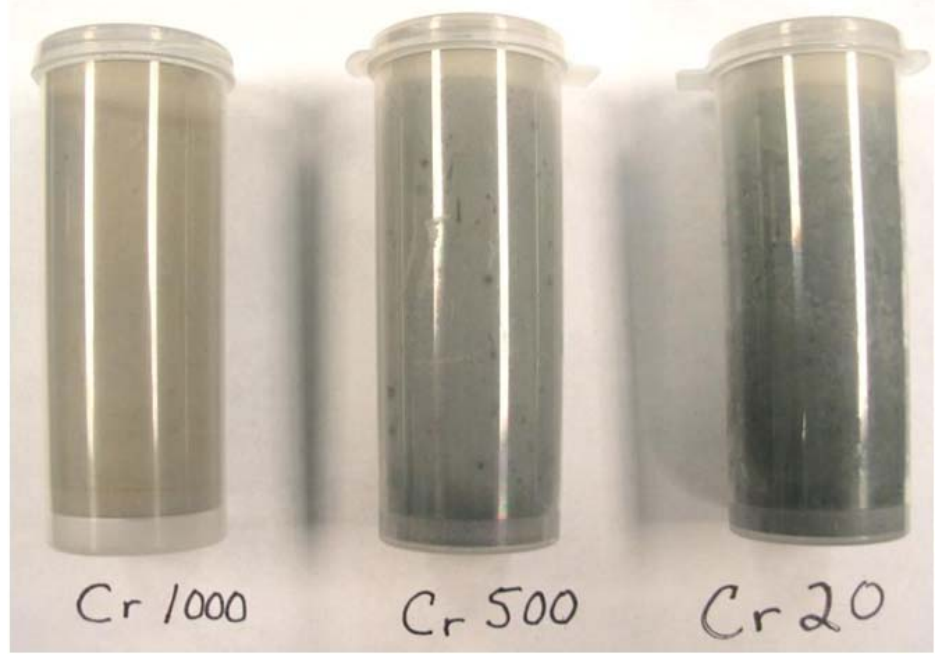

Figure 18. Appearance of three field cured samples illustrating color differences and dark specks in the Cr 500 and Cr 20 samples.

Color differences were also observed in the saltstone samples after they were removed from the $1 \times 4$ inch plastic containers. See Figure 19. Because of the noticeable color change in the top 0.5 to $1 \mathrm{~cm}$ of the samples, relatively thin slices were collected in this region to document expected gradients. Thicker slices were taken deeper in the samples where the color was more uniform. The most subsamples were cut for the last sample analyzed, samples containing $500 \mathrm{mg} / \mathrm{kg}$ chromium, in an attempt to obtain a leaching profile over the entire sample length. 


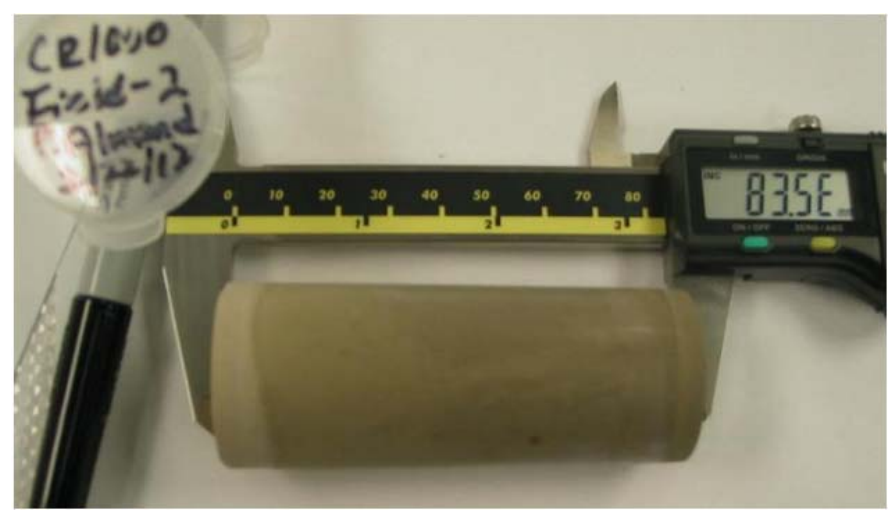

(a) Field-cured sample spiked with $1000 \mathrm{mg} / \mathrm{kg}$ chromium prior to sectioning.

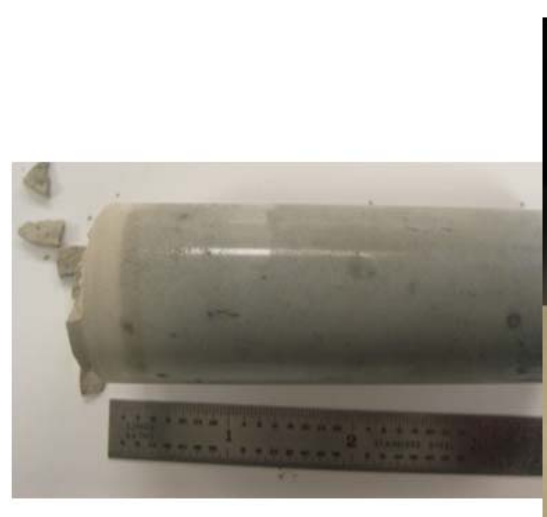

(b) Sample spiked with $500 \mathrm{mg} / \mathrm{kg}$ chromium prior to sectioning w/black specks.

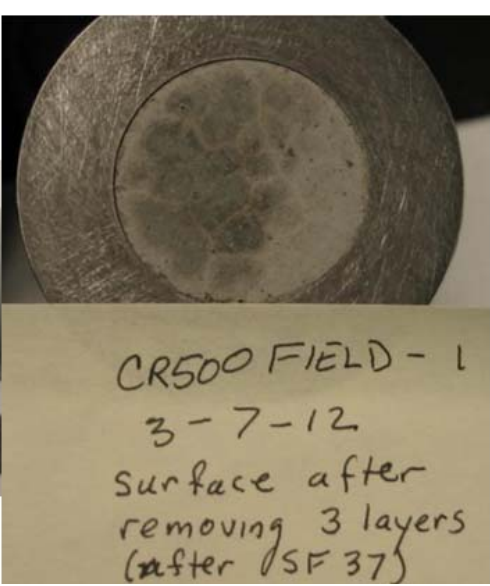

(c) $500 \mathrm{mg} / \mathrm{kg}$ chromium sample illustrating mottled surface $(\sim 7.5 \mathrm{~mm}$ below exposed top surface).

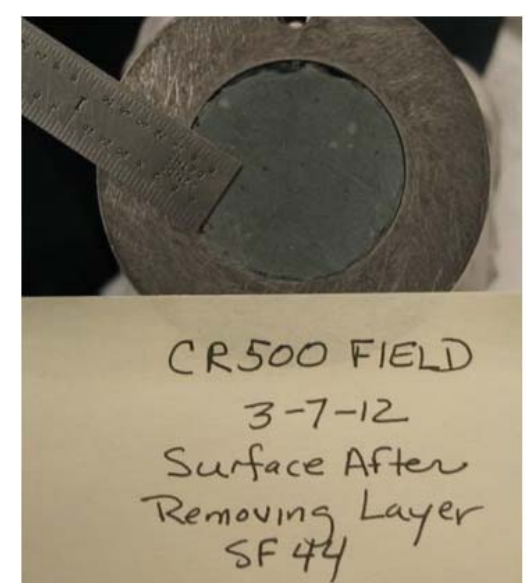

(d) Less mottled surface $(\sim 15$ to 16 $\mathrm{mm}$ below exposed top surface).

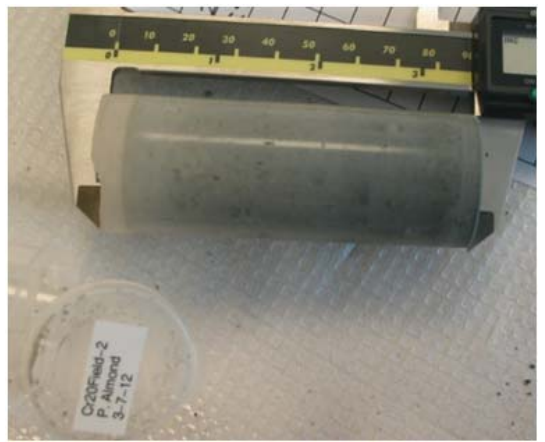

(e) Sample spiked with $20 \mathrm{mg} / \mathrm{kg}$ chromium prior to sectioning w/black specks.

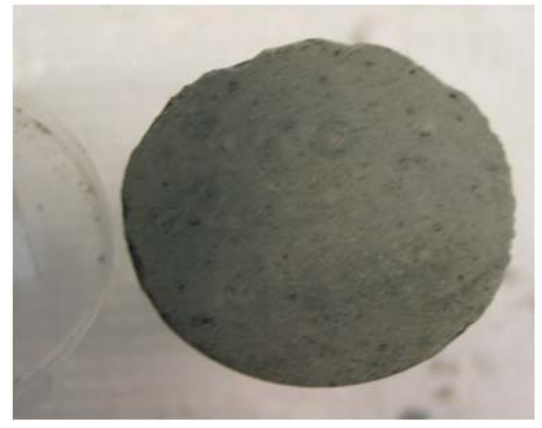

(f) Sample spiked with $20 \mathrm{mg} / \mathrm{kg}$ chromium w/black specks (cut surface).

Figure 19. Appearance of the 3 chromium-spiked saltstone samples leached in this study. 
The cured saltstone samples were removed from the $1 \times 4$ inch containers and sectioned perpendicular to the long axis. A sample holder was fabricated to enable sectioning of slices as thin as 0.1 to $0.2 \mathrm{~mm}$. The samples were crushed ${ }^{6}$ and leached in de-aerated, deionized ASTM Type I water for $18 \mathrm{hr} . \pm 2 \mathrm{hr}$. Leaching was performed using a modified TCLP approach (EPA Method 1311).

After leaching, the leachates were filtered as described in SRNL-L3100-2012-00033 (Langton and Stefanko 2012a) and analyzed for $\mathrm{Al}, \mathrm{Ca}, \mathrm{Cr}, \mathrm{Fe}, \mathrm{K}, \mathrm{Na}, \mathrm{NO}_{2}^{-}, \mathrm{NO}_{3}{ }^{-}$, and $\mathrm{SO}_{4}{ }^{2-}$ concentrations, as well as $\mathrm{pH}$. Photos of the leached saltstone samples in the leaching solution, filtered leachates, and crushed saltstone residues after the leaching solution was decanted are provided in Figures 20 to 22 for the 1000, 20, and $500 \mathrm{mg} / \mathrm{kg}$ chromium-spiked samples, respectively.

Color differences in the filtered leachates collected generated from the Cr-1000 and Cr-500 samples were very noticeable. Leachates collected from the exposed surfaces to a depth of $\sim 12 \mathrm{~mm}$ from the surface are clear. Leachates generated by samples further from the exposed surfaces are yellow. However, none of the leachates from the sample spiked with 20 $\mathrm{mg} / \mathrm{kg}$ chromium were yellow regardless of distance from the top surface (see Figure 20). The color differences appear to be correlated to oxidized versus reduced subsamples and to the ratio of the mass of subsample to leachate. However, additional data are required to fully explain these observations.

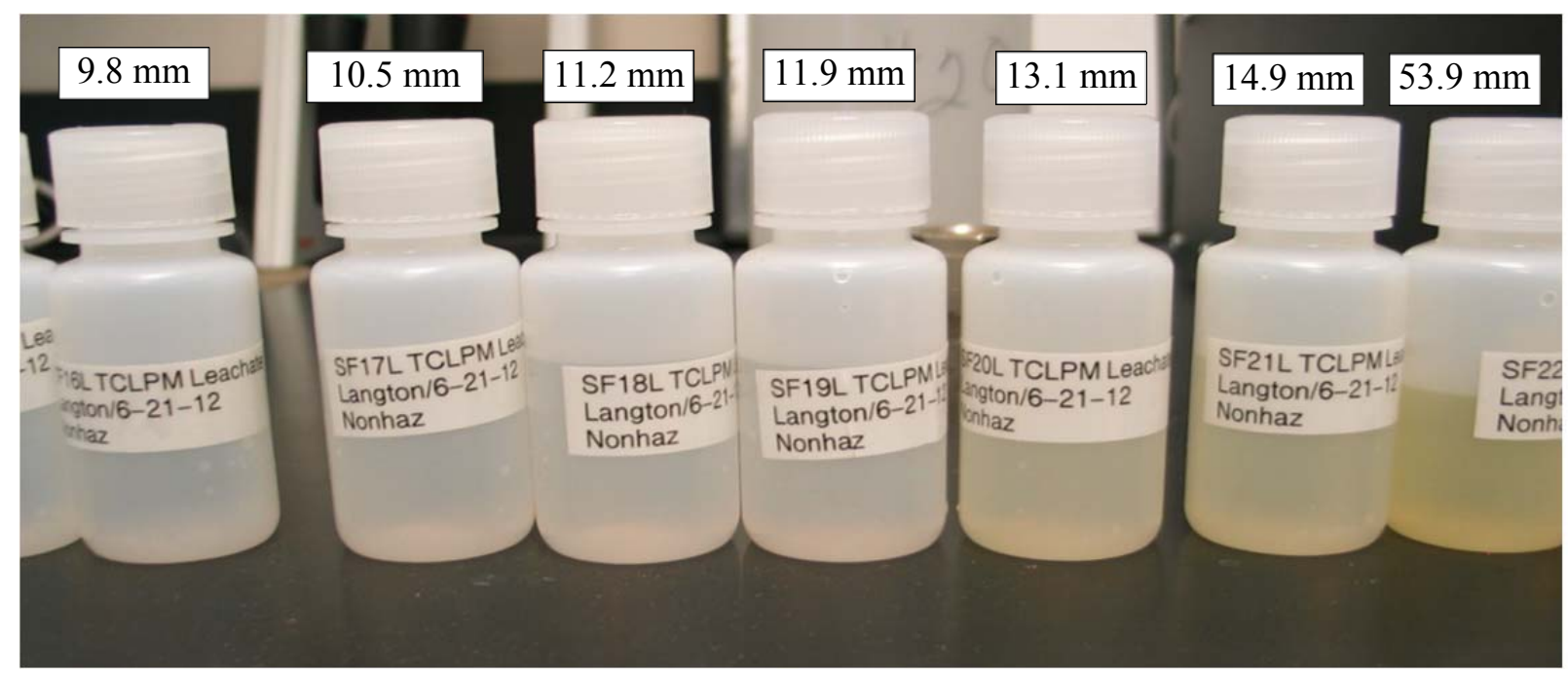

Figure 20. Selected filtered leachates (17L to 22L) for field cured saltstone spiked with $1000 \mathrm{mg} / \mathrm{kg}$ chromium.

\footnotetext{
${ }^{6}$ The final state was a powder. Little crushing was required.
} 


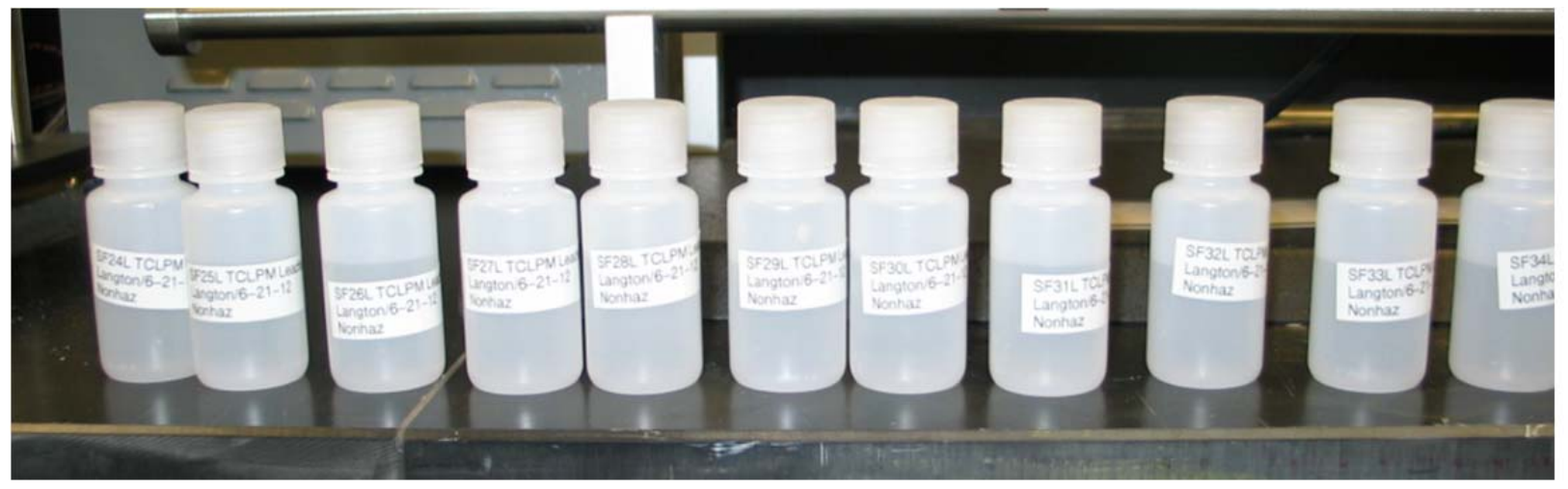

Figure 21. Filtered leachates from all of the subsamples cut from the field cured samples spiked with 20 mg/kg chromium. 


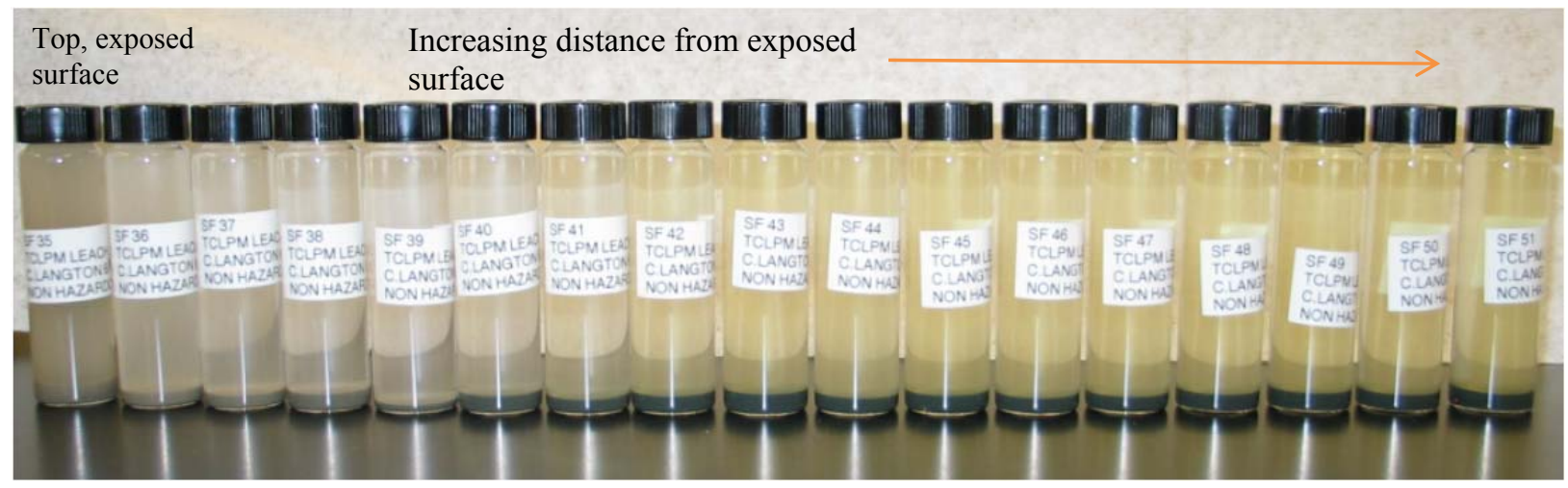

(a) Leached samples (leachate + crushed saltstone) prior to decanting and filtering leachate.

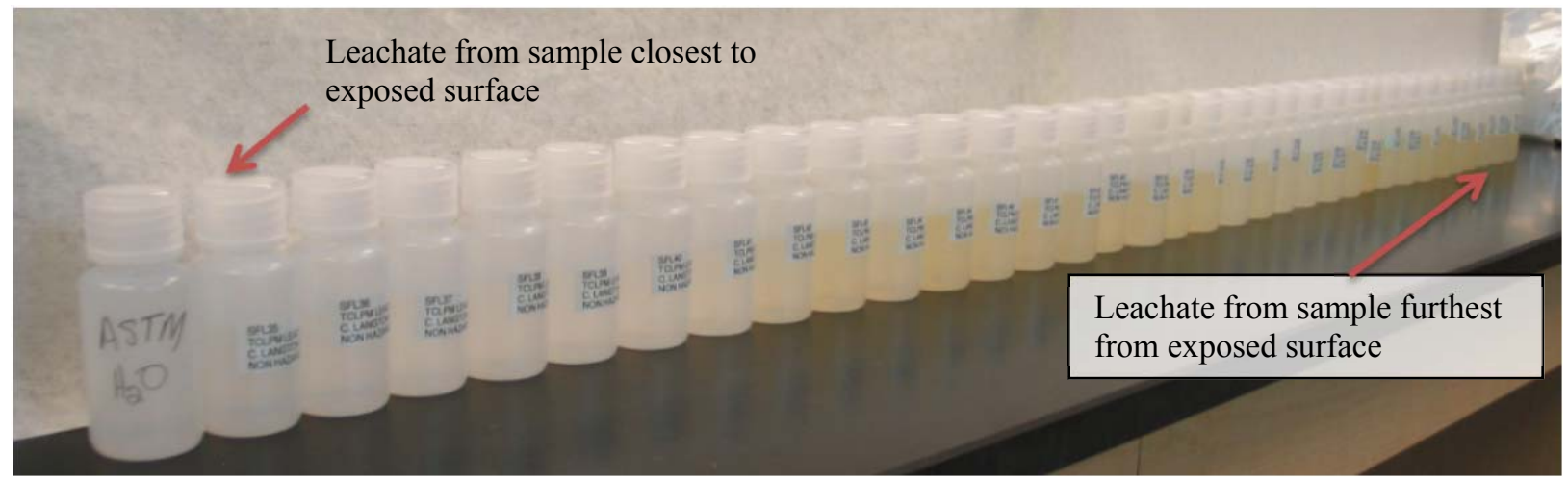

(b) Filtered leachates from all of the slices leached from the field cured spiked with 500 $\mathrm{mg} / \mathrm{kg}$ chromium.

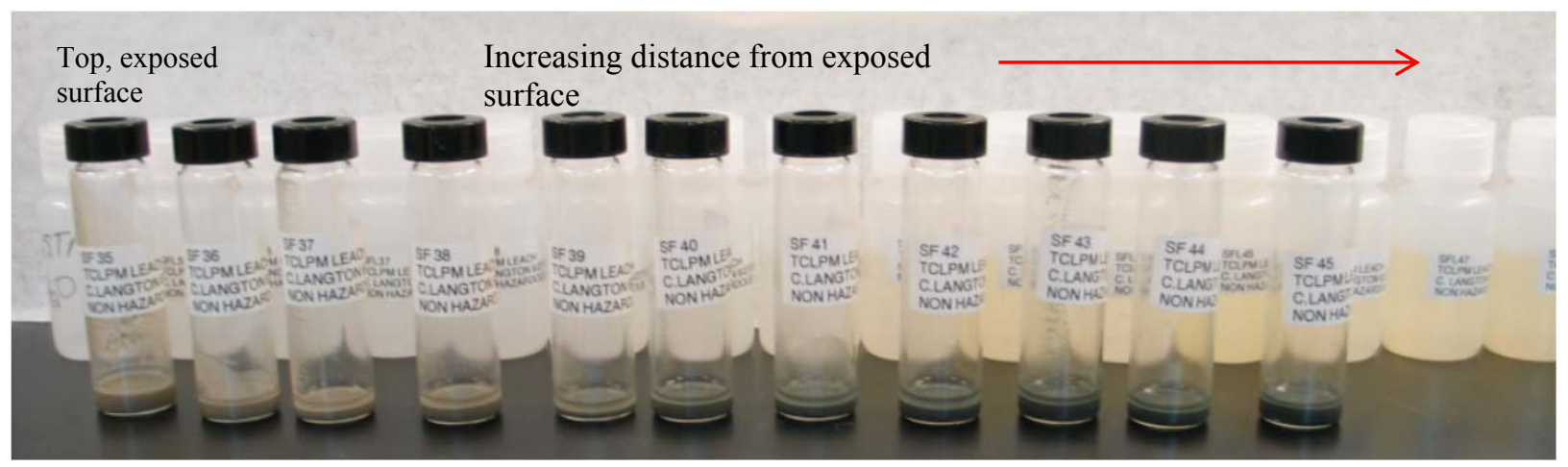

(C) Crushed saltstone residue after decanting the leachate. Color differences in leached saltstone are similar to unleached field cured samples prior to sectioning for $(500 \mathrm{mg} / \mathrm{kg}$ chromium-spiked samples).

Figure 22. Appearance of leachates and residues for the $500 \mathrm{mg} / \mathrm{kg}$ chromium field cured sample. 
Leachates were analyzed for $\mathrm{Cr}, \mathrm{Na}, \mathrm{NO}_{3}{ }^{-}, \mathrm{NO}_{2}{ }^{-}$, and $\mathrm{SO}_{4}{ }^{2-}$ concentrations (components of the salt solution) ${ }^{7}$ and aluminum, calcium, and potassium concentrations (components in the premix) using methods described in SRNL-L3100-2012-00033 (Langton and Stefanko 2012a). Leachate analyses were run in duplicate. Values were averaged and used to calculate the fraction leached (percent leached). The percent of the selected ions leached from the crushed subsamples was determined as described in Section 3.5.1.

\subsubsection{Results}

The fractions leached as a function of sample distance from the exposed top surface are plotted for $\mathrm{NO}_{3}{ }^{-}$, sodium, and chromium in Figures 23 to 25, respectively. These three samples are assumed to be identical except for the amount of chromium added as a spike. ${ }^{8}$

The fractions of $\mathrm{NO}_{3}{ }^{-}$leached as a function of distance from the top of the sample are similar for all three samples. The percentages of sodium leached as a function of distance from the top of the samples are also similar to those for nitrate although the Na profiles as a function of depth from the top are not as sharp and well defined as those for $\mathrm{NO}_{3}{ }^{-}$. For both of these species, about $10 \%$ of the total amount in the first layer is extracted in the 18 hour test. The percentages extracted increase for subsequent layers to 20 to $25 \%$ depending on the sample's depth of 5 to $6 \mathrm{~mm}$ from the top surface. The percentages extracted then decrease to about $15 \%$ at about $12 \mathrm{~mm}$ from the top surface and remain at $15 \%$ throughout the remainder of the sample. About 9 percent of the total sodium was extracted from a subsample cut from the middle of the sample spiked with $1000 \mathrm{mg} / \mathrm{kg}$ chromium. This single data point supports the general pattern but more data are required to better characterize the leaching behavior of sodium.

The leaching behavior for chromium as a function of distance from the top exposed surface has the same pattern as described for $\mathrm{NO}_{3}{ }^{-}$and sodium, i.e., a spike in the percentage leached for subsamples collected about 3 to $5 \mathrm{~mm}$ from the top surface followed by a sharp decrease in the percentages of chromium extracted between 5 and 10 to $15 \mathrm{~mm}$ from the top surface. The percentages of chromium leached as a function of depth from all three chromium field cured samples (chromium spikes of 1000,500, and $20 \mathrm{mg} / \mathrm{kg}$ ) are significantly lower than the percentages of $\mathrm{NO}_{3}{ }^{-}$and $\mathrm{Na}$ leached from the corresponding subsamples.

\footnotetext{
${ }^{7}$ The premix also contains $\mathrm{K}, \mathrm{Na}, \mathrm{Cr}$, and $\mathrm{SO}_{4}{ }^{2-}$. The contribution of these species from the premix was not taken into account in the percent leached calculations. Consequently this calculation was limited to $\mathrm{Cr}$, nitrate and sodium.

${ }^{8}$ Some differences that were encountered include: the samples were cured for slightly different times (111 vs. 118 days) which should not affect the results and they were made from different batches of premix materials.
} 


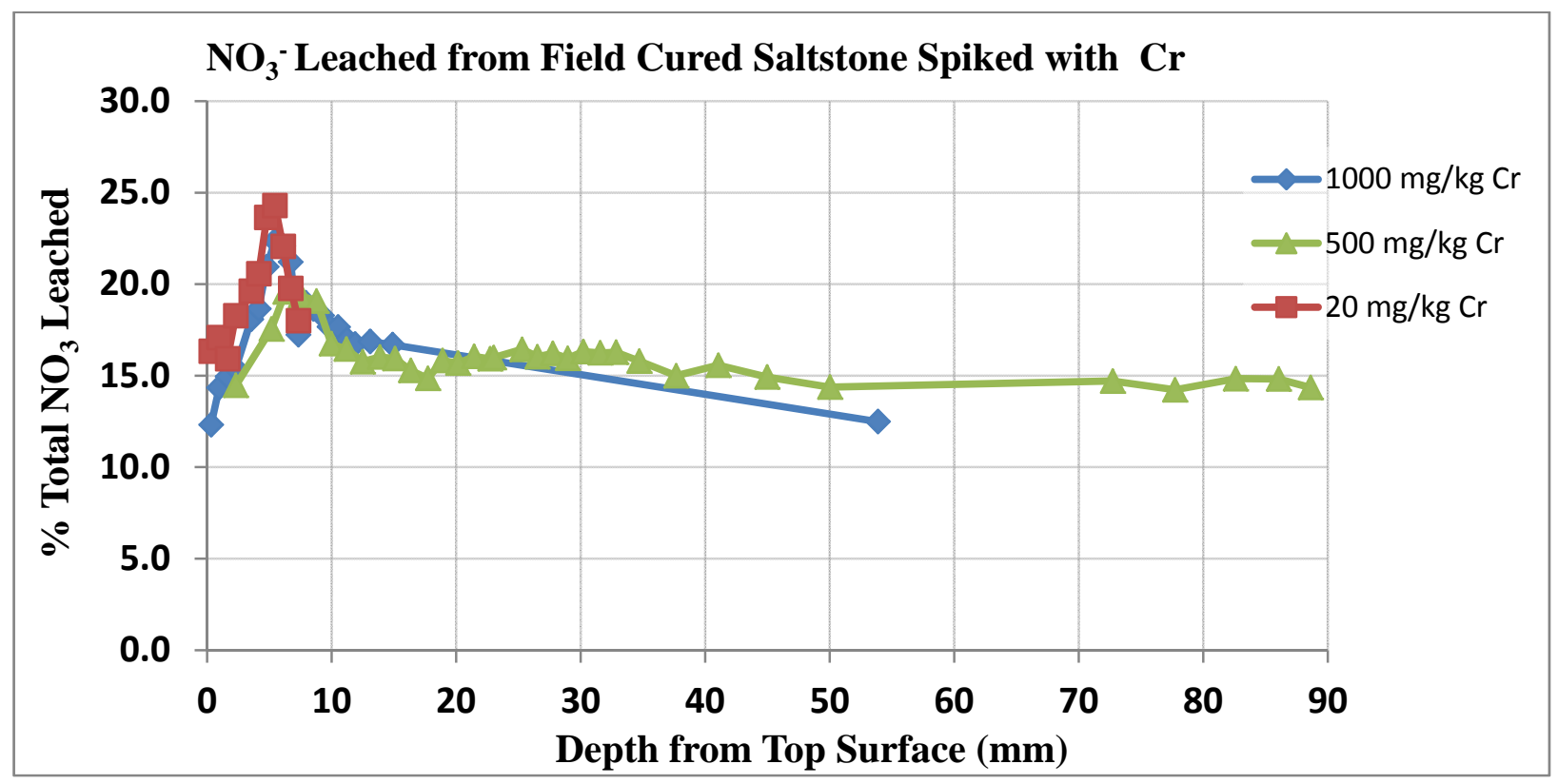

Figure 23. Nitrate leached from field cured saltstone spiked with chromium.

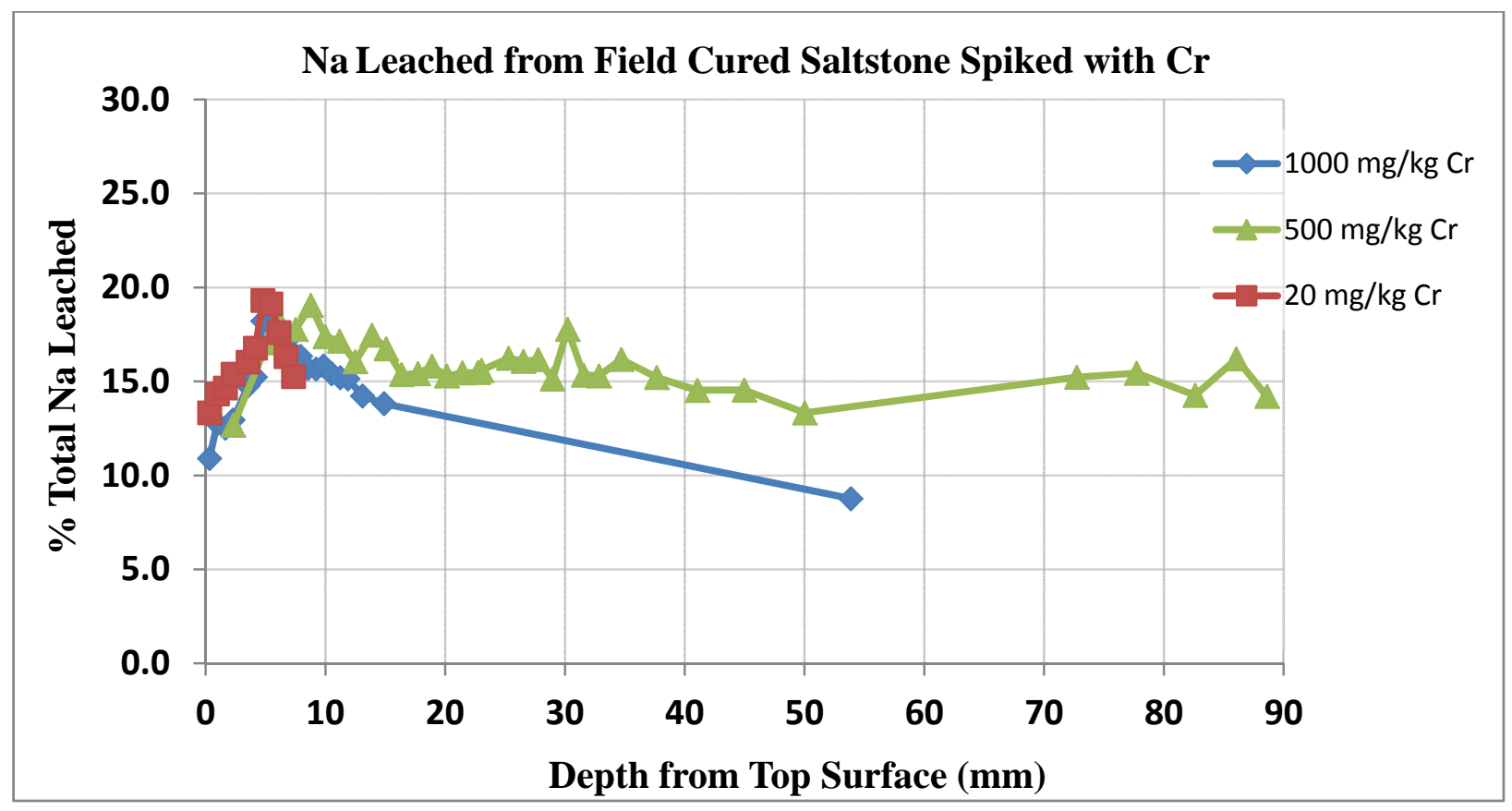

Figure 24. Sodium leached from field cured saltstone spiked with chromium. 


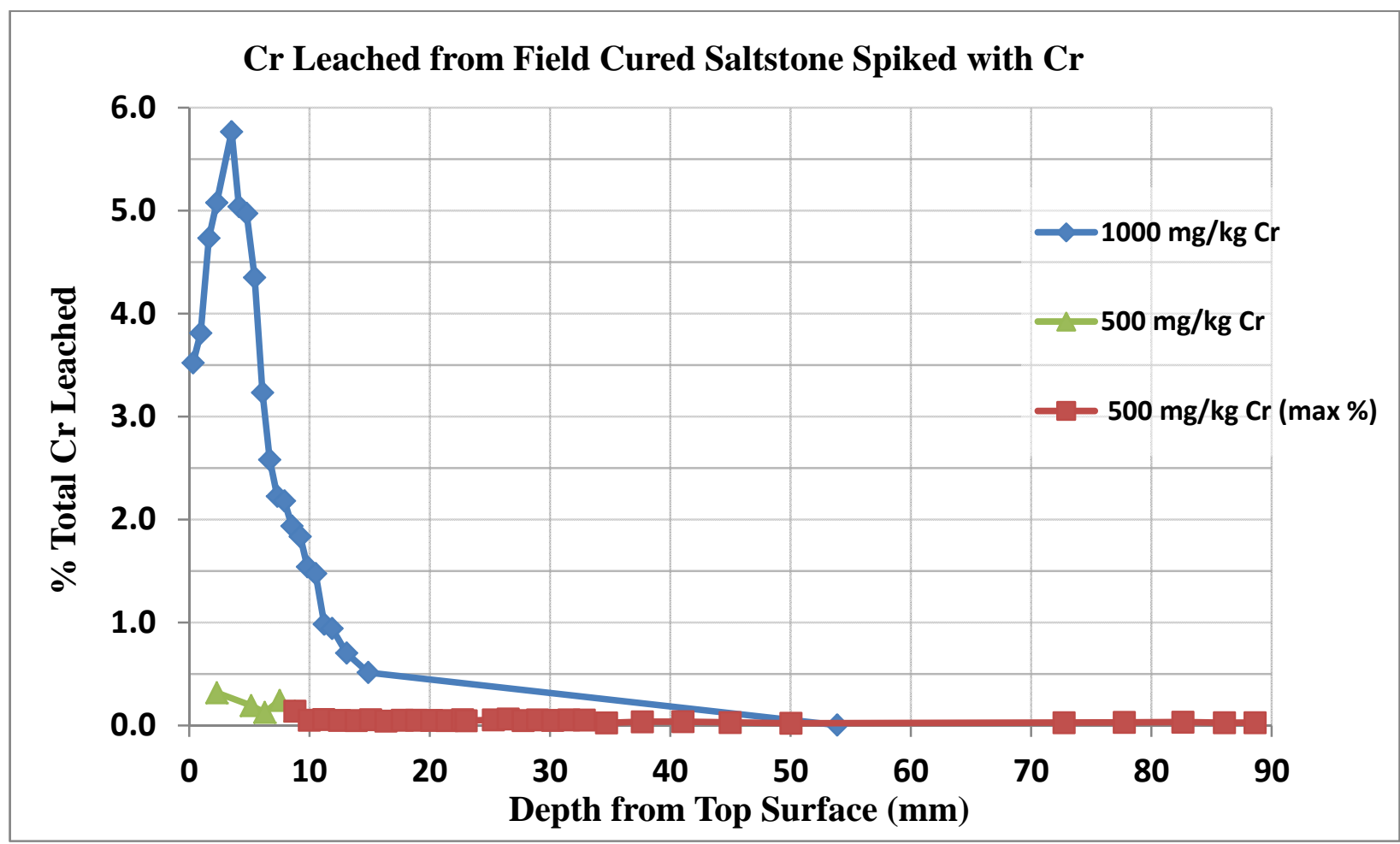

Figure 25. Chromium leached from field cured saltstone spiked with chromium.

The maximum percentage of chromium leached from the sample spiked with $1000 \mathrm{mg} / \mathrm{kg}$ chromium was $5.8 \%$ compared to $22.4,19.4$, and $24.3 \%$, the maximum percentages of $\mathrm{NO}_{3}{ }^{-}$ leached from samples spiked with 1000,500 , and $20 \mathrm{mg} / \mathrm{kg}$ chromium, respectively. In addition between 10 and $20 \mathrm{~mm}$ from the exposed top surface, the amount of chromium detected in the leachates from samples spiked with $500 \mathrm{mg} / \mathrm{kg}$ were below the limit of detection, $0.01 \mathrm{mg} / \mathrm{L}$. All of the leachates from the sample spiked with $20 \mathrm{mg} / \mathrm{kg}$ chromium were below the chromium detection level of $0.01 \mathrm{mg} / \mathrm{L}$. Consequently the percentages reported and plotted are over estimates of the actual values.

\subsubsection{Discussion}

The bulk material was considered to be samples collected from 15 to $90 \mathrm{~mm}$ below the exposed surface. About $15 \%$ of the total nitrate was extracted from crushed (powdered) field cured samples from material collected more than about $15 \mathrm{~mm}$ below the top surface. 9 In comparison, only about $0.05 \%$ of the chromium added to the samples was extracted from subsamples more than about $15 \mathrm{~mm}$ below the top surface for samples spiked with 500 and $1000 \mathrm{mg} / \mathrm{kg}$ chromium. This difference in magnitude is illustrated in the semi-log graph shown in Figure 26. Leachate results for the sample spiked with $20 \mathrm{mg} / \mathrm{kg}$ chromium were all below the detection level, $<0.01 \mathrm{mg} / \mathrm{L}$, consequently meaningful percentages extracted could not be calculated.

\footnotetext{
${ }^{9}$ Higher percentages of nitrate are expected to leach from these samples for longer exposure times; however, this has not been experimentally confirmed. Deionized, de-aerated water was used as the extraction fluid and the leaching test was performed for $18 \pm 2 \mathrm{hr}$.).
} 
These results $\left(\sim 300 \mathrm{X}\right.$ difference in the percentages of $\mathrm{NO}_{3}{ }^{-}$and chromium leached) indicate that the stabilization mechanisms for $\mathrm{NO}_{3}{ }^{-}$and chromium are different. Nitrate is assumed to be physically entrapped in the saltstone matrix because low solubility nitrate phases are not expected to be formed as the result of the hydration reactions, whereas, the chromium leach profile indicates that chromium is chemically stabilized in the saltstone matrix which is not in contact with air or near an exposed surface.

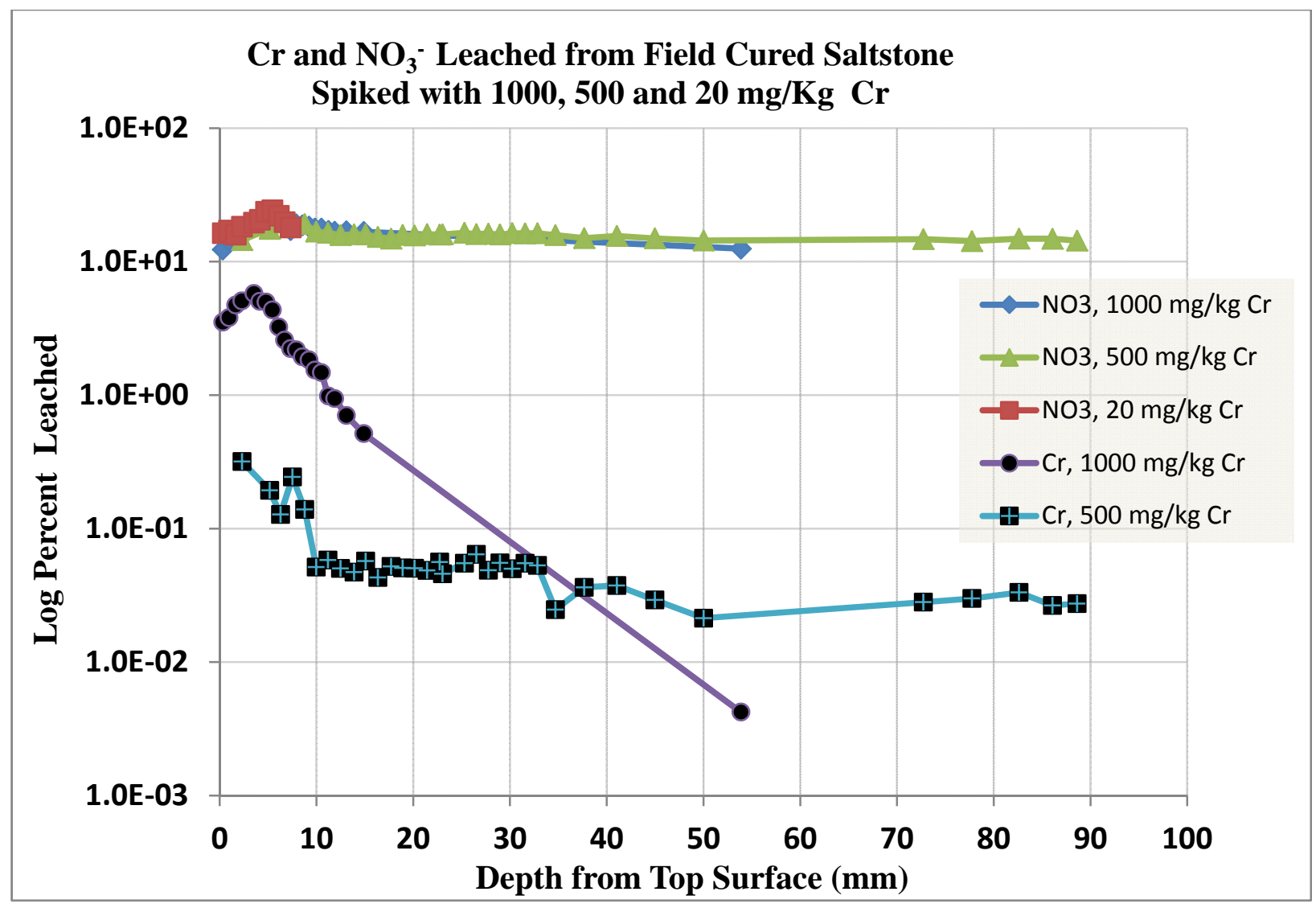

Figure 26. Semi-log plot of percentages of chromium and $\mathrm{NO}_{3}{ }^{-}$leached as a function of sample distance from the exposed top surface.

The percentages of chromium and $\mathrm{NO}_{3}{ }^{-}$leached as a function of distance from the exposed surface to a depth of 10 to $\sim 12 \mathrm{~mm}$ showed similar patterns in the three field cured samples analyzed. ${ }^{10}$ The pattern can be described as follows: lower percentages leached from the top sample(s) followed by a spike in the percentages leached between about 3 and $10 \mathrm{~mm}$ from the top surface depending on the sample. The spikes drop to consistent values between 10 and $20 \mathrm{~mm}$ below the exposed top surface. This pattern is illustrated in the semi-log plot in Figure 26 and also in Figures 23 to 25.

\footnotetext{
${ }^{10}$ The surfaces of these samples were exposed to moist air in the container under the premix silos in Z-Area.
} 
Higher percentages of $\mathrm{NO}_{3}{ }^{-}$were leached from the near surface material to a depth of about 10 to $15 \mathrm{~mm}$.

Chromium leached from the saltstone sample spiked with $1000 \mathrm{mg} / \mathrm{kg}$ chromium showed the same pattern as a function of depth from the exposed surface. This pattern is not apparent for the field cured sample spiked with $500 \mathrm{mg} / \mathrm{kg}$ chromium. However, the field cured sample had an irregular exposed surface and was longer than the sample holder used to prepare the leaching sections. Consequently, some material was lost and the first few subsamples were not totally representative of distance from the exposed surface.

These results suggest a depth of oxidation as reflected in the increased percentage of chromium leached between 2 and $10 \mathrm{~mm}$ from the surface. However, more characterization is required to further understand the chemistry responsible for the observed leaching results as a function of distance from the exposed surface.

Based on the observed leaching profiles (observed spikes between 3 and $10 \mathrm{~mm}$ from the surface) for chromium and $\mathrm{NO}_{3}{ }^{-}$, the top portion of the samples appears to not be representative of the bulk of the samples cured for between 111 and 118 days under field conditions.

The fraction of chromium leached from the top 20 to $30 \mathrm{~mm}$ appears to be a function of the chromium concentration in the sample. The percentages of chromium leached from samples spiked with $1000 \mathrm{mg} / \mathrm{kg}$ chromium were about $10 \mathrm{X}$ higher than the percentages of chromium leached from samples spiked with $500 \mathrm{mg} / \mathrm{kg}$ chromium over this depth. (Comparisons were not possible for samples prepared with $20 \mathrm{mg} / \mathrm{kg}$ chromium because the amount of chromium leached was below the detection level of $0.01 \mathrm{mg} / \mathrm{L}$ and less than values resulted in false percentages that overstate the true values.)

The relationship between the concentration of chromium spiked into the sample and the percentage of chromium that leached as a function of distance from the exposed top surface may be related to the availability of oxygen. Consequently the "effective oxidation" rate may be related to the amount of chromium in the salt solution/saltstone waste form. Additional data are required to further evaluate this correlation.

Laboratory cured samples were initially used to develop the method for sectioning saltstone specimens as a function of distance from an exposed surface and for developing a leaching method. A comparison of the $\mathrm{NO}_{3}{ }^{-}$and chromium leached from a laboratory cured (37 days) and from a field cured (118 days) sample is provided in Figure 27. Both samples were spiked with $1000 \mathrm{mg} / \mathrm{kg}$ chromium and contain identical proportions of ingredients. ${ }^{11}$

The spike pattern for the percentage leached as a function of distance from the exposed surface for subsamples cut near the top of the cylinders is characteristic of $\mathrm{NO}_{3}{ }^{-}$and chromium in the field cured sample. This pattern is present but less well defined for $\mathrm{NO}_{3}{ }^{-}$in

\footnotetext{
${ }^{11}$ The samples spiked with $1000 \mathrm{mg} / \mathrm{kg} \mathrm{Cr}$ were prepared form the same batch of premix. The samples spiked with $500 \mathrm{and} 20 \mathrm{mg} / \mathrm{kg} \mathrm{Cr}$ were prepared with a different batch of premix.
} 
the laboratory cured sample. The pattern was not observed for chromium in the laboratory cured sample (see Figure 27 and SRNL-L3100-2012-00033). The different exposure times, 37 days (lab cured sample) versus 118 days (field cured sample), may account for some or all of this difference. Additional information is required to understand the differences in the field and laboratory cured samples and to determine whether field conditions are more oxidizing than laboratory conditions.

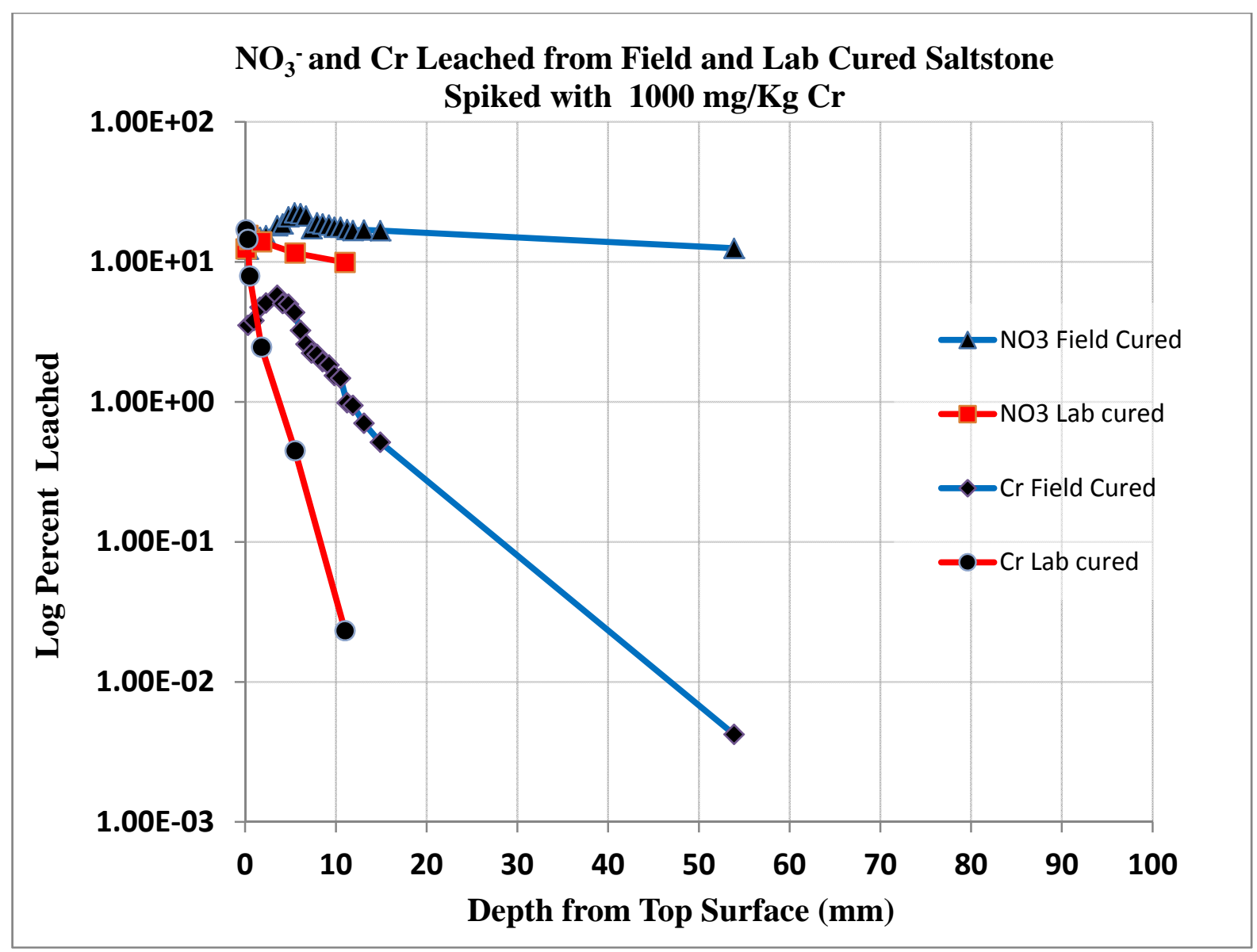

Figure 27. Comparison of $\mathrm{NO}_{3}{ }^{-}$and chromium percentages leached for $\mathrm{Cr}-\mathbf{1 0 0 0}$ field and laboratory cured samples.

The appearance of the saltstone sample spiked with $1000 \mathrm{mg} / \mathrm{kg}$ chromium was fairly uniform except that the top $5 \mathrm{~mm}$ of the sample was a buff color and the exterior surfaces of the rest of cylinder were tan to brown. The top $5 \mathrm{~mm}$ of the saltstone samples spiked with 500 and $20 \mathrm{mg} / \mathrm{kg}$ chromium was light gray and the rest of the exterior surfaces were medium to dark gray. These samples also contained unidentified dark specks throughout the entire sample and on the exterior surfaces. In the top $15 \mathrm{~mm}$, both of these samples also had a mottled appearance characterized by tan lines surrounding gray areas. This pattern was not apparent at deeper locations in the sample spiked with $500 \mathrm{mg} / \mathrm{kg}$ chromium. Only the top portion $(11 \mathrm{~mm})$ of the sample containing $20 \mathrm{mg} / \mathrm{kg}$ chromium was evaluated, therefore no observations were made further from the exposed surface. 
A correlation may exist between the tan color of the top $5 \mathrm{~mm}$ of the $\mathrm{Cr}-1000$ sample and the percentage leached spike for chromium measured for this sample. The top $5 \mathrm{~mm}$ of the Cr500 sample was gray with mottled brown to tan lines. A spike pattern in the leaching results was not observed for the Cr-500 sample.

The cause of the color change in the top $5 \mathrm{~mm}$ may be due to drying, segregation/bleed, oxidation, some other chemical change, or to a combination of these phenomena. Additional testing is required to more fully characterize the cause of the color change.

The color of the leachates generated in this study ranged from clear to yellow. The source of the yellow color is not known at this time but appears to be related to the sample mass to leachate mass and to the amount $(\mathrm{mg} / \mathrm{L})$ of chromium extracted. Leachates containing $<0.01$ $\mathrm{mg} / \mathrm{L}$ chromium were yellow provided that the sample mass to leachate mass was at least 1.5:40. In addition, filtered leachates that were initially yellow became clear upon reexamination about 6 weeks after being analyzed. Additional characterization work is required to understand these observations, but the initial color of the leachates generated in a zero head space vessel using de-aerated ASTM Type I water may be a useful and inexpensive method of identifying an oxidation front.

The leaching experiments performed in this study did not result in equilibrium partitioning of any chemical species between the liquid and solid phases. Leachate concentrations from only one relatively short time interval, $18 \mathrm{hr}$., were evaluated. Therefore, distribution ratios, $\mathrm{R}_{\mathrm{ds}}$, are reported rather than equilibrium distribution coefficients. Distribution ratios are calculated from the same formula as distribution coefficients, $\mathrm{K}_{\mathrm{d}}$ 's as shown the following equation.

\section{$\mathbf{R}_{\mathbf{d}}=$ [Concentration of species in the solid phase] (mg/kg) [Concentration of species in the liquid phase] $(\mathrm{mg} / \mathrm{L})$}

The relationship between percentage leached and distribution ratio is provided in the equation below. Percentages of $\mathrm{NO}_{3}{ }^{-}$and chromium extracted from field cured saltstone were converted into distribution ratios (non- equilibrium) to illustrate the difference between physical stabilization and chemical stabilization in the saltstone matrix and should not be used for PA modeling (see Figure 28).

\section{$\mathbf{R}_{\mathbf{d}}=[100-\%$ leached into the liquid phase $]$ $\%$ leached into the liquid phase}




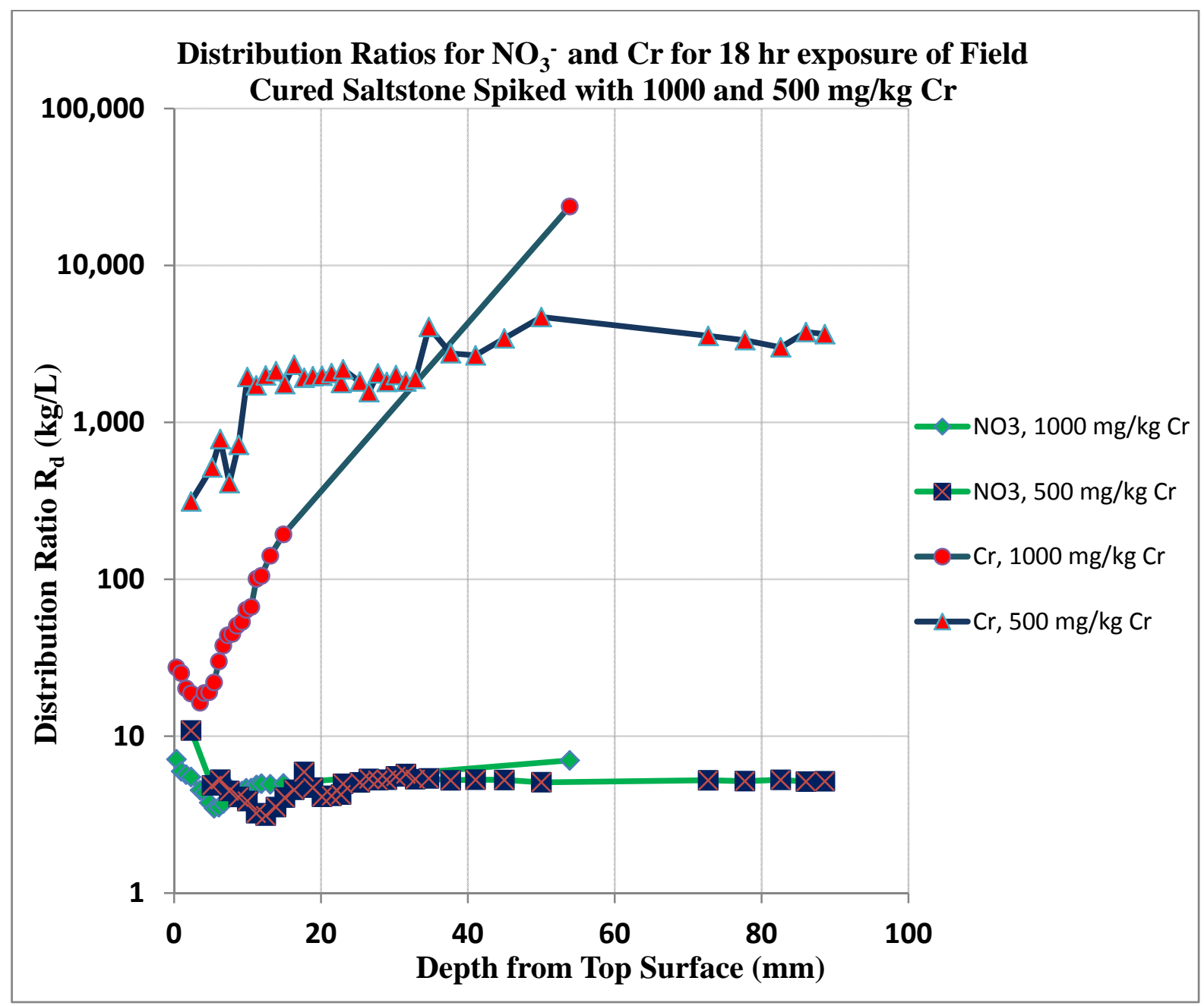

Figure 28. Comparison of $\mathrm{NO}_{3}{ }^{-}$and chromium distribution ratios for the $18 \mathrm{~h}$ extraction of crushed saltstone (powdered) in de-aerated ASTM Type I water.

Based on results to date, leaching of depth-discrete samples is an indicator of the presence of oxidized (soluble) chromium. If one assumes that the initial material contained only reduced chromium (relatively insoluble) ${ }^{12}$ and that the samples are uniform from top to bottom, leaching of a redox sensitive tracer can be used to estimate the rate of oxidation.

However, more than one phenomenon (settling/bleed, drying, wet-dry cycling, oxidation, carbonation, etc.) may be impacting the near surface region of the as-cast, field cured samples. The top 5 to $15 \mathrm{~mm}$ of the samples characterized in this study appear to be compromised relative to the bulk material based on visual observation of mottling, variability in cohesiveness, color, and leaching results for soluble species such as nitrate and sodium. In

\footnotetext{
${ }^{12}$ Insoluble actually refers to non-leachable given the detection limit of $<0.01 \mathrm{mg} / \mathrm{L}$ and the leachate to sample mass ratios used in this study.
} 
this study, the bulk material was considered to be material $20 \mathrm{~mm}$ or more below the as-cast surface.

To date, only one curing time (111 to 118 days) has been evaluated for field cured samples. Samples cured for a range of times (e.g., 6, 12, 18, 24 months) are required to obtain oxidation rate data for samples with an as-cast-surface. In addition, oxidation rate data which are more representative of the bulk material are important in understanding and predicting performance. This information can be better obtained if the top $20 \mathrm{~mm}$ of the samples were removed prior to exposure (assuming this was done within a few weeks after curing).

The near-surface, depth-dependent leaching profiles for $\mathrm{NO}_{3}{ }^{-}$and $\mathrm{Na}$ are similar to those for chromium even though $\mathrm{NO}_{3}{ }^{-}$and sodium are not redox sensitive. This profile (depletion and spike) may be indicative of sample preparation or of mild leaching and downward transport of soluble ions.

\subsection{X-RAY ABSORPTION SPECTROSCOPY}

\subsubsection{Materials and Methods}

A description of sample preparation and curing conditions of the $1000 \mathrm{mg} \mathrm{kg}^{-1}$ chromiumspiked field Samples used in these measurements is presented in Section 4.1. As mentioned above, the samples were spiked with oxidized $\mathrm{Cr}(\mathrm{VI})$, they were placed in the field on $3 / 15 / 2012$ and were removed from the field on 7/6/2012, and the total curing time was 134 days.

A two dimensional map of the oxidation state of chromium in a thin section collected from the field sample was created using XANES measurements. A $1.5 \mathrm{~mm}$ thin-section was wet cut lengthwise down the middle of the chromium-spiked Saltstone sample, perpendicular to the oxidation front, using a Buehler 4000 precision saw, a silicon carbide abrasive blade, and degased Milli-Q water. Practice samples were cut to identify the appropriate blade and to develop techniques to minimize the time that the samples were exposed to air. The sample was exposed to water, possibly removing some leachable $\mathrm{Cr}(\mathrm{VI})$. The sample was exposed to air during sample cutting for about 15 minutes before it was placed in a Tupperware container that was purged with argon. The Tupperware container was in turn placed in an argon purged plastic bag to provide a second envelop of inert atmosphere around the sample. A moist sponge with degased Milli-Q water was placed in the Tupperware to keep the samples moist. A redox indicator was included in the plastic bag to monitor whether oxygen had entered the plastic bag. The sample was delivered to Clemson University where it was brought into an inert atmosphere glovebox for mounting into the XAS sample holder. A saltstone slice $(\sim 2 \mathrm{~cm}$ width $\mathrm{x} \sim 3.5 \mathrm{~cm}$ depth (along the direction that the oxidation front would move) $\times 0.15 \mathrm{~cm}$ thickness) was mounted into the XAS sample holder (cell). The cell was sealed with Kapton tape, purged with argon, and then the inlet- and outlet- gas ports were sealed until analysis, thereby minimizing exposure to the oxygen in the air (Figure 29). The upper $\sim 0.5 \mathrm{~cm}$ of the sample was light gray, suggesting it had dried. While cutting, 
portions of this section crumbled. The $\mu$-SXRF and $\mu$-XANES measurements were collected from a portion of the sample that had not crumbled (see blue line in Figure 29).

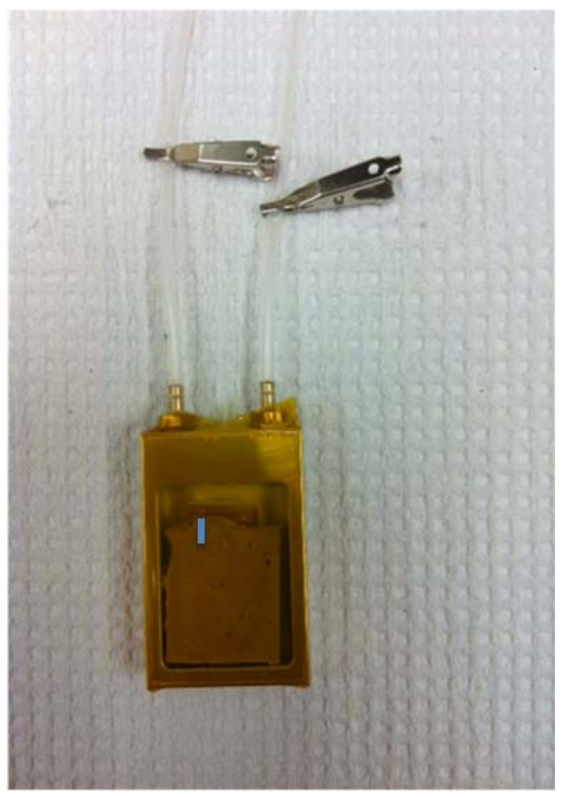

Figure 29. Simulant saltstone sample spiked with $1000 \mathrm{mg} \mathrm{kg}^{-1}$ ( $\sim 2 \mathrm{~cm}$ width $\mathrm{x} \sim 3.5 \mathrm{~cm}$ depth (along the direction that the oxidation front would move) $x 0.15 \mathrm{~cm}$ thickness) used in the $\mu$-SXRF and $\mu$-XANES measurements. Sample holder was designed to maintain an inert environment. Upper portion of sample includes the air/saltstone interface. Blue line indicates location of where chemical analyses were conducted.

Room temperature Synchrotron X-ray Fluorescence ( $\mu$-SXRF) and $\mu$-XANES measurements of the saltstone sample were performed in a helium atmosphere at beamline 2-3 at SSRL. For this experiment, the incident X-ray beam was tuned to $6010 \mathrm{eV}$ using a $\mathrm{Si}(111)$ channel-cut monochromator. The SXRF compositional maps of chromium, calcium, titanium, and potassium were collected above the chromium K-edge (5.989 keV) using a single element Vortex ${ }^{\circledR}$ Silicon Drift Detector (SII NanoTechnology USA Inc. Northridge, CA). Synchrotron microbeam $(2(\mathrm{H}) \times 3(\mathrm{~V}) \mu \mathrm{m})$ XANES spectra were collected up to $180 \mathrm{eV}$ above the chromium K-edge absorption energy in fluorescence mode. Sodium chromate salt was used to calibrate at the chromium K-edge absorption edge energy positions (at the peak of pre-edge $=5,993 \mathrm{eV}$ ). The energy calibration repeated after $48 \mathrm{hr}$, and the calibration was maintained to less than $0.1 \mathrm{eV}$ shifts between the $48 \mathrm{hr}$ measurements, indicating minimal instrumental drift during analysis that would compromise data interpretation and accurate appointing of the chromium oxidation state. In order to determine the chromium oxidation state, three energy maps were collected at 5,993, 6,003, and 6,010 eV using fluorescence mode (Figure 30). The ratio of the fluorescence intensity at 5,993 and 6,003eV was used to generate a $\mathrm{Cr}(\mathrm{VI})$ map, while the threshold energy map at $6,003 \mathrm{eV}$ was used as a $\mathrm{Cr}$ (III) map. 


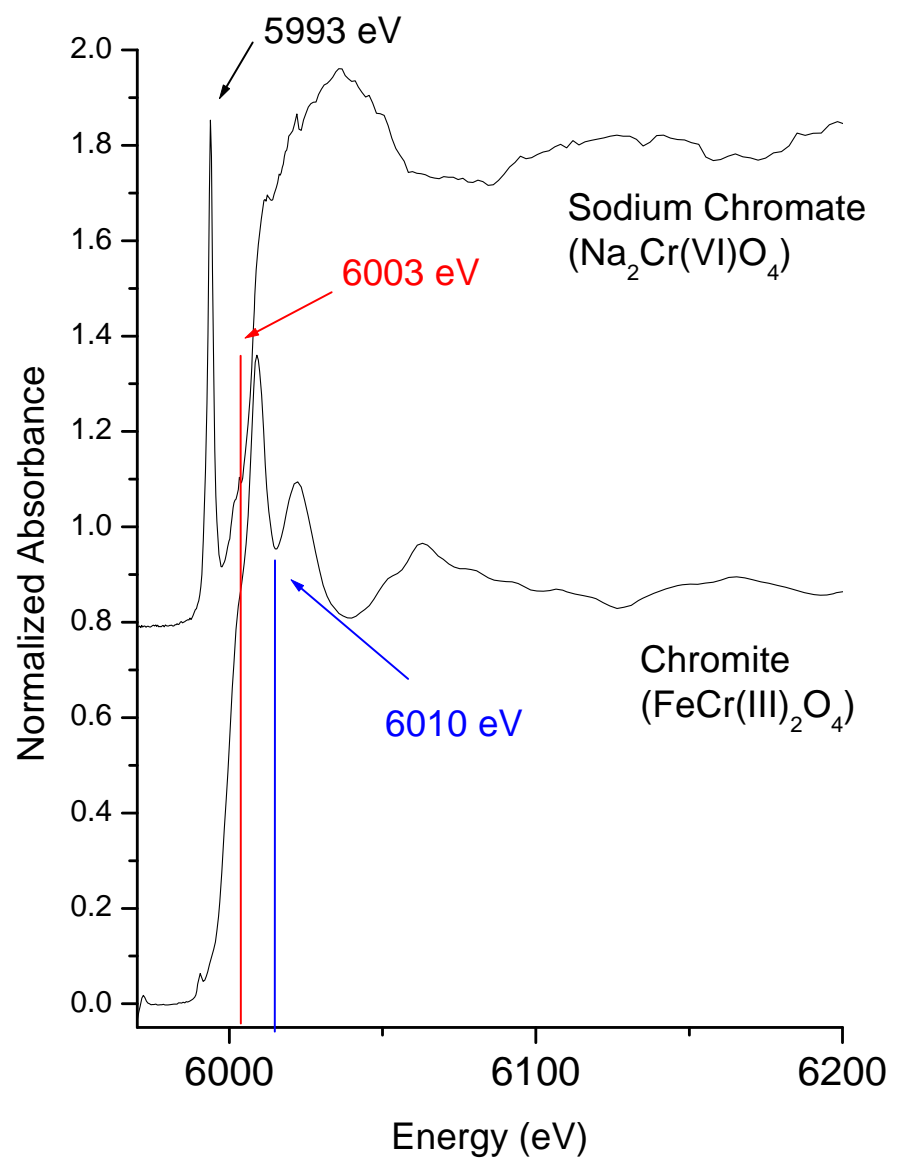

Figure 30. XANES spectra of $\operatorname{Cr}$ (III) and $\operatorname{Cr}(\mathrm{VI})$ standards. To create the $\mathrm{Cr}(\mathrm{III}) / \mathrm{Cr}$ (VI) maps of the field saltstone samples, the ratio of the fluorescence intensity at 5,993 and 6,003eV were used to generate a $\mathrm{Cr}$ (VI) map, while the threshold energy map at 6,003 eV was used as a $\mathrm{Cr}$ (III) map.

\subsubsection{Results and Discussion}

Figure 31 shows a bicolor valence state map of $\mathrm{Cr}(\mathrm{III})$ in red and $\mathrm{Cr}(\mathrm{VI})$ in green taken of the $18.8 \mathrm{~mm}$ depth of the saltstone field sample. Shades between red and green (yellow to orange) indicate the presence of mixed $\mathrm{Cr}(\mathrm{III}) / \mathrm{Cr}(\mathrm{VI})$ oxidation states; black indicates the presence of saltstone void/pore spaces. Figure 31 comprises some 188,000 pixels for which 3 spectra (as described in Figure 29) were collected for each pixel. The $2 \mu \mathrm{m} \times 3 \mu \mathrm{m}$ beam spot-size was moved $10 \mu \mathrm{m}$ between spectrum collection, thereby creating a map that provides insight into the saltstone pore scale, but not the atomic scale. $\mathrm{Cr}$ (III) dominates the saltstone map throughout the $18.8 \mathrm{~mm}$ depth. There were no distinct oxidation fronts as identified by the $\mathrm{Cr}(\mathrm{III} / \mathrm{VI})$ couple. Instead there appears to be very small $\mathrm{Cr}(\mathrm{VI})$ pockets rather randomly distributed in the mapped area. Perhaps more importantly there does not appear to be more $\mathrm{Cr}(\mathrm{VI})$ concentrated at the upper surface, or elsewhere in the map (with 
one possible exception, discussed below). Further data analysis is needed to quantify $\mathrm{Cr}(\mathrm{VI})$ concentrations in the yellow to orange regions of the plot.

There were no regions (fluorescence spectra) containing even a majority of $\mathrm{Cr}(\mathrm{VI})$, as would be identified in Figure 31 as a green region. Importantly, all the fluorescence intensities at the $\mathrm{Cr}(\mathrm{VI})$ pre-edge $(5993 \mathrm{eV})$ were near background, indicating little to no detection of $\mathrm{Cr}(\mathrm{VI})$. Using a more data-intensive analytical approach to validate these results, microfocused XANES spectra at 14 random locations in the XRF map (Figure 31) were collected. None of these XANES data contained the pre-edge feature $(5993 \mathrm{eV})$, confirming the relatively minor concentrations of $\mathrm{Cr}(\mathrm{VI})$ with respect to $\mathrm{Cr}(\mathrm{III})$. Chromium detection limit by this method is in the order of $1 \mathrm{mg} / \mathrm{kg}$ (Bertsch and Hunter, 2001), appreciably lower than $\mathrm{SEM} / \mathrm{EDX}$ that has a total elemental detection limit in the order of $10,000 \mathrm{mg} / \mathrm{kg}$ (and does not provide oxidation state information). Therefore it is entirely possible that $\mathrm{Cr}(\mathrm{VI})$ could exist at concentrations below this detection limit.

One trend that may exist, and again it may be statistically evaluated at a later date, is the presence of a greater percentage of $\mathrm{Cr}(\mathrm{VI})$ in areas near void spaces in the saltstone (Figure 31(b)). There may be a larger amount of $\mathrm{Cr}(\mathrm{VI})$ in regions surrounding the voids, identified as black regions on the map. But again, it is important not to over interpret the Cr(III/VI) distribution in these maps because only trace levels of $\mathrm{Cr}(\mathrm{VI})$ were identified, differences that may be (or are likely to be) statistically insignificant. For the time being, such observations may be useful in providing insight into potential chemical processes and for directing future research direction. 


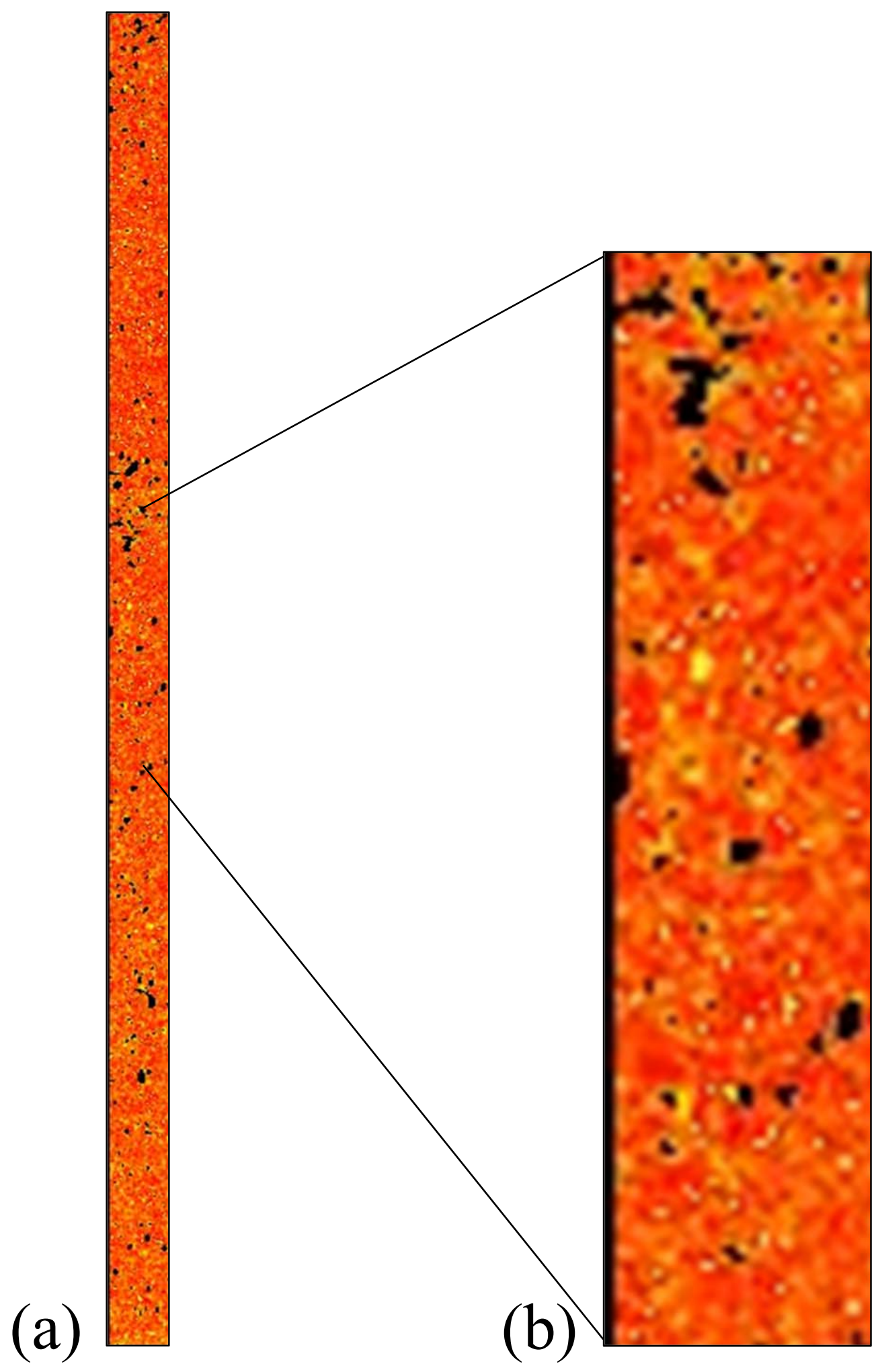

Figure 31. 2-D chromium oxidation state map, with $\mathrm{Cr}$ (III) in red and $\mathrm{Cr}$ (VI) in green (mixed oxidation state samples are some color in between). Black regions are saltstone void spaces. (a) Top of scan represents the air/saltstone interface of the $1 \mathrm{~mm}$ (horizontal) x $18.8 \mathrm{~mm}$ (depth) profile, and (b) detailed enlargement. 


\subsection{CONCLUSIONS}

Four analytical approaches were evaluated for studying oxidation behavior in saltstone: Xray absorption spectroscopy (XAS), diffuse reflectance spectroscopy (DRS), redox indicators, and leaching methods. XAS and thin-section leaching methods were validated as viable methods.

Three field samples containing 20,500, and $1000 \mathrm{mg} / \mathrm{kg}$ chromium were visually characterized and leached. Sample monoliths were separated into thin sections as a function of depth from the surface, crushed, and individually leached. Samples were taken to depths of 18,89 , and $54 \mathrm{~mm}$, respectively for each monolith. The material was subsequently leached in deoxygenated water in zero-head space sealed containers to mitigate oxidation of chromium.

Results indicated a distinct change in chromium leachability as a function of depth from the exposed surface. Based on characterization of samples collected for one exposure time (111 to 118 days) and for two different levels of chromium spike, the oxidation front appears to have advanced from the as-cured exposed surface to a depth of 15 to $20 \mathrm{~mm}$ for the sample spiked with $1000 \mathrm{mg} / \mathrm{kg}$ chromium and to a depth of 5 to $10 \mathrm{~mm}$ for the sample spiked with $500 \mathrm{mg} / \mathrm{kg}$ chromium. The $20 \mathrm{mg} / \mathrm{kg}$ sample results were below analytical detection limits for chromium.

XAS characterization provided a direct indication of chromium oxidation state from a saltstone field sample that cured for 134 days. A slice was cut perpendicular to the exposed surface for analysis. The saltstone slice was stored in inert gases for approximately 10 days from sample cutting through sample analysis at the beam line to preclude oxidation.

A 188,000 point 2-D scan was conducted to create a map of the oxidation state of Cr(III/VI) over a 1 x $18.8 \mathrm{~mm}$ portion of the sample. The resulting image was mottled from red to orange to yellow. A detectable change in chromium oxidation state as a function of distance from the exposed surface was not observed over $18.8 \mathrm{~mm}$ indicative of a well-defined oxidation front. The scan indicated the predominance of $\mathrm{Cr}$ (III) (indicated by red) and potential presence of some $\mathrm{Cr}(\mathrm{VI})$ throughout the sample (indicated by orange to yellow). One observation from the mottled pattern in the 2-D oxidation map was that the occurrence of $\mathrm{Cr}(\mathrm{VI})$ was common near pore spaces.

In summary, two methods - XAS and leaching methods were developed that are applicable to the study of Saltstone oxidation. These two methods were applied to simulated field samples and results were reported. This work is an initial step in developing the capability to experimentally quantify oxidation rates in grout samples cured outside of the laboratory environment. Therefore, a change in the modeling approach to oxidation is not suggested at this time. 


\subsection{REFERENCES}

Allen, P. G., G. Siemering, D. K. Shuh, J. B. Bucher, N. M. Edelstein, C. A. Langton, S. B. Clark, T. Reich, and M. A. Denecke, 1997. Technetium Speciation in Cement Waste Forms Determined by X-Ray Absorption Fine Structure Spectroscopy. Radiochimca Acta. 76: 77-86.

Almond, P. M., D. I. Kaplan. 2011. Distribution Coefficients (Kd) Generated from a Core Sample Collected from the Saltstone Disposal Facility. SRNL-STI-2010-00667. Savannah River National Laboratory, Aiken, SC.

Almond, P. M. and D. I. Kaplan, 2012. Task Technical and Quality Assurance Plan for Method Development and Qualification of the Rate of Movement of the Oxidation Front in Saltstone. SRNL-RP-2011-01408, Rev 1. Savannah River National Laboratory, Savannah River Site, Aiken, SC, 29808.

Angus, M. J., and F. P. Glasser. 1985. The Chemical Environment in Cement Matrices. Scientific Basis for Nuclear Waste Management IX. Mat. Res. Soc. Symp. Proc. 50: 547556.

Arai, Y., and C. C. Fuller. 2012. Effects of sulfate ligand on uranyl carbonato surface species on ferrihydrite surfaces. Journal of Colloid and Interface Sciences. 365: 268-274.

Arai, Y., P. B. Moran, B. D. Honeyman, and J. A. Davis. 2007. In Situ Spectroscopic Evidence for Neptunium(V)-Carbonate Inner-Sphere and Outer-Sphere Ternary Surface Complexes on Hematite Surfaces. Environ. Sci. Technol. 41: 3940-3944.

Bajt, S., S. B. Clark, R. S. Sutton, M. L. Rivers, and J. V. Smith. 1993. Synchrotron X-ray microprobe determination of chromate content using X-ray Absorption Near-Edge Structure. Analytical Chemistry 65: 1800-1804.

Bertsch, P. M., and D. B. Hunter. 2001. Applications of Synchrotron-Based X-ray Microprobes. Chem. Rev. 101: 1809-1842.

Bethke, C. M. 2008. Geochemical and Biogeochemical Reaction Modeling, Second Edition. Cambridge University Press, New York.

EPA Method 1311, Revision 0, July 1992. Toxicity Characteristics Leaching Procedure. U.S. EPA, Washington, DC.

Flach, G. P., J. M. Jordan, and T. Whiteside. 2009. Numerical Flow and Transport Simulations Supporting the Saltstone Disposal Facility Performance Assessment. SRNLSTI-2009-00115 Rev 1, Savannah River National Laboratory, Aiken, SC. 
Flach, G. P. 2011. Oxidation of Fractured Cementitious Materials in Performance Assessments. SRNL-14321-2011-00004, Savannah River National Laboratory, Aiken, SC.

Harbour, J. R., Hansen, E. K., Edwards, T. B., Williams, V. J., Eibling, R. E., Best, D. R., and Missimer, D. M. 2006. Characterization of slag, fly ash and portland cement for saltstone. WSRC-TR-2006-00067, Savannah River National Laboratory, Aiken, SC.

Hunt, G.R. 1977. Spectral signatures of particulate minerals in the visible and near infrared; Geophysics, 42: 501-513.

Icenhower, J. P., N. P. Qafoku, J. M. Zachara, and W. J. Martin. 2010. The Biogeochemistry of Technetium: A review of the Behavior of an Artificial Element in the Natural Environment. American Journal of Science. 310: 721-752.

Kaplan, D.I., T. Hang, and S. E. Aleman. 2005. Estimated Duration of the Reduction Capacity within a High-Level Waste Tank. WSRC-RP-2005-01674, Revision 0. Washington Savannah River Company, Aiken, SC.

Kaplan, D. I., K. Roberts, J. Coates, M Siegfried, S. Serkiz. 2008. Saltstone and Concrete Interactions with Radionuclides: Sorption $\left(\mathrm{K}_{\mathrm{d}}\right)$, Desorption, and Reduction Capacity Measurements. SRNS-STI-2008-00045. Savannah River National Laboratory, Aiken, SC.

Langton, C. A. 1988. Slag-based saltstone formulations. Mater. Res.Soc. Symp. Proc. 112: 61-70.

Langton, C. A. and L. N. Oji, 1994. "Speciation/Nearest Neighbor Configuration of Chromium in Saltstone Using EXAFS," WSRC-RP-94-700, Westinghouse Savannah River Company, Savannah River Technology Center, Savannah River Site, Aiken, SC 29808.

Langton, C. A. and D. B. Stefanko, 2012a. "Oxidation Study: Chromium and Rhenium Leaching Front Results," SRNL-L3100-2012-00033, Rev 0, Savannah River National Laboratory, Savannah River Site, Aiken, SC, 29808.

Langton, C. A. and D. B. Stefanko, 2012b. "Saltstone Oxidation Study: Chromium Leaching Results for Field Cured Samples," SRNL-L3100-2012-00103, Rev 0, Savannah River National Laboratory, Savannah River Site, Aiken, SC, 29808.

Lukens, W. W., J. J. Bucher, D. K. Shuh, and N. M. Edelstein. 2005. Evolution of Technetium Speciation in Reducing Grout. Environ. Sci. Technol. 39: 8064-8070.

MMES (Martin Marietta Energy Systems, Inc., EG\&G Idaho, Inc., Westinghouse Hanford Company, and Westinghouse Savannah River Company). 1992. Radiological PerformanceAssessment for the Z-Area Saltstone Disposal Facility, WSRC-RP-92-1360, Westinghouse Savannah River Company, Aiken, South Carolina. 
Pabalan, R. T., F. P. Glasser, D. A. Pickett, G. R. Walter, S. Biswas, M. R. Juckett, L. M. Sabido, and J. L. Myers. 2009. Review of Literature and Assessment of Factors Relevant to Performance of Grouted Systems for Radioactive Waste Disposal. CNWRA-2009-001, Center for Nuclear Waste Regulatory Analyses, San Antonio, TX.

Pabalan, R. T., G. W.Alexander, D. J. Waiting. 2012. Experimental Study of Contaminant Release from Reducing Grout. Center for Nuclear Waste Regulatory Analyses, San Antonio, TX.

Painter, S.L. and R.T. Pabalan. 2009. Estimated Longevity of Reducing Environment in Grouted Systems for Radioactive Waste Disposal." San Antonio, Texas: Center for Nuclear Waste Regulatory Analyses, San Antonio, TX.

Performance Assessment for the Saltstone Disposal Facility. SRR-CWDA-2009-00017.

Perkins, R. B., and C. D. Palmer. 2000. Solubility of $\mathrm{Ca}_{6}\left[\mathrm{Al}(\mathrm{OH})_{6}\left(\mathrm{CrO}_{4}\right)_{3}\right] \cdot 26 \mathrm{H}_{2} \mathrm{O}$, the Chromate Analog of Ettringite; 5-75 ${ }^{\circ}$. Applied Geochemistry 15: 1203-1218.

Reigel, M.M. 2011. Results for the First Quarter 2011Tank 50 WAC Slurry Sample: Chemical and Radionuclide Contaminant Results. SRNL-STI-2011-00303, Savannah River National Laboratory, Aiken, SC.

Roberts, K. A., and D. I. Kaplan. 2009. Reduction Capacity of Saltstone and Saltstone Components. SRNL-STI-2009-00637. Rev.0, Savannah River National Laboratory, Aiken, SC.

Rosenberger, K. H. and F. M. Smith, 2011. Oxidation Rate Analytical Method Development / Saltstone \& Vault Sample and Analyses Program" SLA-WSTD-00023, Rev 6, C\&WDA, Closure and Waste Disposal Authority.

Smith, F. M. 2012. Technical Task Request. HLW-SSF-TTR-2012-0007, Rev 1, Savannah River Remediation, LLC, Savannah River Site, Aiken, SC, 29808.

Smith, R. W, J. C. Walton. 1993. The Role of Oxygen Diffusion in the Release of Technetium from Reducing Cementitious Waste Forms. Mat Res Soc Symp Proc 294: 247-253.

Standard Specification for Reagent Water. ASTM Method D1193-06, ASTM International.

Standard Test Method for Reflectance Factor and Color by Spectrophotometry using Hemispherical Geometry. ASTM Method E1311-09, ASTM International.

Shuh, D. K., N. Kaltsoyannis, J. J. Bucher, N. M. Edelstein, S. B. Clark, H. Nitsche W. Lukens, W. S. Yang and J. C. Bryan. 1994. Environmental Applications of XANES: Speciation of Tc in Cement after Chemical Treatment and Se after Bacterial Uptake. Mat. Res. Soc. Symp. Proc. 344: 323-328. 
Shuh, D. K., N. M. Edelstein, C. J. Burns, W. W. Lukens, J. J. Bucher, M. G. Fickes, B. L. Scott. 2000. Research Program to Investigate the Fundamental Chemistry of Technetium. EMSP-60296. Lawrence Berkeley National Laboratory. Berkeley, CA.

Tratnyek, P. G., T. E. Reilkoff, A. W. Lemon, M. M. Scherer, B. A. Balko, L. M. Feik, B. D. Henegar. 2001. Visualizing Redox Chemistry: Probing Environmental OxidationReduction Reactions with Indicator Dyes. Chem. Educator. 6: 172-179. 


\section{DISTRIBUTION:}

P. M. Almond, 773-43A

H. H. Burns, 773-41A

B. T. Butcher, 773-43A

L. B. Collard, 773-43A

A. D. Cozzi, 999-W

D. A. Crowley, 773-43A

S. D. Fink, 773-A

G. P. Flach, 773-42A

K. M. Fox, 999-W

B. J. Giddings, 786-5A

J. C. Griffin, 773-A

C. C. Herman, 999-W

R. A. Hiergesell, 773-43A

G. K. Humphries, 705-3C

P. R. Jackson, 703-46A

D. I. Kaplan, 773-43A

C. A. Langton, 777-42A

D. Li, 999-W

S. L. Marra, 773-A

J. J. Mayer, 773-42A

A. M. Murray, 773-A

B. R. Pickenheim, 999-W

F. M. Pennebaker, 773-42A

M. A. Phifer, 773-42A

M. M. Reigel, 999-W

K. A. Roberts, 773-43A

K. H. Rosenberger, 705-1C

F. M. Smith, III 773-42A

W.A. Spencer 999-2W

D. B. Stefanko 773-43A

K. H. Subramanian, 766-H

(1 file copy \& 1 electronic copy), 773-43A - Rm.213 